\title{
Learner satisfaction and learning performance in online courses on bioterrorism and weapons of mass destruction
}

\author{
Tatiana I. Solovieva \\ West Virginia University
}

Follow this and additional works at: https://researchrepository.wvu.edu/etd

\section{Recommended Citation}

Solovieva, Tatiana I., "Learner satisfaction and learning performance in online courses on bioterrorism and weapons of mass destruction" (2005). Graduate Theses, Dissertations, and Problem Reports. 2688. https://researchrepository.wvu.edu/etd/2688

This Dissertation is protected by copyright and/or related rights. It has been brought to you by the The Research Repository @ WVU with permission from the rights-holder(s). You are free to use this Dissertation in any way that is permitted by the copyright and related rights legislation that applies to your use. For other uses you must obtain permission from the rights-holder(s) directly, unless additional rights are indicated by a Creative Commons license in the record and/ or on the work itself. This Dissertation has been accepted for inclusion in WVU Graduate Theses, Dissertations, and Problem Reports collection by an authorized administrator of The Research Repository @ WVU.

For more information, please contact researchrepository@mail.wvu.edu. 
Learner Satisfaction and Learning Performance in Online Courses on Bioterrorism and Weapons of Mass Destruction

\author{
Tatiana I. Solovieva
}

\begin{abstract}
Dissertation submitted to the College of Human Resources and Education at West Virginia University in partial fulfillment of the requirements for the degree of
\end{abstract}

Doctor of Education

in

Technology Education

\author{
John G. Wells, Ph.D., Chair \\ Ronald C. Althouse, Ph.D. \\ Deborah J. Hendricks, Ed.D. \\ Daniel E. Hursh, Ph.D. \\ David L. McCrory, Ph.D. \\ Department of Technology Education
}

Morgantown, West Virginia

2005

Keywords: Online Courses, Bioterrorism, Weapons of Mass Destruction, Satisfaction, Performance, Learning, Online Learning, Achievement, E-learning

Copyright 2005 Tatiana I. Solovieva 


\section{ABSTRACT \\ Learner Satisfaction and Learning Performance in Online Courses on Bioterrorism and Weapons of Mass Destruction}

\section{Tatiana I. Solovieva}

This study examined the relationships between measures of (a) learner satisfaction with online courses on weapons of mass destruction (WMD) and bioterrorism intended to address the educational needs of responder Communities of Practice (CoP) and (b) degrees of accomplishment by the learner with those online courses. Provided that course design characteristics were similar between courses and that content was different, it was important to examine learner satisfaction with course common aspects in relation to learning outcomes and identify the predictors of effectiveness and relations between the learner satisfaction with the course characteristics and the learner achievement for potential design improvements in the future. Specifically, the investigator set out to explore multiple measures of learner satisfaction (Content, Accuracy, Navigation, Look, Flow, Assessment, and Value) in relation to multiple measures of learner achievement (Pre-Post Gain, Follow-up Personal Benefit, Follow-up Organizational Benefit, Follow-up Subject-Matter Retention, and Follow-up Simulation Scenarios).

The results from the 67 participants' data analyses indicated that (1) navigation appeared to be a statistically significant predictor of learning achievement scores and (2) estimate of personal benefit was associated with value judgments placed on the course. Those participants who initially estimated that the courses were valuable later indicated that those courses had personal benefit to them. The learner's initial satisfaction with navigation was related to the determination of personal benefit from the course. The study contributes to further understanding web-based, process-product, and satisfaction-learning interactions by emphasizing the importance of navigation quality in web-based courseware as it relates to learning achievement and personal benefit for adult learners. The findings heighten the designers' awareness of the courseware aspects associated with learning effectiveness of exponentially growing web-based education on WMD and bioterrorism for responder communities. 


\section{ACKNOWLEDGEMENTS}

I want to thank Dr. John Wells, my advisor, who supported me in person and at a distance through my studies at West Virginia University (WVU). I also want to express my gratitude to my committee members for providing helpful feedback at various stages of the research process: Dr. David McCrory, Dr. Daniel Hursh, Dr. Deborah Hendricks, and Dr. Ronald Althouse. Thanks to Dr. Richard Walls for his assistance, feedback, and moral support above and beyond his formal responsibilities. Thanks to Dr. Ernest Goeres for his help and encouragement. I appreciate the faculty and staff members of Technology Education Program and the College of Human Resources and Education at WVU.

I want to thank all employees of $\mathrm{VMC}^{\circledR} /$ Homeland Security Programs who supported my efforts toward finishing the dissertation and exploring future career opportunities. I am especially appreciative of my colleagues who volunteered to help with this research on several occasions: Maria Cazares, Mark Fischer, Richard Glass, Brian Lauffer, Sandra Markovic, Dr. Floyd Russell, Kim Shiemke, Nish Suvarnakar, Dr. Christine Weigandt, and Jinsong Zhang. Last but not least, I am grateful to my family and personal friends. Praise to all of you!!! 


\section{TABLE OF CONTENTS}

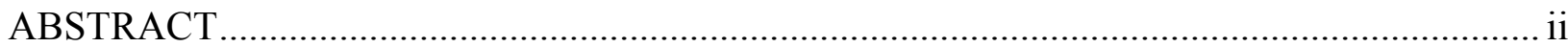

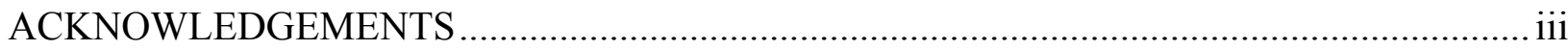

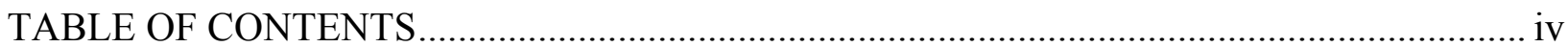

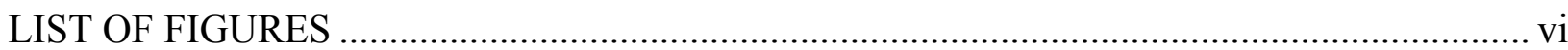

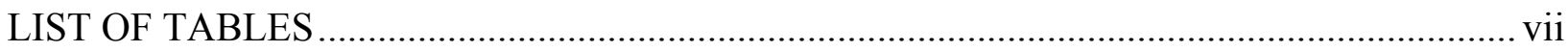

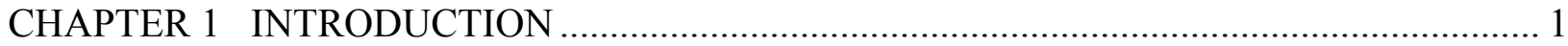

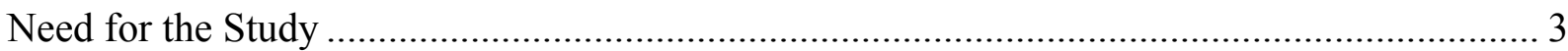

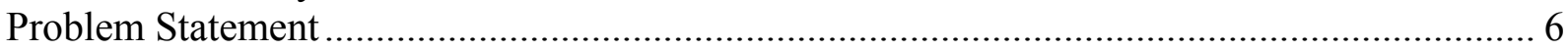

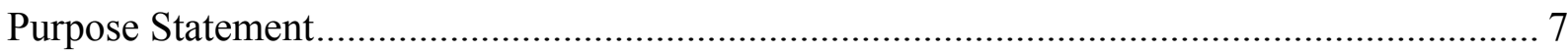

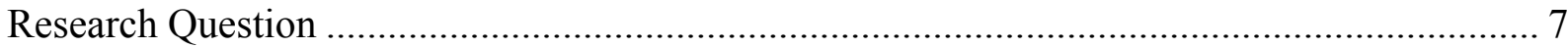

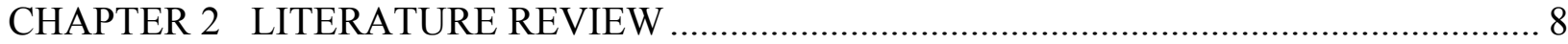

E-learning and Knowledge Management.......................................................................... 9

Information Systems Effectiveness Measurement Approaches................................................. 14

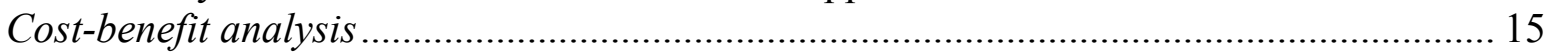

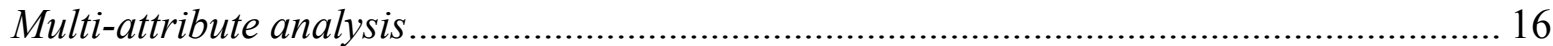

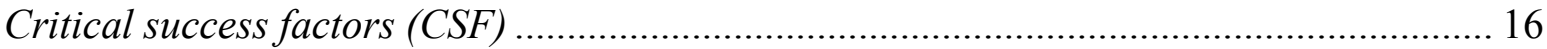

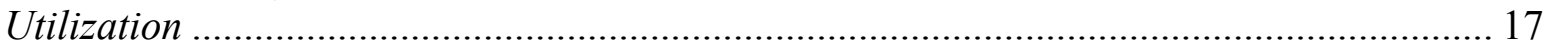

Information, communication, and knowledge quality..................................................... 17

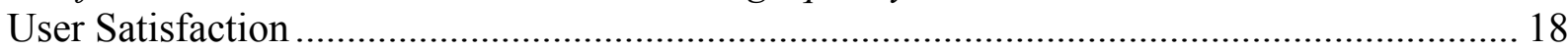

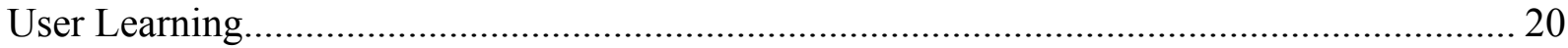

The Integration of Information System, Satisfaction, and Learning …………...................... 27

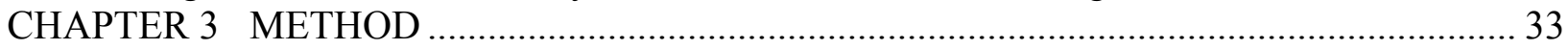

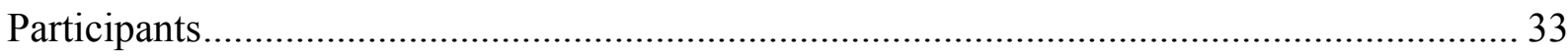

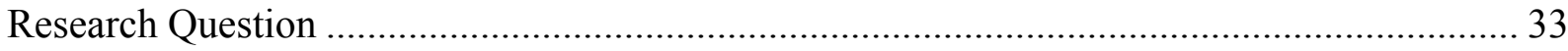

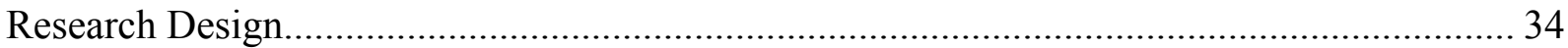

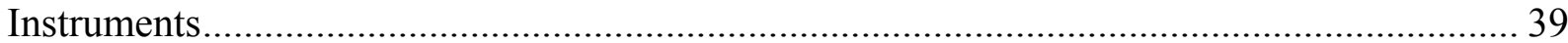

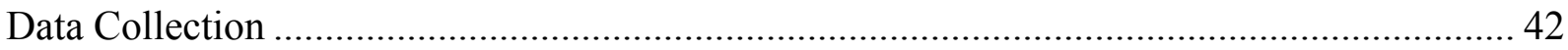

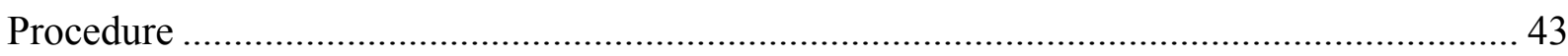

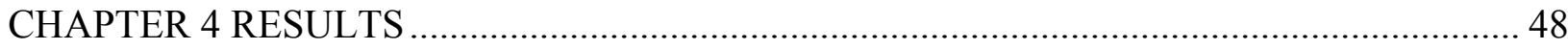

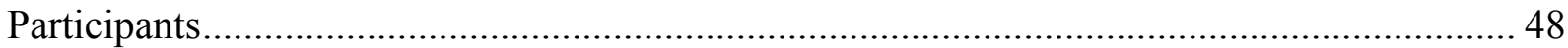

Satisfaction Questionnaire: Quantitative and Qualitative Data Analysis ................................ 50

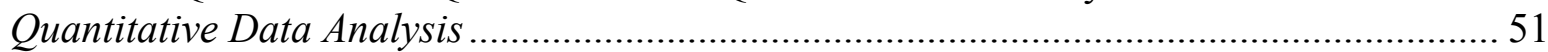

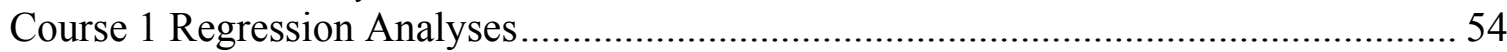

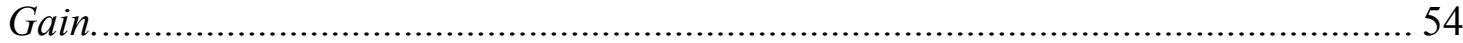

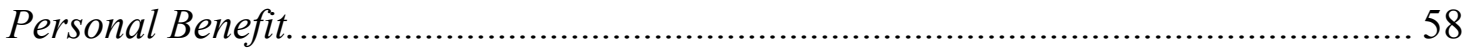

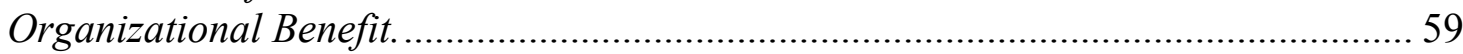

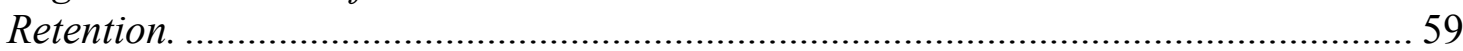

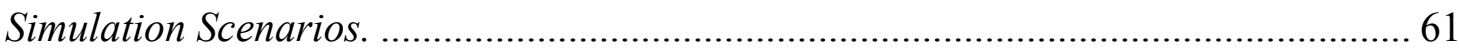

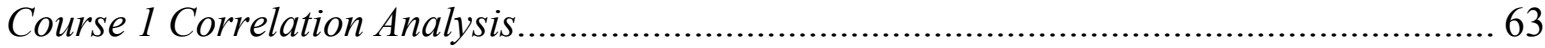

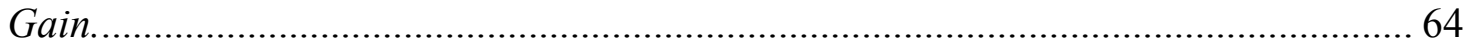

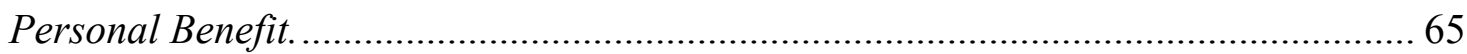

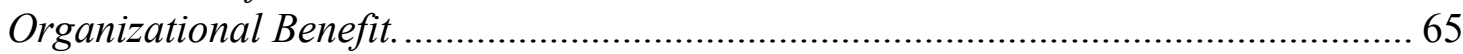

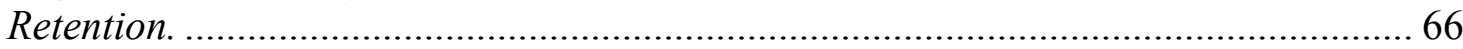

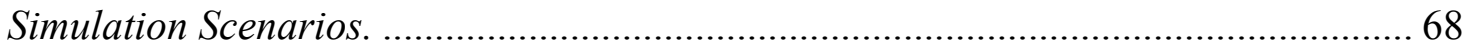

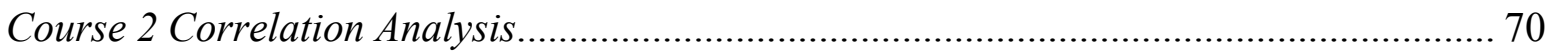




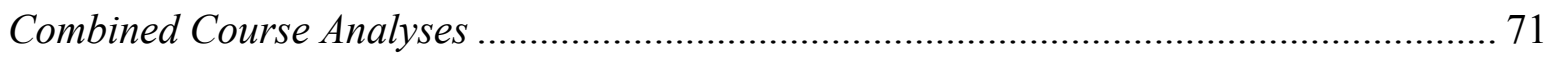

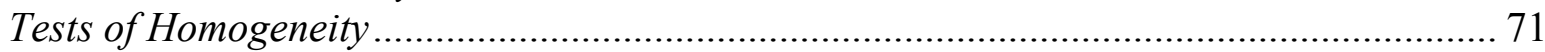

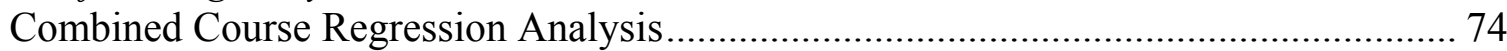

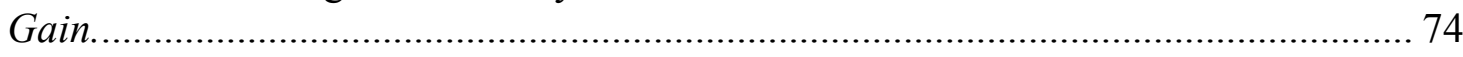

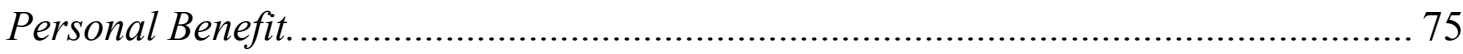

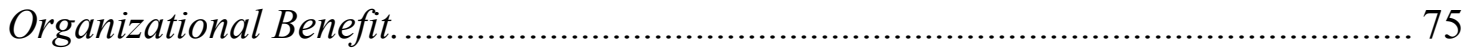

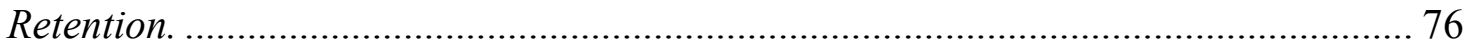

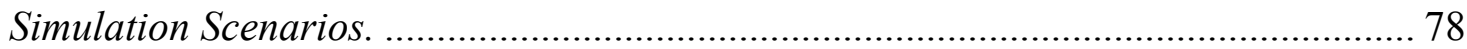

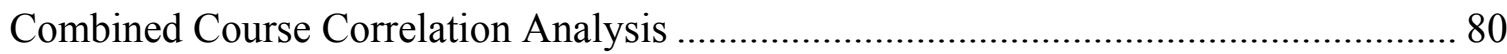

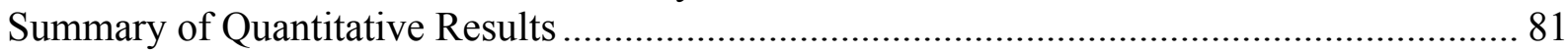

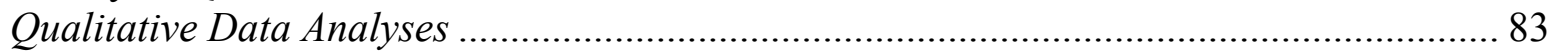

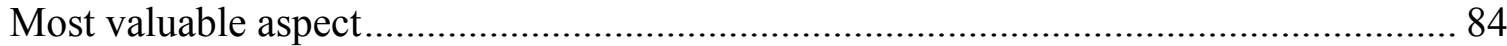

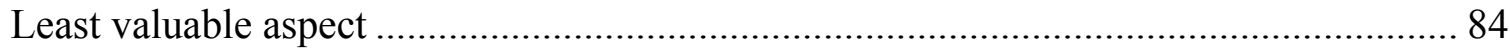

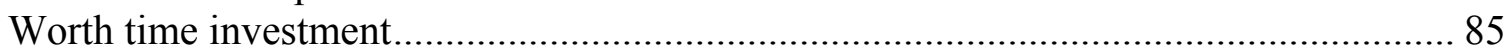

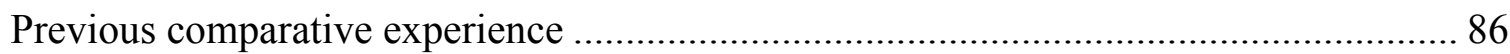

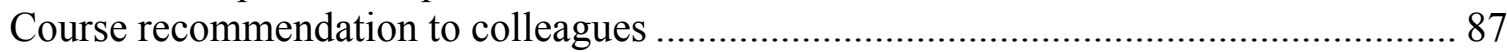

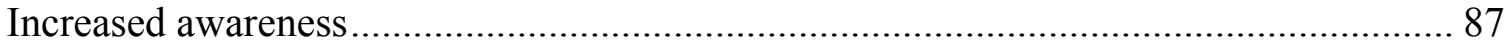

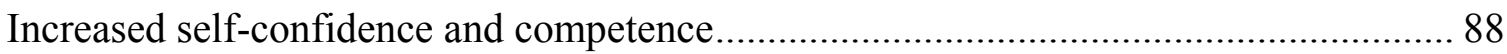

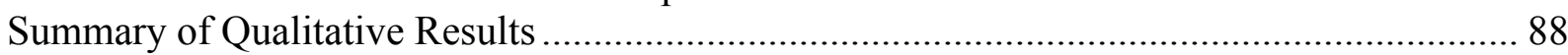

Summary of Overall Analysis: Quantitative and Qualitative ............................................ 89

CHAPTER 5 CONCLUSIONS, IMPLICATIONS, RECOMMENDATIONS ........................... 91

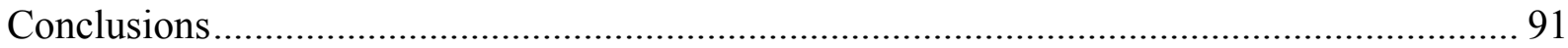

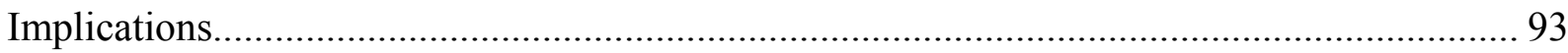

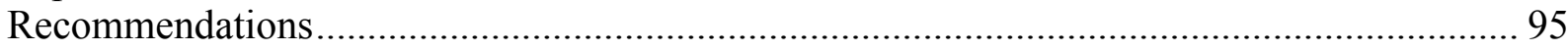

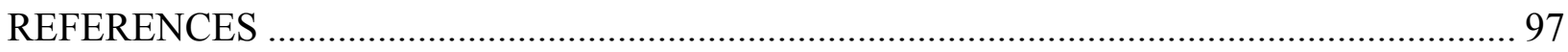

Appendix A Pre-Test and Post-Test Samples ......................................................................... 112

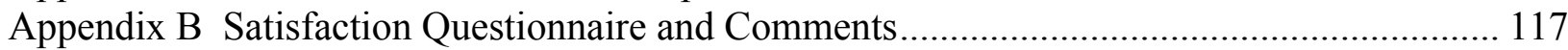

Appendix C Follow-up Questionnaire and Simulation Scenarios for Course 1 ....................... 121

Appendix D Follow-up Questionnaire and Simulation Scenarios for Course 2 ...................... 125

Appendix E Results for Open-Ended Questions for Course 1.............................................. 129

Appendix F Results for Open-Ended Questions for Course 2 .............................................. 140

Appendix G Registration Instructions for Course 1 and 2 Participants.................................... 148 


\section{LIST OF FIGURES}

Figure 1. Responder education enrollment for FEMA online courses.................................... 9

Figure 2. Cognitive and community models for knowledge management................................ 12

Figure 3. The $\mathrm{VMC}^{\circledR} /$ Homeland Security Programs' Integrated Knowledge Base (IKB $\left.{ }^{\mathrm{TM} / \mathrm{SM}}\right) .13$

Figure 4. Scatterplots with (a) no correlation, (b) positive correlation, (c) negative correlation. 37

Figure 5. Course content example and corresponding test questions.................................... 42

Figure 6. Course 1 key answers.................................................................................... 44

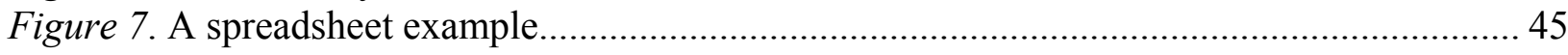

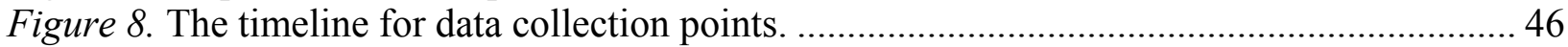

Figure 9. Regression standardized predicted value on Gain. ............................................ 56

Figure 10. Regression standardized predicted value on Retention....................................... 59

Figure 11. Regression standardized predicted value on Simulation Scenarios....................... 61

Figure 12. Regression standardized predicted value on Gain. ............................................ 64

Figure 13. Regression standardized predicted value on Retention.......................................... 66

Figure 14. Regression standardized predicted value on Simulation Scenarios........................ 68

Figure 15 . Regression standardized predicted value on Gain. ........................................... 74

Figure 16. Regression standardized predicted value on Retention.......................................... 76

Figure 17. Regression standardized predicted value on Simulation Scenarios.......................... 78 


\section{LIST OF TABLES}

Table 1 Web-based Educational Solutions for Preparation and Response to Acts of Bioterrorism

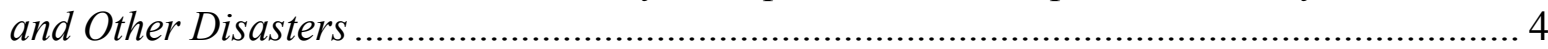

Table 2 Studies on Learners' Satisfaction and Learning Performance .................................... 31

Table 3 Correlation Cross between the Measures of Learner Satisfaction and Learning Performance.

Table 4 Response Scales for the Learner Satisfaction Measures (Predictor Variables) and the Learning Performance Measures (Criterion Variables) ................................................. 47

Table 5 Frequency and Percent of Occupation for Both Courses Combined ......................... 49

Table 6 Correlation Types between Variables of Learner Satisfaction and Learning

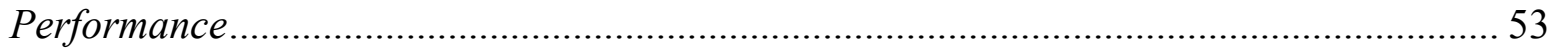

Table 7 Multiple Regression on Gain Using Seven Predictors $(N=36)$................................. 58

Table 8 Multiple Regression on Retention Using Seven Predictors $(N=36)$.......................... 60

Table 9 Multiple Regression on Scenario Using Seven Predictors $(N=36)$.......................... 62

Table 10 Correlations among Learner Satisfaction and Course (Course 1) $(N=36)$.............. 63

Table 11 Multiple Regression on Gain Using Seven Predictors $(N=31)$............................... 65

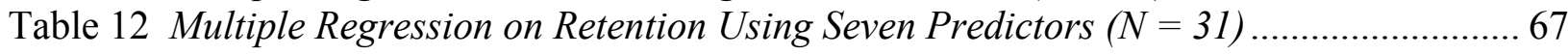

Table 13 Multiple Regression on Scenario Using Seven Predictors $(N=31)$.......................... 69

Table 14 Correlations among Learner Satisfaction and Course (Course 2) $(N=31)$.............. 71

Table 15 t-tests on Research Variables by Course .............................................................. 72

Table 16 Means and Standard Deviations on Scores by Course ............................................ 73

Table 17 Multiple Regression on Gain Using Seven Predictors $(N=67)$................................ 75

Table 18 Multiple Regression on Retention Using Seven Predictors $(N=67)$........................... 77

Table 19 Multiple Regression on Scenario Using Seven Predictors $(N=67)$........................... 79

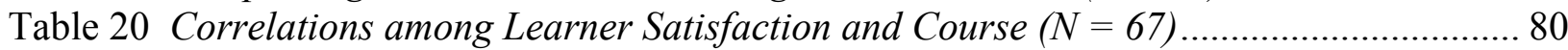

Table 21 Significant Associations among Select Variables ................................................. 82 


\section{CHAPTER 1}

\section{INTRODUCTION}

The tragic events of September 11, 2001, in New York, Washington, D.C. and Pennsylvania, revealed many deficiencies within the emergency responder community in terms of mitigation and adequate response execution in the context of large-scale terrorist attacks in the United States. In order to participate effectively in coordinated and multidisciplinary response to a disaster event, the public health workforce needs to collaborate more effectively with law enforcement, fire safety, and government decision-making authorities in preparation to deal with bioterrorism and other terrorism related events.

The eminent threat of terrorism enhances the acutely growing demand for rapid mobilization of most relevant knowledge resources to ensure appropriate decision-making and response. It is especially critical for those communities of practice (CoP), whose members can be potentially involved in emergencies caused by the weapons of mass destruction (WMD), to cultivate the most current knowledge. Preparation is vital. Knowledge Management (KM) initiatives are perceived as critical sustenance for the new knowledge economy in connection to terrorism and WMD related crisis prevention (Brennan, 2002; Eastwood, 2003; Glick, Jerome-D’Emilia, Nolan, \& Burke, 2004; Strickland, 2002).

The Department of Homeland Security/Office for Domestic Preparedness (DHS/ODP), the Department of Health and Human Services/Federal Emergency Management Agency (DHHS/FEMA), and the Department of Health and Human Services/Health Resources Services Administration (DHHS/HRSA) fund the development for web-based portals specifically oriented toward meeting educational needs of emergency management and WMD responder CoP. 
Communities of Practice (CoP) are groups of people that have common professional concerns. CoP are networks that connect people who have related professional responsibilities. Lathlean and Le May (2002) described a CoP as " a group of people who may not normally work together but who are acting and learning together in order to achieve a common task whilst acquiring and negotiating appropriate knowledge" (p. 396). They are communities led by experts. Expertise is bound into CoP, and CoP do not exist without expertise, which is always changing.

Technologies are enabling tools. "Technology platforms may assist, but no technology will stimulate the flow of knowledge without attention to the cultural and organizational contexts in which people are encouraged to develop and share their knowledge," concluded Clarke (2001, p. 195). In the context of e-learning such communities are categorized as Virtual Learning Communities of Practice (Luppicini, 2003).

There is a need in $\mathrm{CoP}$ to be able to have comprehensive and sound information to control vulnerabilities that affect the ability to define threat and respond to adverse events in terms of reduced or removed risks. The strategy to respond has to be clarified more and more.

A survey sponsored by the Agency for Healthcare Research and Quality and the American Academy of Family Physicians (AAFP) confirmed the poor level of health care providers' preparation to deal with bioterrorism or natural disasters and stated the urgent need for more education and training (Chen, Hickner, Fink, Galliher, \& Burstin, 2002). Published in 2004, more recent survey results revealed that eight out of 10 respondents from a total pool of 499 health care professionals were not confident in their preparation to deal with bioterrorism or natural disasters. Therefore, the need for such training has been established for this community of practice (Available: http://www.bordersalertandready.com/news/newsletter_archive.php?letterid=4). Providing ensured quality-learning web-based experiences to the CoP members professionally involved in crisis 
management is one viable solution for educating the members of responder CoP, so essential for our turbulent times.

$$
\text { Need for the Study }
$$

In a global environment, the real need for the communities of practice involved in the catastrophic events to cooperate better prompted the call for such web portals as the WVU $\mathrm{VMC}^{\circledR} /$ Homeland Security Programs’ Integrated Knowledge Base (IKB). It serves as a nationwide portal providing baseline distance education and training for the communities of first and emergency responder professionals. The web-based courses provided via such portals are a part of a blended learning model that combines (1) web-based learning, (2) videoconferencing, and a (3) hands-on (tabletop training exercise) experience with disaster planning and response.

The US government and federal agencies supported the initiatives of web portal creation with substantial tangible and intangible resource investments (Isaacs, 2004). Across the country, many organizations competed for such contracts. A variety of portal solutions have been under development for the past year. For example, there are some web-based solutions (Table 1) under development now, which serve healthcare professional practitioners in preparation for and response to acts of bioterrorism and other disasters.

These portals with web-based courses are still in the process of construction and now are coming into the first product testing stage. The need to evaluate these courseware arises, since the designers and the investors want to know how effective their product is in meeting its intended purposes and goals. 
Table 1

Web-based Educational Solutions for Preparation and Response to Acts of Bioterrorism and Other Disasters

\begin{tabular}{|c|c|c|}
\hline Developer & Type of Solution & Information Source \\
\hline $\begin{array}{l}\text { University of } \\
\text { Arkansas for } \\
\text { Medical } \\
\text { Sciences } \\
\text { (UAMS) }\end{array}$ & $\begin{array}{l}\text { UMAS } \\
\text { Bioterrorism } \\
\text { Preparedness } \\
\text { Web Portal }\end{array}$ & $\begin{array}{l}\text { Haugh (2004) } \\
\text { http://rpweb.uams.edu/BTPortal/UAMS BTPORTAL.asp }\end{array}$ \\
\hline $\begin{array}{l}\text { South Carolina } \\
\text { Area Health } \\
\text { Education } \\
\text { Consortium } \\
\text { (SC AHEC) }\end{array}$ & $\begin{array}{l}\text { WebMentor site } \\
\text { and Portal }\end{array}$ & http://et12.library.musc.edu/bioterrorism/ \\
\hline $\begin{array}{l}\text { University of } \\
\text { Kansas Medical } \\
\text { Center }\end{array}$ & $\begin{array}{l}\text { A web-based } \\
\text { repository and } \\
\text { resource }\end{array}$ & http://wichita.kumc.edu/bioterror/websites.html \\
\hline $\begin{array}{l}\text { University of } \\
\text { North Dakota } \\
\text { School of } \\
\text { Medicine and } \\
\text { Health Sciences }\end{array}$ & $\begin{array}{l}\text { BORDERS, the } \\
\text { Biochemical } \\
\text { Organic } \\
\text { Radiological } \\
\text { Disaster } \\
\text { Educational } \\
\text { Response } \\
\text { System, } \\
\text { organized into a } \\
\text { web-portal }\end{array}$ & http://www.bordersalertandready.com/aboutus/aboutus.php \\
\hline $\begin{array}{l}\text { The Texas } \\
\text { A\&M } \\
\text { University }\end{array}$ & $\begin{array}{l}\text { Domestic } \\
\text { Preparedness } \\
\text { Campus Portal }\end{array}$ & http://www.teexwmdcampus.com/index.cfm \\
\hline
\end{tabular}


In order to address the rising need for reliable and timely knowledge management groundwork, the West Virginia VMC ${ }^{\circledR} /$ Homeland Security Programs is currently in the process of designing and implementing its own portal. The $\mathrm{VMC}^{\circledR} /$ Homeland Security Programs' Integrated Knowledge Base (IKB) is intended to support WMD preparedness for first responders and health care institutions in the USA.

The purpose of the WVU VMC ${ }^{\circledR} /$ Homeland Security Programs' IKB is to "serve as a repository of training materials, provide access to information for rapidly updating training, and for facilitating first and emergency responder participation in response to a terrorist or similar event" (http://www.vmc.wvu.edu/projects ikb.html). Together, the online training delivery system and knowledge management system provide pre-event information for first and emergency responder preparedness and post-event analysis for improvement of preparedness training and planning programs.

The WVU VMC ${ }^{\circledR} /$ Homeland Security Programs' IKB portal's HRSA-sponsored online courses providing training in terrorist event recognition are based on the following topics:

1. Acute care needs for vulnerable populations such as pediatrics and geriatrics;

2. Alerting the public health systems of an event at the community state, and national levels;

3. Participating in a coordinated, interdisciplinary response to terrorist events and other public health emergencies.

The merging nature of technologies and human/computer interface enhance organizational capacity to face catastrophic events. CoP use such technologies as web portals with online courseware to take advantage of continuous education opportunities in crisis management. The effectiveness of learning via online courses needs not only to be assessed, but potential usability factors that contribute to learning performance have to be solicited in order to improve the quality of 
virtual training, especially in such critical areas as emergency responder education. The best way to test the usability and the provided learning outcomes is to involve the learners. Thurmond, Wambach, Connor, and Frey (2002) reported the results of their evaluation of student satisfaction in a web-based environment related to performance outcomes, controlling for student characteristics. They concluded that student satisfaction was impacted by the online environment, and was not due to student characteristics. Therefore, satisfaction with online environment appears to be linked to learning outcomes; yet, the detailed picture of such possible relationships remains to be researched.

Many stakeholders are interested in the results of this proposed study: developers, designers, sponsoring agencies, other federal organizations, respective communities of practice, technology education enthusiasts and professionals, who, once given a chance to contribute to a similar project, would want to ensure that their project, when implemented, satisfied the needs of the users, and as a result, was adequately used, and facilitated great learning performances.

\section{Problem Statement}

The issue dominating the national education agenda of protective agencies and programs is focused on the quality of web-based e-learning solutions continues to challenge technology educators (Luyben, Hipworth, \& Pappas, 2003; Meyer, 2003). The key issue deals with the age-old inquiry into "what facilitates learning" and sets the platform for this process-product dilemma. What INPUT (course design and value added elements) interacts with what PROCESS (system utility) to yield what EDUCATIONAL OUTCOME (learning performance)? 


\section{Purpose Statement}

The intent of this investigation was to explore the potential relationships between measures of learner satisfaction with online courses on WMD and bioterrorism that address the educational needs of responder CoP and degrees of accomplishment by the learner with those online courses. Multiple measures of learner satisfaction (Content, Accuracy, Navigation, Look, Flow, Assessment, and Value) were administered and examined in relation to multiple measures of learner accomplishment (Pre-Post Gain, Follow-up Personal Benefit, Follow-up Organizational Benefit, Follow-up Subject-Matter Retention, and Follow-up Simulation Scenarios). The research was formulated to address gaps identified in the process-product literature of web-based education. Although there was prior research of relevance to some of the relationships tested in the present investigation, the full compliment of such Learner Satisfaction to Learning Performance links had by no means been altogether addressed. The research contributes further to understanding web-based, process-product, satisfaction-learning interactions.

\section{Research Question}

Given web-based courses on Bioterrorism and WMD offered through an Integrated Knowledge Base (IKB) portal, what are the relationships among (a) measures of Learner Satisfaction with the courses (Content, Accuracy, Navigation, Look, Flow, Assessment, Value) and (b) measures of Learning Performance (Pre-Post Gain, Follow-up Personal Benefit, Follow-up Organizational Benefit, Follow-up Subject-Matter Retention, and Follow-up Simulation Scenarios)? 


\section{CHAPTER 2}

\section{LITERATURE REVIEW}

The key question in e-learning as part of Knowledge Management (KM) for weapons of mass destruction (WMD) responder community is what constitutes success. An information system's success appears to be a surrogate concept formed by user satisfaction with the environment measured via usability evaluations, on one hand, and by educational value (gain) measured via performance assessments, on the other. The literature review was structured on the premise that user satisfaction and user learning were products of an effective system that facilitates KM. To address user satisfaction and user learning relationship in this study, the recent research in five areas was reviewed: (a) E-learning and Knowledge Management, (b) Information Systems Effectiveness Measurement Approaches, (c) User Satisfaction, (d) User Learning, and (e) the Integration of Information System, Satisfaction, and Learning for the benefit of improving the quality of webbased courseware, that could result from evaluation.

Alkaabi (1999) pointed out that there is a conceptual difference between the concepts of evaluation and assessment. "Evaluation is the act of placing a value on the object" (p. 4). Assessing is to qualitatively answer the question: "How good is the performance?" According to Fenton (1996), "Assessment is the collection of relevant information that may be relied on for making decisions. Evaluation is the application of a standard and a decision-making system to assessment data to produce judgments about the amount and adequacy of what has taken place" (p. 13). However, in the literature both words were used interchangeably at times (Benson, 2003).

Evaluation in the systems design and development is often described as the forgotten step for various reasons, mainly due to the lack or shortage of funds during or after the implementation 
(Benamar, 1992). Wong, Greenhalgh, Russell, Boynton, and Toon mentioned "Evaluation is often added as a 'bolt-on extra' by course developers" (2003, p. 1020). The reasons for assessment and evaluation are: problem-solving, new requirement or regulation, implementation of a new idea/technology, overall systems improvement (Alkaabi, 1999).

Web design usability, user satisfaction, and learning effectiveness have been a subject of numerous explorations (e.g., Proctor et al., 2002). Baber (2002) suggested that "usability was the ‘soup-stone' of Human-Computer Interaction” (p. 1021), for which taste depended on the cook’s input ingredients. The author pointed out that usability was more than a feature of a device and its constituents. It was said to be more a consequence of the interactive process between user and device to perform tasks, and therefore, usability was influenced by "all manner of prior experiences, expectations and attitudes of users" (p. 1022). Combining user satisfaction with usability quality and learning outcomes seems to be a good way to think about evaluating web-based experiences.

\section{E-learning and Knowledge Management}

The appeal for building new courses and their consumption as on-line primary emergency management training is rising. Federal Emergency Management Agency (FEMA) web-based course completion rates have increased over 640 percent from 1997 through 2003 . The director of on-line education for FEMA presented the following statistics (Figure 1) on on-line responder education enrollment since 1997 (M. Fischer, personal communication, April 21, 2004).

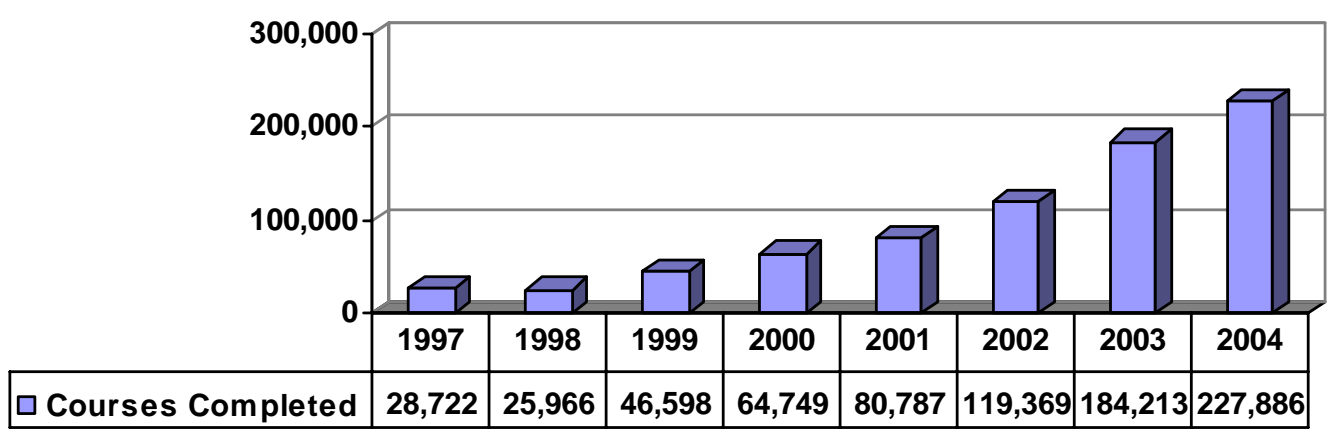

Figure 1. Responder education enrollment for FEMA online courses (2004 estimated) 
The environment of the modern world is in a flux. The changing labor picture in the context of globalization and exponential growth of information carried via information communication technologies make new demands on contemporary knowledge-based organizations. The employees of such organizations undergo multiple retraining phases and become rehired for individual expertise (Murphy, 2000). One of the conditions for being a flexible, highly marketable employee who meets the challenges of today's information flow is the ability to continue actively taking part in the process of lifetime learning.

Andrew Carnegie is often credited for the following statement (as cited in Abell, 2001): “The only irreplaceable capital an organization possesses is the knowledge and the ability of its people. The productivity of that capital depends on how effectively people share their competence with those who can use it" (p. 5). Knowledge grows exponentially; its paradox is the more one knows, the more he/she does not, as explained in Berkenholz (1999). Expansion and exchange of knowledge is implanted in the concept of knowledge management (KM) (Wasko, 2002). Vaas (2002) defined knowledge management as "the delivery of right information to the right person at the right time" (p. 40).

First introduced in the late 1950s, KM became the most influential management philosophy of the late 1990s. It is overwhelmingly growing to be omnipresent in the new millennium (Wang, Hejlmervik, \& Bremdal, 2001). Despite the lack of a good definition, KM has lots of applications and supporting technologies, grouped by Luan and Serban (2002) into the following categories: business intelligence, knowledge base, collaboration, content and document management, portals, customer relationship management, data mining, workflow search, e-leaning. Higher education institutions are employing KM for e-learning (Maurer \& Sapper, 2001). The e-learning heart in KM is on "just-in-time knowledge," accessible anytime and anywhere. Mobilization of trusted resources 
and knowledge transfer on needed bases and just-in-time knowledge is one of the urgent needs of knowledge workers in government, business industries, and professional communities (Alley, 1999; Candy, 2000; Serban \& Luan, 2002; Stromquist \& Samoff, 2000).

Throughout human history the world's economy has experienced many transitions, from agrarian economies to industrialism to contemporary information-led economies. The proliferation of literature on the new stage of the world's economic development indicates huge socio-technical changes associated with our transition to the new economy of the twenty-first century. In the knowledge-based society, the key competitive resources are knowledge and information. Thurow (1999) addresses the vision for the creation of wealth in the global economic development emphasizing the value of knowledge in the new era of the post-industrial society. According to the statement by Tony Blair MP, Prime Minister of Great Britain (as cited in Abell, 2001), during the Industrial Revolution, capital was in short supply and labor was cheap. In the $21^{\text {st }}$ century, financial capital becomes the commodity, and intellectual capital is in short supply. Knowledge is the key, whether for economic development or safety and protection.

Malhotra (2004) suggests that knowledge management based on static interpretation of knowledge creation and a transfer cycle that downplays the socio-cultural dynamics was shown on September 11, 2001. The key to overcoming these vulnerabilities involves the users of information systems, built around two polarizing visions of KM, individual and social. The research includes two visions, the professional (individual) and his or her professional community (social).

Sørensen and Snis (2001) discuss both views of the technology mediated knowledge management process (individual and social). They are embodied in cognitive and community models, respectively (Figure 2). 


\begin{tabular}{|l|l|}
\hline Cognitive model (Codification) & Community model (Personalization) \\
\hline $\begin{array}{l}\text { Knowledge for innovation is equal to } \\
\text { objectively defined concepts and facts }\end{array}$ & $\begin{array}{l}\text { Knowledge for innovation is socially constructed and } \\
\text { based on experience }\end{array}$ \\
\hline $\begin{array}{l}\text { Knowledge can be codified and transferred } \\
\text { through text: information systems have a } \\
\text { crucial role }\end{array}$ & $\begin{array}{l}\text { Knowledge can be tacit and transferred through } \\
\text { participation in social networks including } \\
\text { occupational groups and teams }\end{array}$ \\
\hline $\begin{array}{l}\text { Gains from knowledge management } \\
\text { include exploitation through existing } \\
\text { knowledge }\end{array}$ & $\begin{array}{l}\text { Gains from knowledge management include recycling } \\
\text { of the exploration through the sharing and synthesis of } \\
\text { knowledge among different social groups and } \\
\text { communities }\end{array}$ \\
\hline $\begin{array}{l}\text { The primary function of knowledge } \\
\text { management is to codify and capture } \\
\text { knowledge }\end{array}$ & $\begin{array}{l}\text { The primary function of knowledge management is to } \\
\text { encourage knowledge sharing through networking }\end{array}$ \\
\hline The critical success factor is technology & The critical success factor is trust and collaboration \\
\hline $\begin{array}{l}\text { The dominant metaphors are the human } \\
\text { memory and jigsaw (fitting pieces of } \\
\text { knowledge together to produce a bigger } \\
\text { picture in predictable ways) }\end{array}$ & $\begin{array}{l}\text { The dominant metaphors are the human community } \\
\text { and the kaleidoscope (creative interactions producing } \\
\text { new knowledge in sometimes unpredictable ways) }\end{array}$ \\
\hline
\end{tabular}

Figure 2. Cognitive and community models for knowledge management.

Web-based training offered via the West Virginia University $\mathrm{VMC}^{\circledR} /$ Homeland Security Programs' IKB can be accessed from a home or workplace using standard web browsers. The IKB contains online WMD management training courses within the WVU VMC ${ }^{\circledR} /$ Homeland Security Programs’ Learning Management System (LMS) and vital document resources that comprise an integrated Knowledge Management System (KMS). Once registered in the LMS, learners have access to the system threaded discussion group for discussion and interaction with other learners enrolled in courses. System-generated messages inform the learners of changes, updates, and availability of resources.

The West Virginia University (WVU) VMC ${ }^{\circledR} /$ Homeland Security Programs' Integrated Knowledge Base $\left(\mathrm{IKB}^{\mathrm{TM} / \mathrm{SM}}\right)$, mapped in Figure 3, is being developed under DHHS Contract. 


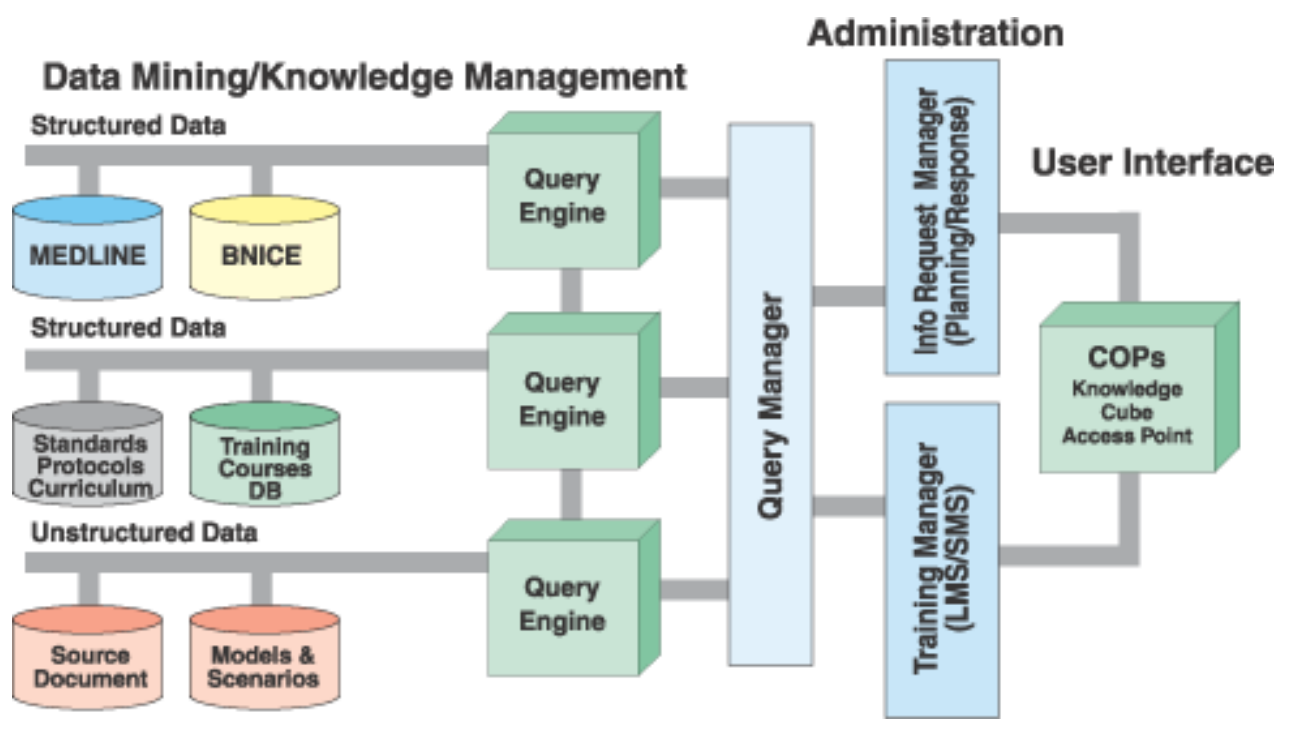

Figure 3. The $\mathrm{VMC}^{\circledR} /$ Homeland Security Programs' Integrated Knowledge Base (IKB $\left.{ }^{\mathrm{TM} / \mathrm{SM}}\right)$.

The IKB is a central knowledge repository for First and Emergency Responders of federal, state, and local organizations to large-scale disaster events at state, local, and national levels, weapons of mass destruction (WMD) terrorism related emergencies included. The IKB's goal is to provide online training access and to make relevant information available to the user in a secure and timely manner, meeting the needs of the following key disciplines or communities of practice (COP), whose personnel need to be trained to respond to incidents involving WMD. The advantages of web-based training utilizing the IKB portal are the following:

1. Reduced search cost due to a single-point of access to a wealth of content and personalized and secure access to specific information given the user profile.

2. Instruction can be accessed anywhere in the world.

3. The curriculum is discipline-specific and is customized to accommodate participants with different fields of expertise, providing them with content based on their needs; users will also be able to measure their comprehension of the material.

4. The web-based training is supplemented with onsite community-based field experiences and opportunities to interact with content experts and other first responders.

5. Participants earn continuing education credits.

For the organizations that sponsored the design and implementation of this IKB and the organization that built it there were some risks: organizational (does the system produce a benefit?) 
and technical (can the system be developed?). The technical risk has been dealt with; yet, the organizational one still has to be assessed. "Organizational risks are overcome if the system is effective in use (after implementation)" (Phelps \& Mok, 1999, p. 108).

\section{Information Systems Effectiveness Measurement Approaches}

An information system can be viewed from the perspective of the computer system domain and from the perspective of the user domain. Both agents are involved in forming a system that produces synergistic outcomes. A body of literature exists that describes the research on earlier innovative information systems such as data warehouses and expert systems (Goodhue, 1988; Storey \& Goldstein, 1993; Tague-Sutcliffe, 1996; Van Rekom, 2000; Wixom \& Watson, 2001).

For the past three decades, many researchers have entered the ongoing contentious debate on what constitutes a successful information system, and subsequently, what to measure as a dependent variable and, consequently, what factors would become independent variables (DeLone \& McLean, 1992; Gatian, 1994; Seddon \& Kiew, 1994). Since the system's performance measurement is highly unlikely to be observed directly and objectively, there have been many attempts to propose surrogate measures to be tested empirically or considered conceptually for future inclusion into evaluations and assessments. Arnold (1995) explained, “... as a result of the failure to examine the underlying variables used as surrogates for information systems success, research findings in this domain are often suspect given the doubt as to whether the measures that are chosen (such as usage and satisfaction) are really reasonable surrogates for information systems success" (p. 85).

There have been various constructs presented in the literature that contribute to or even define the system success. Bailey and Pearson (1983) identified 39 factors of information system success that influenced user satisfaction and proposed a valid instrument for its measurement. Li (1997) added seven more factors to the original work by Bailey and Pearson. Some authors stressed 
the importance of certain aspects to the existing pool of variables, such as user involvement and participation (Hwang \& Thorn, 1999; McKeen et al., 1994) and legal liabilities of the designers and developers (Clarke, 1988; Clarke, 2001; Sipior, Ward, \& Wagner, 1998).

From the literature, the approaches to measure Information Systems effectiveness fall into several categories: (a) cost/benefit analysis, (b) multi-attribute analysis, (c) the critical success factors, (d) utilization, and (e) information-communication-knowledge quality, as identified by numerous authors over the last thirty years (Baroudi \& Orlikowski, 1998; Doll \& Tokzadeh, 1998; Hamilton, 1980; Ives \& Olson, 1984; Ives, Olson \& Baroudi, 1983; King \& Rodriguez, 1978; Zmud, 1979).

\section{Cost-benefit analysis}

Achieved through employing various quantitative methods, cost/benefit analysis entails the selection of factors that contribute system cost vs. benefit values. It is used to assess the return on investment (ROI), which quantifies the system's impact on organizational performance in terms of currency (Hamilton, 1980). This approach has been used frequently and is considered traditional. However, it has been criticized for reducing all variables in evaluation study to money and overlooking the value of the intangible benefits (Benamar, 1992). Cost-benefit effectiveness is difficult or maybe impossible to assess in application to WMD mitigation related training. Learning or clients served or other forms of human-service outcomes often are considered as legitimate components of the cost-benefit ratio. As noted, traditional cost- benefit approach has limited applicability in the context of WMD preparedness. User satisfaction, user learning, personal and organizational benefits to the users are meaningful measures of system success as opposed to a formal cost-benefit ratio. 


\section{Multi-attribute analysis}

Multi-attribute analysis involves a difficult challenge of compiling numerous system attributes into some holistic overall effectiveness measure (Remenyi, 1996). Having dealt with the growing dissatisfaction among the researchers of IS effectiveness caused by the lack of consistent evaluation results, Ives, Olson, and Baroudi (1983) proposed a standard instrument to measure "user information satisfaction" that is intended to elicit the information system effectiveness (Seward, 1973), which was subsequently shortened by Baroudi and Orlikowski (1988).

\section{Critical success factors (CSF)}

The critical success factors (CSF) method has been used for information system evaluation by comparing, quantitatively (via ratings) and qualitatively (via surveys and interviews), the enduser information needs in order to assess the usefulness and accessibility of critical information. The CSF mentioned in the work by Higgins (2001) are the following: (a) a committed champion, (b) appropriate resources, (c) technical infrastructure with appropriate management of data, and (d) stored knowledge with a clear link to objectives. In the field of distance learning, for example, the UK researchers (Urquhart et al., 2002) determined three CSFs for delivery of health information management and health informatics programs: (a) integration of learning in the workplace into curriculum and assessments since learning needs to be of relevance to students, (b) implementing computer conferencing for students to have opportunities to learn from one another, and (c) conducting needs assessment from potential students before implementing the delivery system.

\section{Utilization}

Utilization is presented in the literature as a general effectiveness measure, obtained by employing the variables of actual use and perceived effectiveness measure, also known as a user satisfaction variable. Srinivasan (1985) suggested that both variables had to be used together because 
neither one of them by itself could be a sufficient measure. Utilization analysis successfully can be undertaken to either (a) reveal the system's design flaws in terms of user wasting time nonproductively or (b) to attest to the design success in terms of minimizing the time spent by the user on obtaining the desired outcome.

\section{Information, communication, and knowledge quality}

Measures for information, communication and knowledge quality include quality of the content of knowledge elements, quality of the knowledge structure and linking, quality of the metaknowledge, participants' confidence in the knowledge, reliability of contents, currency, accuracy, conciseness, relevance, and quality of format (Maier, 2002).

The work by Serafeimidis (2002) provided us with a thorough review of evaluation approaches to information systems success that differs somewhat from the previous five-factor effectiveness analysis. Stone (1990) listed four areas of information systems (IS) evaluation: "Methodological prescription research in IS evaluation has been generally in four areas: (1) user satisfaction evaluations, (2) cost-benefit analyses, (3) evaluations as experiments, and (4) frameworks for choosing methods" (p. 2). Sing and Der-Thanq (2004) also reflected on user satisfaction. They called user satisfaction evaluation method user retrospection, the purpose of which is to understand the system from the user's point of view.

If we are looking at a way to test the effectiveness of web-based education with dispersed communities of practice (CoP) learners, then let's talk about user (student) satisfaction, which is part of the "five pillars of quality" (i.e., learning effectiveness, cost effectiveness, access, student satisfaction, faculty satisfaction) or effectiveness of online learning, according to Asynchronous Learning Networks (ALN) research community (Benbunan-Fich, Hiltz, \& Harasim, 2005). Learning effectiveness refers to mastery of course materials. Satisfaction does not vary directly with 
effectiveness, yet it is an integral part of the learning success dynamics. Overtly (as a feedback loop generator) and covertly (as a cost effectiveness by-product), satisfaction is related to learning success.

\section{User Satisfaction}

Shi, Holahan, and Jurkat (2004) pointed out that overall satisfaction in library users was predicted to be a function of two independent sources: satisfaction with the information product and satisfaction with the information system. According to Ives et al. (1983), user satisfaction is defined as the extent to which users believe the information system (IS) available to them meets their information requirements (as cited in Nicolaou et al., 1995). Although there are differing points of view, there is little consensus on a conceptual definition, user satisfaction provides the most useful assessment of system effectiveness, according to Hamilton (1980). Gelderman (1998) suggested that user satisfaction is the most appropriate measure for information systems success. "In summary, user satisfaction (US) has been found in IS research to be an appropriate surrogate for IS effectiveness and success," concluded Burkman (2002, p. 18). Crowther, Keller, and Waddoups (2004) included user satisfaction (defined as how much people enjoyed using the application) as one of six usability attributes. The other five were: utility (how useful the application was), learnability (how easy it was to learn), efficiency (how much it streamlined the work process), retainability (how easy it was to remember application operations), and errors (how many errors occurred during work). Linking attitudes (i.e., satisfaction) and behavior measures (how the software was used) taken for an indirect and a direct user group of the same information system in 39 organizations resulted in affirmation that a relationship exists between satisfaction and behavior for both user groups (Gatian, 1994).

In the literature on the factors associated with expert systems success determinants, major variables (quality of system's output, system's ease of use, ease of learning, and the usefulness of 
available documentation) have been identified and empirically tested, in terms of user satisfaction (Yoon et al., 1995). Fu and Salvendy (2002) suggested that inherent usability was the main contributor to a user's satisfaction in searching and browsing tasks on the Web. According to Henneman (1999), usability is a key factor that influences user satisfaction. Lucas (1975) emphasized the importance of a high level of user satisfaction, based on the criteria important to users.

End user input (as opposed to the experts) is the best indication of interface quality (Dillon, 2001; Dimitrova, Sharp, \& Wilson, 2001). However, Langefords (1977) did not recommend excluding all other stakeholders and focusing only on the end-user in evaluation systems effectiveness. Hertzum and Jacobsen (2001) suggested the simplest way to cope with the evaluator effect, where the average agreement range of identified usability problems could be from $5 \%$ to $65 \%$ for 2 evaluators, would be to involve multiple evaluators in usability evaluations.

Essentially, Communities of Practice (CoP) are as good as institutionalized knowledge embedded in social norms, policies, and accepted practices. Institutionalization (the extent to which other people in the organization like it and use it) can be used as a dependent variable in studies of information system success (Higgins, 2001). "If the systems are not user-friendly, potential users will not be drawn to use the systems; and many current users will eventually give up on the system" (p. 276). The issue is the users' perceptions (Moreno-Muñoz et al., 2002). "When a user in a particular community sees a document vetted by someone of their own community, someone who they recognize as an expert, then that document will be much more readily accepted as an example of quality" (p. 280). The use of SMEs lends credibility to the contents and contributes to institutionalization. Ease of retrieval (usability) is important. Information quality (usability) is key. The questions that Higgins (2001) suggests are about the timeliness of the content, whether the 
personnel involved in the content review process is understood/perceived by the users of the system to be THE experts in that content area, whether the users are adequately trained in the use of the system, and whether the system is facing significant organizational resistance, or not. Thus, institutionalization can be included in the evaluation of user satisfaction.

In sum, the variables that have been recommended or demonstrated to relate to user satisfaction include user-friendliness, quality of content, credibility of sources of content, institutionalization, ease of retrieval, timeliness of content, adequate training in use of the system, and practical utility. Many of these variables often are said to contribute to "usability." The more satisfied the users are with the course, the better chances of learning effectiveness can the users manifest, given that the learners intuitively express their learning mastery through satisfaction.

\section{User Learning}

E-learning presents a marriage of instructional design and technology, which needs to be treated as a synergetic system that embraces and promotes learning. Satisfaction and learning are desired outcomes of learning processes. They are important constituents for examining the issue of usefulness of web-based environments. The question of what variables make learning effective in web-based environments is key to improving our understanding of user learning and our judgments of the web-based courseware quality.

The U. S. Department of Education invests in research efforts on educational technology and its impact on student learning (Bailey \& Mageau, 2004). Reynolds, Treharne, and Tripp (2003) expressed concerns over the lack of an apparent base of measured student performance. Jacobs (1999) shared the same concern, having added that all evaluations seemed to be subjective. However, despite the accuracy problem of learning outcome measurements, historically, technology 
and education are marked by long-term intimate associations, dating back to the introduction of the printing movable type (Curran, 2001), which impacted the spread of literacy.

Yet, the issue of media's impact on learning effectiveness is controversial. It is difficult to par and attribute compound variables to a degree of educational significance in dynamic web-based system of learning performance. Clark and Craig (2001) argued that any kind of medium would not be an independently significant transmitter of codified material, whereas Rice, Hiltz, and Spencer (2005) described several studies that did find a way to show a significant independent contribution of medium to learning effectiveness. Since web-based courseware is a complex systemic product that goes far beyond the computer screen exhibits, it is essential to review its components recommended as learning effectiveness evaluation criteria in order to establish user satisfaction variables for the instruments in this research.

The instruments to measure user satisfaction in this research study were based on these criteria taken from recommendations listed below. User learning may be related to various constructs (e.g., navigation, motivation, consistency). Hall (1997) recommended ten evaluation criteria for web-based courseware: content (right amount and quality of information), instructional design (designed in a way to ensure learning), interactivity (engaging learners for their input), navigation (exit options, course map, clear labels and icons), motivational components (novelty, humor, game, testing, adventure, and surprise elements), use of media (video, animation, music, sound and visual effects), evaluation (section quizzes, final exam), aesthetics (attractive, appealing to eye and ear), record keeping (completion level, time, final scores), and tone (professional, neither condescending, nor pedantic) (pp. 404-5). Hassan and Li (2001) identified seven criteria for evaluating website usability: screen design, content, accessibility, navigation, media use, interactivity, and consistency. Mehlenbacher (2002) summarized the recommendations of other researchers on 17 usability criteria, 
which included but were not limited to navigation and user movement, organization and information relevance, quality of writing and readability, consistency and layout, and aesthetic appeal.

Kidney and Puckett (2003) identified six different factors: content, motivation, assessment of learning, interactivity, navigation and visual design, and technology. Six dimensions of online courseware were measured by Wong et al. (2003): course materials, the interactive learning environment, tutor performance and development, assessment, student communication and support, and administrative and technical support. Williams (2004) published an online instruction evaluation checklist that included language and grammar, layout, presentation, navigation, questions, exercises, text, learner control, and interaction sections. Crowther, Keller, and Waddoups (2004) reported on users' testing the online chemistry course design in terms of order, navigation, layout, instructional aids, pace and flow of the material, and aesthetic appeal.

More than a decade ago, as cited in Brickell (1993), Apple Computer Inc. placed navigation at the top of most important components in successful hypermedia design and gave the following guidelines for the online courseware designers related to navigation. Apple proposed that the less the users have to "think where they are or what to do next, the more they can concentrate on the subject matter being presented, and hence the more complete their learning” (p. 4). Brickell also stated that most people learn by doing, and thus, learning cannot be sufficient if the user gets disoriented and frustrated, and as a result of poor navigational experience, gives up. The cognitive load on the navigator is decreased and learning is enhanced when the skill confidence is developed by the user with gaining experience in using the online courseware.

Hedberg, Harper, and Brown (1993) defined the relationship between navigation and learning outcome: "if the navigation tools are such that the user is unable to access most of the content, there will not be any significant learning gain" (p. 16). Pollock (1996) noted: "if the 
navigation is noticed by the user this could be an indication of a deficiency due to complexity, confusion or error" (p. 7).

Bateman and Harvey, Rogers and Erickson seemed to consider navigation critical (as cited in Farrell, 2000). Navigation in a new information space was considered a paradigm shift in human computer interaction (HCI) by Benson (n.d). Although others thought it was a limited metaphor (Dillon \& Vaughan, 1997). It is interesting to have identified a peculiar link between navigation and learning supported by other researchers of instructional hypermedia. "Research that treats navigation as a separate entity to be manipulated is fairly recent" (Farrell, 2000, p. 23).

Major dimensions of good instructional software that contributes to user learning are usability and interactivity. Interactivity boosts learning outcomes (Evans \& Sabry, 2003). Usability is measured in terms of the amount of time required to use a program and the number of errors made by the user. "A program that has high usability will take little time to learn and will result in few errors" (Kearsley, 1986, p. 6). Usability is the extent to which a system supports its users in completing their tasks efficiently, effectively, and satisfactorily. Usability includes an aesthetic component. On the web, usability extends to speed, intuitiveness of navigation, clarity, ease of use, personalization, and readability. Usability problems are of three categories: critical (prevent from completing a task), important (significantly slow down from completing a task), annoying (irritate the user without preventing from accomplishing the task).

Design strategies include instructional strategies that are designed to facilitate learning. A course must be useful to the students; they must feel that they have learned from it. In a "transparent" system, users completely forget that they are interacting with computer and focus totally on the task (Kearsley, 1986, p. 50). Good design means paying attention to pertinent information, content, surfing, exploring, and gathering. Tricker et al. (2001) emphasized the 
importance of the quality of content. Macdonald (2004) stressed the importance of assessments in elearning education. Urquhart et al. (2002) pointed out that the educational intervention had to be valuable to adult professional learners.

Dividing the material into small modules also would seem to contribute to usability and learning. Some benefits of modularization are described by Kearsley (1986). According to this source, educational programs should be designed, developed, and tested in small pieces, or "modules." Johnson and Aragon (2003) recommended "chunking” or segmenting the material into small units to avoid memory overload, which could lead to poor retention (learning and memory). Modularization (dividing a program into small units) makes it easier for the designer to debug a program, and it also makes it easier to revise a program. In addition, modularization provides better user control since it allows the user to get in and out of the program faster. Errors are much easier to find and fix if the modules are created and tested individually. Then they may be combined. The idea to divide the program into modules that are no longer than 15 to 20 minutes each appears to be very attractive for the designer and for the user as well (Kearsley, 1986).

Consistency was said to contribute to usability as an asset for learning. Consistency is one of the keys to good design (Williams, 1994). A good program must be consistent in the way it works and free of bugs. However, Ozok and Salvendy (2000) conducted an experimental study with 40 users (four groups with ten people in each) on web page design consistency and its effects on performance time and user satisfaction. Their study resulted in a conclusion that consistency was not always sound for performance and satisfaction. In respect to the task completion time, the researchers suggested the priorities for the user were taken into consideration. Time was very important for the users. However, the errors were likely to be viewed as retrievable by the users. Thus, in inconsistent interface design, users spent the same amount of time for the tasks; yet, their 
error rate increased. The authors also concluded that users might not have been satisfied with consistent interfaces, since many of the screen elements have happened to look very alike to each other on the same screen or on different screens. Therefore, users were not significantly more satisfied with consistent interfaces, compared to inconsistent ones.

To allow the users to tailor the program to their needs and interests, a good system must offer a lot of flexibility of pace and sequencing. It is important that in addition to control of pacing, the user is also in control of some aspects of sequencing. The user has the capability to go back to a previous screen, question or event, and to exit at any time to a menu or command level. The glossary should be designed in a way that it does not disrupt the workflow of the user. It always returns the user to the point in the program where s/he left to get help. When the user returns from glossary item description, the original application display is recreated.

The clarity involves the overall look of the screen and the individual items in it. Kearsley (1986) recommended "the combination of both factors of the design, namely two types of clarity: (a) visual clarity (how thing look on the screen) and (b) semantic clarity (what things mean)" (p. 82). Readability (semantic clarity) is a number-one concern for all the users. Attention should be given to the design of displays because screens are what people see and are often a primary factor used to judge the quality of the programs.

According to Crozier (1999), "The screen design should include: a combination of text, graphics, pictures and audio, which provide a high level of interactivity. Coll and Wingertsman (1990) studied user performance in relation to interactive screen complexity (density). They pointed out that users preferred to work with a medium-complexity screen, which allowed for gaining best results. Visual clarity basically means the idea of keeping the screen simple. It is a good approach not to crowd screens. "As a general rule, it is enough to put no more than twelve to sixteen lines of 
text and one graphic per screen. Each screen should present one idea" (Black, 1997, p. 44). People tend to loose information as it rolls off the screen. The use of different type sizes and styles is recommended for emphasis and variety. It attracts the user and makes the display more visually interesting. As a general rule, there should be a maximum of four different type styles/sizes per display.

It is good to have only one or two typefaces. The best combination is two: one light and one bold to achieve contrast. "One of the most effective, simplest, and satisfying ways to add contrast to a design is with type" (Williams, 1994, p. 80). To letter space lowercase is in fashion today. "To look at books these days, you'd think it was sheer brilliance. It might look hip now to letter space lowercase, but wait five years and look again" (Black, 1997, p. 38). The harm is at that, the natural, built-in rhythm of letters is ruined. High contrast between the background color and the colors of the text, title, and graphics is desired. "Black on a yellow background commands attention" (Taylor, 1994, p. 21). Constructive background and foreground colors will not strain the eyes.

White is the best background. It is the brightest color. "In print, white is the absence of all color, while in video, it is every color firing at full strength" (Black, 1997, p. 36). Black makes the highest contrast to white, and also it can be the first choice for type set on a white background or vice versa. Red headlines are used to sell magazines on newsstands twice as fast as any other color. Red is nature's danger color and it is a great way to add more interest to black and white page. "The first color is white. The second color is black. The third color is red" (Black, 1997, p. 34). They are the best colors: striking, readable, in perfect contrast, and have been used since day one. Calligraphers and early printers used them over 500 years ago, and experience has proved them exactly right. However, a new suggestion is that "complementary colors used together, such as orange and blue, are most interesting to the eye-especially if one color dominates" (Taylor, 1994, p. 
21). However, Levingston (1991) concluded that monochromatic displays were effective in information transfer despite the lack of color, and multicolored programs impacted memory overload. "When legibility was critical, Snowberg (1973) found the following ranking of background colors from best to worst were (1) white, (2) yellow, (3) green, (4) red, (5) blue...In a study by Start (1989), acuity was reported to be greatest for white, followed by three values of yellow" (as cited in Pett \& Wison, 1996, p. 21).

In sum, the variables that have been recommended or demonstrated to relate to user learning include usability and interactivity aspects, quality of content, its presentation, modularization, navigation, consistency, visual and semantic clarity, screen complexity, assessments, and value. User learning is one of the suggested constituents for examining the issue of usefulness of web-based environments.

The Integration of Information System, Satisfaction, and Learning

Satisfaction and learning are desired outcomes of learning processes (Benbunan-Fich, Hiltz, \& Harasim, 2005). User learning and user satisfaction should not be examined in isolation, rather in context of system effectiveness.

Jones and Paolucci (1999) remind us that learning outcomes are critical in evaluating instructional technology effectiveness. Jones and Lui (2001) stated that students' perceptions of web-based instruction ultimately impacted its value and use. Thurmond et al. (2002) concluded that students' satisfaction with the online course was influenced by the online environment and was not due to student characteristics, for which their study took control, having involved 120 students.

Thurmond et al. controlled for the following student inputs: computer skills, number of webbased courses taken, knowledge and use of electronic communications technology, resident distance from main campus, and age. The results demonstrated that student characteristics did not influence 
the web-based environment and did not influence the outcome of student satisfaction with the courses. "By controlling for students characteristics, the design of the study helped to provide a causal inference of the web-based environment as the source of student satisfaction" (p. 187). What happens in the web-based environment contributes to student satisfaction and student satisfaction is important in assessing students' perception of their learning environment, stated the authors.

Although Thurmond et al. (2002) controlled for student characteristics such as computer skills, they did not include pre-test measures of the content knowledge. Accordingly, learner satisfaction could be assessed in relation to learner perception of the web-based environment but not to the learning outcomes.

The usability of an educational environment is related to its pedagogical value (Kirkpatrick, 1994). Tselios, Avouris, Dimitracopoulou, and Daskalaki (2001) stated that effective learning was ... related to educational environments and tools that provide the students with incentives for active participation in the learning process. So the characteristics of the tools used to support learning are factors affecting the process. One of the most important features of any software tool is its usability, that is the effectiveness, efficiency, and satisfaction that it gives to the user in a given context of use and task (p. 356).

However, Tselios et al. in their experimental study failed to establish a significant relationship between individual student performance and usability evaluation. Yet, the authors acknowledged the ongoing debate on usability and learnability. According to Crowther, Keller, and Waddoups (2004), “... usability testing improved the quality of a computer-based course and facilitated a clearer analysis of the learning effectiveness of the course" (p. 289).

Richardson (2003) found that students' academic achievement was positively associated with their perceptions of academic quality of a short web-based course. The users' grades were significantly correlated with the overall measure of perceived quality $(r=+0.46)$, and most strongly associated with perceptions of workload, assessment, and generic skills. The students' grades 
("marks") were also significantly correlated with their general course satisfaction ratings $(r=+$ 0.48). Richardson and Price (2003) established a strong link between approaches to studying in electronically delivered courses and students' perceptions of the academic quality of those courses.

In the study by Mikk and Luik (2003), 54 Estonian tenth grade students participated in an eight months experimental study that aimed at determining the relationship between the 133 software characteristics of 35 units from different multimedia books and the acquired knowledge reflected in the students' post-test scores. The researchers set out to explore which characteristics of the software can influence the level of gained knowledge. Correlation coefficients disclosed five factor groups related to the post-test scores: text, presentation of information on the computer screen, graphics, navigation, and students' self-control.

MacGregor and Lou (2004) conducted a study with two fifth-grade classes (26 students in each) taught by the same teacher. Among the goals of research on WebQuests were (a) students perceptions of the usefulness of accessed websites, and (b) the relationships among tasks, resources, and student performance. The researchers found a relationship between the content rating of the web site and the students' scores on the "What I Learned" free recall assessment $(r=0.45, p<.05)$. This finding indicates that site design features can affect how much a student learns from a particular site. A second relationship was found between students' scores on the study guide and theirs scores on the same free recall post-test $(r=0.38, p<.05)$. It signified that the amount and quality of information from the website had a positive influence on learning outcome. Also, there was a significant correlation between ratings of multimedia for the sites and students' scores on their study guide $(r=0.65 . p<.01)$. Quality and the relevance of the content of student-designed multimedia slide show projects were associated with the quality of multimedia features offered at the site. "The quality of multimedia features offered at the site $(r=0.59, p<.01)$ and the relevance and clarity of 
the content $(r=0.59, p<.01)$ were associated with higher quality presentations“" $(\mathrm{p} .171)$. The correlations between students' perceptions of the websites and their study guide score had significance $(r=0.34, p<.05)$. The researchers suggested that the visited website perception was related to the amount of information students were able to gain in order to fill out the study guide. For adult learners such research remains to be desired. In the $5^{\text {th }}$ grade, the students appeared to intuitively link their learning effectiveness and their perception or satisfaction with web-based educational resources and reflect on their learning through perception. All of these studies together indicate there is a strong relationship between learning outcomes and user satisfaction.

The relationship between usability ratings and educational evaluation is an important issue to be addressed since user satisfaction imbedded in usability and learning gains imbedded in educational value are integral to improving the quality and effectiveness of computer-mediated instruction (Crowther, Keller, \& Waddoups, 2004). Table 2 presents the examples of studies that link some aspects of learners' satisfaction and learning performance. 
Table 2

Studies on Learners' Satisfaction and Learning Performance

\begin{tabular}{|c|c|c|c|c|}
\hline Authors & $\begin{array}{l}\text { Satisfaction } \\
\text { Variables }\end{array}$ & $\begin{array}{l}\text { Learning } \\
\text { Performance } \\
\text { Variables }\end{array}$ & Research & Conclusions \\
\hline $\begin{array}{l}\text { Coll \& } \\
\text { Wingertsman } \\
(1990)\end{array}$ & $\begin{array}{l}\text { Interactive screen } \\
\text { complexity (density) }\end{array}$ & $\begin{array}{l}\text { Performance } \\
\text { time }\end{array}$ & Two experiments & $\begin{array}{l}\text { Individuals prefer to } \\
\text { work with a } \\
\text { medium-complexity } \\
\text { screen, which allows } \\
\text { to gain best } \\
\text { outcomes }\end{array}$ \\
\hline $\begin{array}{l}\text { Levingston } \\
\text { (1991) }\end{array}$ & Color (look) & $\begin{array}{l}\text { Time on } \\
\text { task, the } \\
\text { number of } \\
\text { matching } \\
\text { attempts, and } \\
\text { the number } \\
\text { of multiple } \\
\text { opened } \\
\text { hidden } \\
\text { objects } \\
\text { exposures }\end{array}$ & Experimental & $\begin{array}{l}\text { Monochromatic } \\
\text { displays are } \\
\text { effective in } \\
\text { information transfer } \\
\text { despite the lack of } \\
\text { color, multicolored } \\
\text { programs impact } \\
\text { memory overload }\end{array}$ \\
\hline $\begin{array}{l}\text { Bell, } \\
\text { Fonarrow, } \\
\text { Hays, \& } \\
\text { Mangione } \\
(2000)\end{array}$ & $\begin{array}{l}\text { Satisfaction with a } \\
\text { Web-based tutorial }\end{array}$ & $\begin{array}{l}\text { Post-test } \\
\text { scores, } 4-6 \\
\text { months } \\
\text { follow-up } \\
\text { scores }\end{array}$ & Experimental & $\begin{array}{l}\text { Satisfaction with a } \\
\text { Web-based tutorial } \\
\text { produced high } \\
\text { immediate student } \\
\text { learning outcomes, } \\
\text { compared to a } \\
\text { delayed retention }\end{array}$ \\
\hline $\begin{array}{l}\text { Kim, Brock, } \\
\text { Orkand, \& } \\
\text { Astion } \\
(2001)\end{array}$ & $\begin{array}{l}\text { Navigation using the } \\
\text { GramStain-TutorTM } \\
\text { (GST) CD-ROM }\end{array}$ & $\begin{array}{l}\text { Time spent } \\
\text { on tasks }\end{array}$ & Experimental & $\begin{array}{l}\text { Navigational } \\
\text { difficulties affected } \\
\text { user outcomes }\end{array}$ \\
\hline $\begin{array}{l}\text { Quilter \& } \\
\text { Chester } \\
\text { (2001) }\end{array}$ & $\begin{array}{l}\text { Web-based } \\
\text { conferencing }\end{array}$ & $\begin{array}{l}\text { Post-test } \\
\text { scores }\end{array}$ & $\begin{array}{l}\text { Weak } \\
\text { Experiment } \\
\text { No control group }\end{array}$ & $\begin{array}{l}\text { Web-based } \\
\text { conferencing } \\
\text { increased student } \\
\text { learning outcomes } \\
\text { in online statistics } \\
\text { course }\end{array}$ \\
\hline $\begin{array}{l}\text { Shany \& } \\
\text { Nachmias } \\
\text { (2001) }\end{array}$ & $\begin{array}{l}\text { Satisfaction (overall } \\
\text { course) }\end{array}$ & $\begin{array}{l}\text { Liberal } \\
\text { thinking } \\
\text { style }\end{array}$ & $\begin{array}{l}\text { Non- } \\
\text { experimental }\end{array}$ & $\begin{array}{l}\text { Independent } \\
\text { thinkers are more } \\
\text { successful and more } \\
\text { satisfied with web- } \\
\text { based courses }\end{array}$ \\
\hline
\end{tabular}


Table 2 continued

\begin{tabular}{|l|l|l|l|l|}
\hline $\begin{array}{l}\text { Mikk \& Luik } \\
(2003)\end{array}$ & $\begin{array}{l}\text { Text, presentation of } \\
\text { information on the } \\
\text { computer screen, } \\
\text { graphics, navigation, } \\
\text { and students' self- } \\
\text { control }\end{array}$ & $\begin{array}{l}\text { Post-test } \\
\text { scores as } \\
\text { percentages }\end{array}$ & Experimental & $\begin{array}{l}\text { The characteristics } \\
\text { of the software } \\
\text { influence the } \\
\text { efficiency of } \\
\text { learning and } \\
\text { outcomes }\end{array}$ \\
\hline $\begin{array}{l}\text { Crowther, } \\
\text { Keller, \& } \\
\text { Waddoups } \\
(2004)\end{array}$ & Navigation (usability) & $\begin{array}{l}\text { Learning in } \\
\text { online } \\
\text { chemistry } \\
\text { course }\end{array}$ & Experimental & $\begin{array}{l}\text { Usability difficulties } \\
\text { impeded the users' } \\
\text { ability to engage in } \\
\text { significant learning }\end{array}$ \\
\hline
\end{tabular}

Together, studies suggest that satisfaction with educational environment can be related to learning and performance. Better understanding of learning can be reached within the context of a set of variables that speak to satisfaction with educational environment such as appropriate design of stimulus materials, meaningful presentation of instructional content, facile web-based instructional design, visual clarity, and semantic interpretability, which leads to user satisfaction, the learning outcomes may be affected. 


\section{CHAPTER 3}

\section{METHOD}

\section{Participants}

Potential participants for this study were those who had completed one or both of the following web-based WMD courses sponsored by Health Resources and Services Administration (HRSA): (1) "Recognition and Reporting of a Terrorist Incident or Public Health Emergency" (Course 1), and (2) “A Multidisciplinary Response for Threat Preparedness" (Course 2). Members of the target population (learners) were representatives of the following communities of practice, but not restricted to these fields: Emergency Management Agencies, Emergency Medical Services, Firefighting, Government Administrations, Hazardous Materials, Forensic Laboratories, Mass Fatality Teams, Law Enforcement and Investigation, Public Health, Forensic Investigation, Health Care, Public Safety Communications, Public Works, Forensic Science, Medical Examination. Participants were adult learners who had successfully completed Course 1 and/or Course 2 with a total population being greater than 30 individuals in each of those two courses to ensure statistical integrity of this research.

The participants had been encouraged to participate in the courses for professional and organizational benefits. University policy requires the permission to conduct research involving human subjects from the WVU Institutional Review Board for the Protection of Human Subjects (IRB). The permission to conduct this research was obtained from the WVU IRB.

\section{Research Question}

Given a web-based course offered through an Integrated Knowledge Base (IKB) portal, what are the relationships among (a) measures of Learner Satisfaction with the course (Content, Accuracy, Navigation, Look, Flow, Assessment, Value) and (b) measures of Learning Performance 
(Pre-Post Gain, Follow-up Subject-Matter Retention, Follow-up Personal Benefit, Follow-up

Organizational Benefit, and Follow-up Simulation Scenarios)?

\section{Research Design}

The research design examined the Learner Satisfaction (with the course) variables in relation to Learning Performance (in the course) variables, which was accomplished using a 7 x 5 cross between Learner Satisfaction and Learning Performance. A matrix to illustrate this cross is shown in Table 3.

Learner Satisfaction with the course was measured in terms of (1) Content (relevance, inclusion), (2) Accuracy (correct, error-free), (3) Navigation (access, movement), (4) Look (media, graphics), (5) Flow (logic, sequence), (6) Assessment (quizzes, exercises), and (7) Value (to me, in my organization). Learning Performance was assessed in terms of (1) Pre-Post Gain, (2) Follow-up Personal Benefit, (3) Follow-up Organizational Benefit, (4) Follow-up Retention, and (5) Follow-up Simulation Scenarios. Percentage measures were used for comparability. Analyses considered the potential relationship of (a) the variables associated with the Learner Satisfaction with the course and (b) the variables representing the measures of Learning Performance.

To determine if the overall complement of Learner Satisfaction variables has predictive value for the Learning Performance measures, a series of multiple-regression analyses were computed. In each of these three multiple-regression analyses, the predictor variables were (1) Content, (2) Accuracy, (3) Navigation, (4) Look, (5) Flow, (6) Assessment, and (7) Value. The criterion variables for these three multiple-regression analyses were (1) Pre-Post Gain, (2) Subject-Matter Retention, and (3) Simulation Scenarios. 
Table 3

Correlation Cross between the Measures of Learner Satisfaction and Learning Performance

\begin{tabular}{|c|c|c|c|c|c|}
\hline \multirow{4}{*}{$\begin{array}{l}\text { LEARNER } \\
\text { SATISFACTION } \\
\text { (with the course) } \\
\text { variables }\end{array}$} & \multicolumn{5}{|c|}{ LEARNING PERFORMANCE } \\
\hline & \multicolumn{5}{|c|}{ Achievement } \\
\hline & \multirow{3}{*}{$\begin{array}{l}\text { Immediate } \\
\text { Pre-Post Gain } \\
\text { (Scores) }\end{array}$} & \multicolumn{4}{|c|}{ Delayed (Follow-up) } \\
\hline & & \multicolumn{2}{|c|}{\begin{tabular}{l}
\multicolumn{1}{c}{ Benefit } \\
(Dichotomous Data \\
"Yes" or "No")
\end{tabular}} & $\begin{array}{l}\text { Retention } \\
\text { (Ordinal } \\
\text { Data 0-4) }\end{array}$ & $\begin{array}{l}\text { Transfer } \\
\text { (Ordinal } \\
\text { Data 0-6) }\end{array}$ \\
\hline (Ordinal Data) & & Personal & Organizational & $\begin{array}{l}\text { Subject- } \\
\text { Matter } \\
\text { Retention }\end{array}$ & $\begin{array}{l}\text { Simulation } \\
\text { Scenarios }\end{array}$ \\
\hline $\begin{array}{l}\text { 1. Content } \\
\text { (relevance, } \\
\text { inclusion) }\end{array}$ & & & & & \\
\hline $\begin{array}{c}\text { 2. Accuracy } \\
\text { (correct, error-free) }\end{array}$ & & & & & \\
\hline $\begin{array}{c}\text { 3. Navigation } \\
\text { (access, movement) }\end{array}$ & & & & & \\
\hline $\begin{array}{c}\text { 4. Look } \\
\text { (media, graphics) }\end{array}$ & & & & & \\
\hline $\begin{array}{c}\text { 5. Flow } \\
\text { (logic, } \text { sequence) }\end{array}$ & & & & & \\
\hline $\begin{array}{r}\text { 6. Assessment } \\
\text { (quizzes, exercises) }\end{array}$ & & & & & \\
\hline $\begin{array}{r}\text { 7. Value } \\
\text { (to me, in my } \\
\text { organization) }\end{array}$ & & & & & \\
\hline
\end{tabular}


The proportion of variance accounted for $\left(R^{2}\right)$, the overall significance $(\alpha=0.05)$ of the multiple-regression analysis, and the significance level $(\alpha=0.05)$ of the product-moment correlation of each of the individual predictors with that criterion variable were determined. Computation of a multiple-regression analysis (a) allows overall prediction of the relationship between predictor variables and the criterion variable and (b) protects against experiment-wise error rate for subsequent correlations. That is, if the overall analysis yields a significant finding at $p<0.5$ level, then subsequent (follow-up) correlations may be performed at the $p<.05$ level without the fear of inflating the likelihood of declaring a relationship to be significant (by chance) that actually is not significant (Type-One Error). Thus, the three multiple-regression analyses and two logistic regression analyses were followed by appropriate correlation analyses, as shown in Table 3 .

Correlations were generated for each cell in Table 3. The Pearson Product-Moment is used when the variables are measured using “interval scales” or "ratio scales." Spearman's rho is used when one of the variables is ordinal. An ordinal scale contains the mutually exclusive categories that can be ordered or ranked in terms of the amount of a given characteristic. The size of a difference in the amount is unknown. "A researcher wishing to evaluate students' responses to a particular course uses a five-point scale running from (1) It's terrible to (5) It's Great... The researcher cannot specify how much more positive a rating of 5 is than a rating of 4 . Although many rating scales used in psychological and educational research are, strictly speaking, ordinal scales, they are frequently treated statistically as if they were interval scales” (Davitz \& Davitz, 1996, p. 44). Point-Biserial correlation is used when one of variables is dichotomous and the other is interval (Gravetter \& Wallnau, 2000, p. 552). Andrews et al. (1998) suggested if dichotomous and ordinal variables were used to identifying relationships the solution was to perform Point-Biserial correlations (p. 14). 
Accordingly, Spearman rank-order correlations were used to calculate the correlations between (1) Pre-Post Gain, Follow-up Subject-Matter Retention, and Follow-up Simulation Scenarios and (2) Learner Satisfaction variables. Point-Biserial correlations were used to determine relationships between (1) Follow-up Personal Benefit, Follow-up Organizational Benefit, and (2) Learner Satisfaction variables.

To assist with interpretation of the expected relationships, three diagrams are shown in Figure 4. They are scatter plots illustrating (a) no correlation, (b) positive correlation, and (c) negative correlation. It was expected, for instance, that there would be a positive correlation between Value (predictor) and Subject-Matter Retention (criterion). The strongest relationships were expected to be positive, rather than negative. Strong positive relationships should be seen for navigation with performance measures. If learners cannot find the correct link, and they become frustrated with resuming a page that disappeared, they are less likely to declare the course to have been of benefit (Personal Benefit or Organizational Benefit).

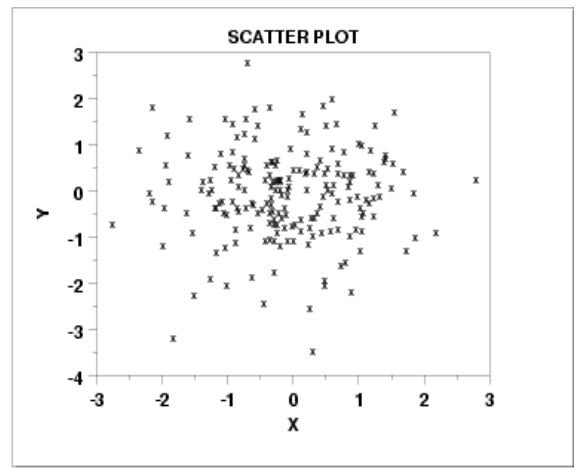

(a) No relationship

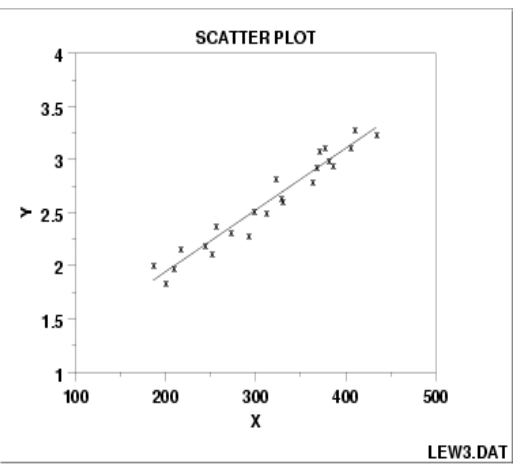

(b) Positive correlation

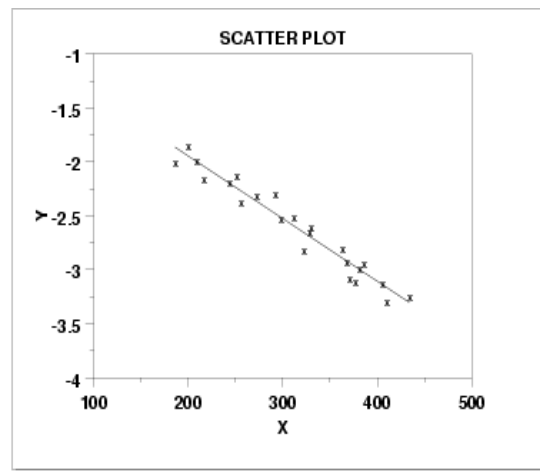

(c) Negative correlation

Figure 4. Scatterplots with (a) no correlation, (b) positive correlation, (c) negative correlation. 
If the person had high satisfaction with the content, it is considered likely that he or she would show higher learning performance (Pre-Post Gain) than an individual learner who expressed low content satisfaction. With approximately 30 learners, a correlation of $r=+.36$ or higher is significant at the $p<.05$ level, and a correlation of $r=+.46$ or higher is significant at the $p<.01$ level. Thus, a correlation of $r=+.70$ between a Learner Satisfaction variable and a Learning Performance variable would indicate an exceptionally strong association. The strongest relationships would deserve the most attention from the course designers.

The measures of Learning Performance were correlated with the same individual's measures of Learner Satisfaction. For example, as illustrated in Table 3, Learner Satisfaction with the Content (relevance, inclusion) may be related to Follow-up Personal Benefit. This may or may not be a stronger relationship than that of Learner Satisfaction with Navigation (access, movement) to Follow-up Personal Benefit. There are seven Learner Satisfaction variables and five Learning Performance variables shown in Table 3 . Thus, 35 relationships $(7$ x 5) were examined.

Although, some of these relationships were likely to be statistically significant $(p<.05)$, no specific hypotheses were proposed. The same direction of the relationship (plus or minus) and significance $(p<.05$ or $p>.05)$ would determine replication. For example, if the correlation between satisfaction with the content and follow-up retention was $r=+.48, p<.05$ for Course 1 and was $r=+.55, p<.05$ for Course 2 , then those findings would be interpreted as a replication of the relationship between satisfaction with the content and follow-up retention. Descriptive statistics, as well as graphic display, also were used to illustrate identified relationships contributing to answering the Research Question (RQ) of this investigation. 


\section{Instruments}

There were three instruments used to collect data for this study: (a) Pre-Test and Post-Test, (b) Satisfaction Questionnaire and Comments, and (c) Follow-up Questionnaire and Simulation Scenarios. Pre-Test and Post-Tests consisted of 20 questions for HRSA Course 1 or 18 questions for HRSA Course 2, randomly sampled for each participant from the Learning Management System (LMS) database. A sample Pre-Test and a sample Post-Test are shown in Appendix A. It was possible to receive some of the same items in the Pre-Test and Post-Test.

Content validity is the extent to which the relevant domain of information is represented in a fair way (rather than biased or with gaps in coverage). Fair representation of the relevant information may be determined by review of literature and/or judgment of "experts" on the topic. Content validity is, thus, a rationale for the representativeness and relevance of the items in an instrument rather than a statistical test (e.g., correlation coefficient) of relevant coverage (Rubio, Berg-Weger, Tebb, Lee, \& Rauch, 2003). Validity may be assessed for different types of measures using different metrics. Some such measures of validity would be inappropriate for assessing a test of subject-matter for a course (e.g. construct validity). As noted, a measure of validity that is appropriate for a test of course subject-matter would be content analysis. The analysis presents a rationale and the results of examination of the correspondence between the content of the course and the test questions.

The approach described above was used in the development of pre- and post- instruments by the subject-matter experts (SMEs), who were employed by the $\mathrm{VMC}^{\circledR} /$ Homeland Security Programs. The SMEs team was composed of faculty from the WVU Medical School. They designed test questions to relate to each Terminal Learning Objective (TLO) and Enabling Learning Objective of Course 1 and Course 2. As such, these faculty members (M.D.s and Ph.D.s) constituted a panel of experts. 
Two examples of the relationship among (a) course content, (b) Enabling Learning Objective, and (c) test question are provided in Figure 5. In the course content (top of Figure 5), the picture and text refer to Point of Distribution (POD). The enabling Learning Objective (middle of Figure 5) requires the participants to be able to describe POD. The test question (bottom of Figure 5) gives four multiple-choice options to select a correct answer, which is option A. Answer A corresponds directly to the first defining sentence in the content on the HTML page under the title "Points of Distribution." The correct answers for the test questions were taken from the course content either word-for-word or as close derivatives. Thus, the content to enabling objective to test question path yields consistent evidence of the content validity of these pre- and post tests. The same subject-matter experts who wrote the course content generated the test questions. This provides a further argument for the content validity of the Pre- Tests and Post- Tests. Measures of internal consistency (reliability) are not appropriate for course tests. Such measures of reliability are recommended when an instrument is constructed that proposes to measure a single construct (concept) rather than the content knowledge for a course of study. Inter-rater reliability is not a concern for a Follow-up procedure because all answers have been specified in the courses by the SMEs. For example, one item in the Course 1 Follow-up asks the learner to specify which agent (chemical, biological, radiological, or nuclear) would likely be the cause when people at a basketball game show symptoms of pupil constriction, runny nose, shortness of breath, convulsions, and stopped breathing. The course materials indicate that this agent would be "chemical" and that the Public Health Department should be contacted. 


\section{Multidisciplinary Response Multidisciplinary Response Awareness}

Topic Menu open

Treatment Issues in a Response $\backslash 2$ : Points of Distribution

Points of Distribution (POD)

A point of distribution (POD) is a special clinic created for providing mass prophylaxis. Planning for clinic sites to facilitate distribution of antibiotics or delivery of vaccines should be the current practice in all communities

The proper implementation of mass prophylaxis or immunization requires coordination with other emergency response authorities at all levels. Public health officials will need to explain clearly to the public the need for prophylaxis, who should receive it, what population each POD will serve, and how it will operate. Local officials will need to know the details of the layout of the area, including the population distribution, road configuration and traffic patterns, an approximation of available local resources, and available labor pools upon which they can draw.

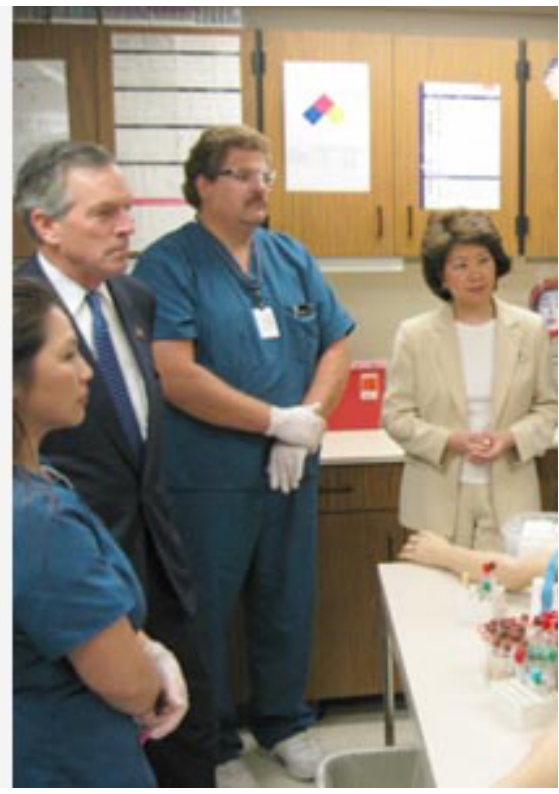

Click the Next button to continue

Objective 11: The participant will be able to describe a "Point of Distribution" (POD). T1 (TP 2.3.2.1)

A "point of distribution" is

A. a special clinic for providing mass prophylaxis

B. the unique storage point for the strategic national stockpile

C. the single master facility for local incident commands

the controlling agency for joint information centers

Figure 5. Course content example and corresponding test questions. 
The measures of Learner Satisfaction with the Course are shown in Table 3. They are measured with the instrument, which is called "Satisfaction Questionnaire and Comments." The questionnaire is shown in Appendix B. It consists of two parts: rating (Likert-scale) and open-ended comments. The first part has several course evaluation criteria (e.g., Content, Accuracy, Navigation, Look, Flow, Assessment, and Value). Each of those items is asked in the form of an incomplete sentence, followed by the four choices (Poor, Acceptable, Good, and Excellent). For example, Item 1 is presented as follows: "1. The content (relevance, inclusion) was Poor, Acceptable, Good, Excellent." The second part includes seven questions about the experience with the course that imposed "Yes" or "No" choice with the option to type user's comments.

\section{Data Collection}

The data are being collected from (a) Pre-Test, which the learners take before entering into course content modules, (b) Post-Test, which the learners take immediately after course modules, (c) Satisfaction Questionnaire and Comments, which the learners fill out after the Post-Test, as well as (d) Follow-up Questionnaire and Simulation Scenarios, which the learners take (via email) within several months after course completion. The Learning Management System (LMS) registers and stores all student records automatically.

\section{Procedure}

Extant data from the LMS were extracted by the manager of the system and given to the researcher in a digital format in Excel sheet on a floppy disk. The data included (a) participant number, (b) occupation, (c) Pre-Test Total score (percentage), (d) Post-Test Total score (percentage), (e) Pre-Post Gain (percentage), (f) rating of Satisfaction with Content (1 = "Poor," 2 = "Acceptable," $3=$ "Good," 4 = "Excellent"), (g) rating of Satisfaction with Accuracy $(1,2,3,4)$, (h) rating of Satisfaction with Navigation $(1,2,3,4),(\mathrm{g})$ rating of Satisfaction with Look $(1,2,3,4)$, (k) rating of 
Satisfaction with Flow (1, 2, 3, 4), (1) rating of Satisfaction with Assessment (1, 2, 3, 4), (m) rating of Satisfaction with Value $(1,2,3,4)$. After 4 to 7 months, a similar process was used for extracting the data collected via the third instrument "Follow-up Questionnaire and Simulation Scenarios." These data included $(\mathrm{n})$ report of Personal Benefit $(0=$ "No," $1=$ "Yes"), (o) report of Organizational Benefit $(0,1)$, (p) Subject-Matter Retention score (percentage), and (q) Simulation Scenarios score (percentage).

The data from the scenarios part of the "Follow-up Questionnaire and Simulation Scenarios" were from open-ended responses which allowed variability in the interpretation for scoring. If the response was correct, the score was determined as 1 point; if it was incorrect the response was given 0 points. Therefore, the maximum number of points for six questions was 6 , and the minimum number was 0 when no correct answers were provided. Yet, open-endedness of the responses required a reliability test. When there is a possibility of differences in the judgment of responses for accurate scoring, inter-rater reliability is necessary to establish the consistency (i.e., reliability) of two different testers scoring the same test from the same students. Inter-rater reliability is needed for objectivity. It is defined as "the degree to which different raters/observers give consistent estimates of the same phenomenon" (http://www.niu.edu/assessment/ resourc/gloss.shtml). The percentage of inter-rater reliability is calculated, according to the following formula: Percentage of inter-rater reliability $=(($ number of agreements / (number of agreements + disagreements $)) \times 100$.

Two independent raters in different rooms simultaneously scored the responses. They were selected because they initially created the content for the questions and were familiar with the subject-matter. Both raters were instructed in the same way to utilize the copies of the same written key answers. The responses were numbered according to the participant number, so the raters could match them. No names were disclosed. There were six items to score scenario responses. There were 
three questions with two sub-questions (e.g., 1(a) and 1(b) question). The raters had Excel spreadsheets in front of them with participant numbers (vertical list) and question numbers (horizontal list). The key answer for Course 1 is given in Figure 6 below.

\section{Scenario 1 - Chemical}

(1a) Agent - Chemical, Nerve Agent, e.g., Tabun (GA), Sarin (GB), Soman (GD), GF, VX (1b) Agency - 911 or Public Health Department

\section{Scenario 2 - Radiological}

(2a) Agent - Radiological, Radioactive Material, "dirty bomb," radioactive material in a public area

(2b) Agency - 911 or Public Health Department

\section{Scenario 3 - Biological}

(3a) Agent - Biological, Smallpox, Variola virus (inhaled), or contact with an infected person while rash is present

(3b) Agency - 911 or Public Health Department

Figure 6. Course 1 key answers.

Participant numbers were used to preserve anonymity. Figure 7 presents a spreadsheet example. Column “a” was a participant number, and columns 'b' through ' $q$ ' had results " $x$ " for each participant.

\begin{tabular}{|l|l|l|l|l|l|l|l|l|l|l|l|l|l|l|}
\hline a & b & c & d & e & f & g & j & k & l & m & n & o & p & q \\
\hline Participant No.1 & x & x & x & x & x & x & x & x & x & x & x & x & x & x \\
\hline Participant No.2 & x & x & x & x & x & x & x & x & x & x & x & x & x & x \\
\hline
\end{tabular}

Figure 7. A spreadsheet example.

Pre-Post Gain results were calculated as a difference between the results of Pre- and Post-

Tests. The gain score is "the difference between the second and first measurement (i.e., how much was "gained" from the first to second measurement)" (Weinfurt, 2000, p. 355). Satisfaction Questionnaire results were correlated with the Pre-Post Gain, Personal Benefit, Organizational Benefit, Retention, and Simulation Scenarios results, using a statistical software package. Multiple 
regression analyses were calculated for the three criterion variables (Pre-Post Gain, Retention, and Simulation Scenarios). A forward stepwise binomial logistic regression using Wald statistic was conducted on Personal Benefit, Organizational Benefit. In each of these regression analyses, the predictor variables were the seven satisfaction measures (Satisfaction with Content, Satisfaction with Accuracy, Satisfaction with Navigation, Satisfaction with Look, Satisfaction with Flow, Satisfaction with Assessment, and Satisfaction with Value). The response scale for measuring each predictor variable and each criterion variable is shown in Table 4. In addition, individual correlations were reported for each cell in Table 3, mentioned in Research Design section. The timeline for data collection points is presented in Figure 8. The analysis was performed on the data from Course 1 participants and Course 2 participants separately. Additionally, Course 1 and Course 2 data were combined for supplementary analyses, when the correlations in Course 1 and Course 2 were not significantly different from each other.

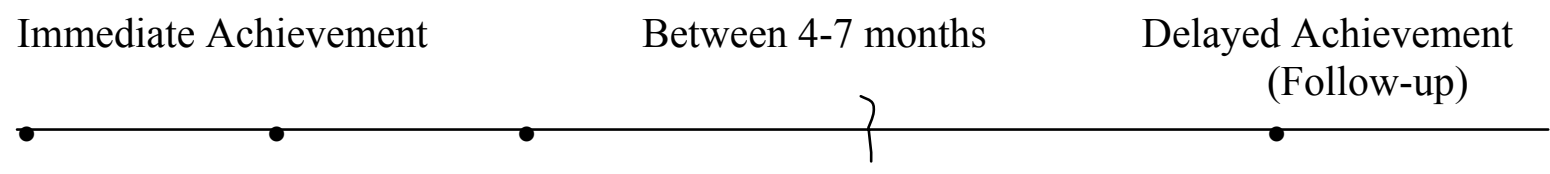

Pre-Test Post-Test Satisfaction Questionnaire Follow-up Questionnaire and Scenarios

Figure 8. The timeline for data collection points. 
Table 4

Response Scales for the Learner Satisfaction Measures (Predictor Variables) and the Learning Performance Measures (Criterion Variables)

\begin{tabular}{|c|c|}
\hline Variable & Response Scale \\
\hline \multicolumn{2}{|c|}{ Learner Satisfaction (Predictor) } \\
\hline Content & $1=$ Poor, $2=$ Acceptable, $3=$ Good, $4=$ Excellent \\
\hline Accuracy & $1=$ Poor, $2=$ Acceptable, $3=$ Good, $4=$ Excellent \\
\hline Navigation & $1=$ Poor, $2=$ Acceptable, $3=$ Good, $4=$ Excellent \\
\hline Look & $1=$ Poor, $2=$ Acceptable, $3=$ Good, $4=$ Excellent \\
\hline Flow & $1=$ Poor, $2=$ Acceptable, $3=$ Good, $4=$ Excellent \\
\hline Assessment & $1=$ Poor, $2=$ Acceptable, $3=$ Good, $4=$ Excellent \\
\hline Value & $1=$ Poor, $2=$ Acceptable, $3=$ Good, $4=$ Excellent \\
\hline \multicolumn{2}{|c|}{ Learning Performance (Criterion) } \\
\hline Pre-Post Gain & Post-Percent minus Pre-Percent \\
\hline Personal Benefit & $0=$ No, $1=$ Yes \\
\hline Organizational Benefit & $0=\mathrm{No}, 1=\mathrm{Yes}$ \\
\hline Subject-Matter Retention & $\begin{array}{l}\text { Scores: } 0=\text { Not Correct, } 1=\text { One Answer Correct, } \\
\text { Range: } 0-4 \text { for four questions }\end{array}$ \\
\hline Simulation Scenario & $\begin{array}{l}\text { Scores: } 0=\text { Not Correct, } 1=\text { One Answer Correct, } \\
\text { Range: } 0-6 \text { for six questions }\end{array}$ \\
\hline
\end{tabular}




\section{CHAPTER 4}

\section{RESULTS}

In this chapter, results are reported on data collected and analyzed to answer the Research Question described in Chapter 3. The research question sought to determine the relationships among (a) measures of Learner Satisfaction with the web-based courses offered through an Integrated Knowledge Base (IKB) portal (Content, Accuracy, Navigation, Look, Flow, Assessment, Value) and (b) measures of Learning Performance in the courses (Pre-Post Gain, Follow-up Subject-Matter Retention, Follow-up Personal Benefit, Follow-up Organizational Benefit, and Follow-up Simulation Scenarios). This chapter organizes the results of data analysis by first describing the participants by course (separately and combined), followed by a presentation of the Satisfaction Questionnaire data (quantitative and qualitative). Quantitative results with regressions and correlations are offered first, analyzing each course separately and then both courses combined, followed by a presentation of qualitative results for both courses combined. When appropriate, various tables and figures are used to illustrate and simplify the results of analyzed data. Other data, as noted, are included in the Appendices of this document.

\section{Participants}

Participant data are first presented for each course separately, and then both courses combined in order to illustrate a consistent pattern of findings. The major occupation group for Course 1 was Health Care workers, represented by 22 participants and accounting for $61 \%$ of the total participant pool. Five Governmental Administrative persons represented 14\%. Health Administration and Public Health were even in their representation with three people in both groups (8\% each). There were two Emergency Medical Services personnel (6\%) and only one participant representing the Public Works occupation. 
The major occupation group in Course 2 was comprised of Health Care workers, representing $71 \%(n=22)$ of those participating in the second course. Governmental Administrative persons represented 10\% $(n=3)$, Emergency Medical Services personnel 7\% $(n=2)$, and Health Administration, Public Health, and Public Works each representing 3\% $(n=1)$.

A total of sixty-seven individuals, $26(39 \%)$ male and $41(61 \%)$ female, participated in this study. Table 5 presents the overall course participant frequencies and percentages of occupations, where most $(n=44,66 \%)$ were in the Health Care profession. Eight Governmental Administrative representatives accounted for 12\%. Emergency Medical Services and Public Health occupations were evenly represented by four people in each group (6\%). Three participants were in the Health Administration field (5\%). Two people identified themselves as Public Works personnel (3\%). Fire Services and Public Safety Communications were in the minority, only represented by one person in each category $(2 \%$ each).

Table 5

Frequency and Percent of Occupation for Both Courses Combined

\begin{tabular}{lrrrr}
\hline \multicolumn{1}{c}{ Occupation Groups } & $\begin{array}{c}\text { Frequency } \\
\text { Course } 1\end{array}$ & $\begin{array}{c}\text { Frequency } \\
\text { Course } 2\end{array}$ & $\begin{array}{c}\text { Frequency } \\
\text { Total }\end{array}$ & \multicolumn{2}{c}{ Percent Total } \\
\hline Health Care & 22 & 22 & 44 & $65.7 \%$ \\
Governmental Administrative & 5 & 3 & 8 & $11.9 \%$ \\
Emergency Medical Services & 2 & 2 & 4 & $6.0 \%$ \\
Public Health & 3 & 1 & 4 & $6.0 \%$ \\
Health Administration & 3 & 0 & 3 & $4.5 \%$ \\
Public Works & 1 & 1 & 2 & $3.0 \%$ \\
Public Safety Communications & 0 & 1 & 1 & $1.5 \%$ \\
Fire Services & 0 & 1 & 1 & $1.5 \%$ \\
\end{tabular}


Satisfaction Questionnaire: Quantitative and Qualitative Data Analysis

In this section the data collection and response rates from the Satisfaction Questionnaire and Comments are presented. Quantitative results including regressions and correlations are offered first for each course separately. Subsequently, the results of regressions and correlations are presented for both courses combined. They are followed by a presentation of qualitative results to corroborate the findings of the quantitative analyses pertinent to the research question of the study.

The Satisfaction Questionnaire and Comments consisted of closed-ended and open-ended questions given online (Appendix B). The Satisfaction Questionnaire and Comments was filled out by the Course 1 and Course 2 participants following the completion of the courses. Courses were to be completed within August 4, 2004 and January 31, 2005 for participants to qualify to complete the Follow-up Questionnaire and Simulation Scenarios emails, which were sent four months after the latter date. A total of 209 people completed Course 1, 19 of whom could not be reached afterwards due to unusable email addresses. From the remaining 190 Course 1 participants available for completing the Follow-up Questionnaire and Simulation Scenarios via email, 44 responses (23\%) were received. Of those 44 participants, eight (18\%) individuals met the exclusion criterion (not submitting the evaluation survey), resulting in a total of 36 useable participant data sets for Course 1 of this study. The overall response rate was $19 \%$.

Course 2 became available online on August 2, 2004. Course 1 and Course 2 were available simultaneously within the August 4, 2004 and January 31, 2005 time frame, with146 participants completing Course 2 during that time period. Nine (6\%) individuals who finished this course could not be reached for a follow-up due to unusable email addresses. Of the remaining 137 (94\%) Course 2 participants who were available for the Follow-up Questionnaire and Simulation Scenarios (via 
email), 43 responses were received, 12 of which were eliminated for missing data. Therefore, 31 remaining participants were included in Course 2 of this study, resulting in a response rate of approximately $31 \%$.

Inter-rater reliability tests were performed to accurately score responses to the scenarios presented in the "Follow-up Questionnaire and Simulation Scenarios." The test of inter-rater reliability on the scoring of Scenarios yielded $97 \%$ reliability and $94 \%$ reliability respectively for Course 1 and Course 2 with two raters.

\section{Quantitative Data Analysis}

A series of multiple-regression and logistic regression analyses were computed for quantitative data collected on Course 1, Course 2, and both courses combined. In all three multipleregression analyses, the predictor variables were (1) Content, (2) Accuracy, (3) Navigation, (4) Look, (5) Flow, (6) Assessment, and (7) Value. The criterion variables for these three multipleregression analyses were (1) Pre-Post Gain, (2) Subject-Matter Retention, and (3) Simulation Scenarios. Regressions were performed in order to identify the strongest predictors when all seven predictor variables were regressed on the single criterion variable at one time and to protect against experiment-wise error rate $(\alpha=.05)$.

Selection of statistical tests was based on the suggestions from Andrews et al. (1998), given the types of variables. Cone and Foster (1993) highly recommended this source. "Andrews, Klem, Davidson, O’Maley, and Rodgers (1981) provide an extensive decision tree for selecting appropriate statistics. Their material includes correlational, nonparametric, and parametric tests, provides a reference for each statistic they mention, and refers you to statistical packages that will do the analyses you select” (Cone \& Foster, 1993, p. 198). Seven independent variables (Content, Accuracy, Navigation, Look, Flow, Assessment, and Value) were ordinal, as were the two dependent 
variables Follow-up Subject-Matter Retention and Follow-up Simulation Scenarios. The dependent variable Gain was continuous, quantitative normal. Two dependent variables, Follow-up Personal Benefit and Follow-up Organizational Benefit, were dichotomous with "yes" or "no" options. The recommendation (Andrews et al., 1998) for working with dichotomous and ordinal variables in regard to identifying relationships is to perform Point-Biserial correlations (p. 14). Spearman correlations are appropriate for ordinal types of data or when at least one variable is ordinal (Gravetter \& Wallnau, 2000, p. 545; http://bmj.bmjjournals.com/statsbk/13.shtml). Regressions were performed appropriate to the types of variables, according to the suggestions by Andrews et al. (1998). Multiple regression analyses were completed first, and forward stepwise binomial logistic regressions were performed when the variable was dichotomous in the instances of Personal and Organizational Benefit data. In a forward procedure of stepwise variable selection the variables are added to the model one at a time (Duarte Silva \& Stam, 1995). However, given that such variables as Follow-up Subject-Matter Retention, and Follow-up Simulation Scenarios were treated as ordinal, multiple regressions were substituted with chi-square test values from crosstabulations, considering the guidelines by Andrews et al. (1998).

Binomial logistic regression analyses were performed for Course 1, Course 2, and both courses combined when the predictor variables were ordinal (content, accuracy, navigation, look, flow, assessment, and value), and the criterion variables were dichotomous (personal and organizational benefit). The types of correlations that were generated for Course 1, Course 2, and both courses combined are shown for each cell in Table 6 . All missing and inadequate data were eliminated. The quantitative data analyses were conducted using the SPSS software package 8.0. 
Table 6

Correlation Types between Variables of Learner Satisfaction and Learning Performance

\begin{tabular}{|c|c|c|c|c|c|}
\hline \multirow{5}{*}{$\begin{array}{l}\text { LEARNER } \\
\text { SATISFACTION } \\
\text { (with the course) } \\
\text { Variables }\end{array}$} & \multicolumn{5}{|c|}{ LEARNING PERFORMANCE MEASURES } \\
\hline & \multicolumn{5}{|c|}{ Achievement } \\
\hline & \multirow{3}{*}{$\begin{array}{l}\text { Immediate } \\
\text { Pre-Post } \\
\text { Gain }\end{array}$} & \multicolumn{4}{|c|}{ Delayed (Follow-up) } \\
\hline & & \multicolumn{2}{|c|}{ Benefit } & Retention & Transfer \\
\hline & & Personal & Organizational & $\begin{array}{l}\text { Subject- } \\
\text { Matter } \\
\text { Retention }\end{array}$ & $\begin{array}{l}\text { Simulation } \\
\text { Scenarios }\end{array}$ \\
\hline $\begin{array}{l}\text { Content } \\
\text { (relevance, } \\
\text { inclusion) }\end{array}$ & Spearman & Point-Biserial & Point-Biserial & Spearman & Spearman \\
\hline $\begin{array}{l}\text { Accuracy } \\
\text { (correct, error- } \\
\text { free) }\end{array}$ & Spearman & Point-Biserial & Point-Biserial & Spearman & Spearman \\
\hline $\begin{array}{l}\quad \text { Navigation } \\
\text { (access, } \\
\text { movement) }\end{array}$ & Spearman & Point-Biserial & Point-Biserial & Spearman & Spearman \\
\hline $\begin{array}{l}\text { Look } \\
\text { (media, graphics) }\end{array}$ & Spearman & Point-Biserial & Point-Biserial & Spearman & Spearman \\
\hline $\begin{array}{l}\text { Flow } \\
\text { (logic, sequence) }\end{array}$ & Spearman & Point-Biserial & Point-Biserial & Spearman & Spearman \\
\hline $\begin{array}{l}\text { Assessment } \\
\text { (quizzes, } \\
\text { exercises) }\end{array}$ & Spearman & Point-Biserial & Point-Biserial & Spearman & Spearman \\
\hline $\begin{array}{l}\text { Value } \\
\text { (to me, in my } \\
\text { organization) }\end{array}$ & Spearman & Point-Biserial & Point-Biserial & Spearman & Spearman \\
\hline
\end{tabular}




\section{Course 1 Regression Analyses}

Three multiple regressions and two logistic regressions were conducted on the five criterion variables (Gain, Personal Benefit, Organizational Benefit, Retention, and Simulation Scenarios) using seven predictors (Content, Accuracy, Navigation, Look, Flow, Assessment, and Value). The objective of multiple regression is to predict a dependent variable from a set of independent predictors. Logistic regression is employed when the dependent variable to be predicted is dichotomous (binary, i.e., only two values).

Gain. A multiple regression on Gain using the seven predictors was conducted. Prior to multiple regression analysis, variables were examined in SPSS for assumptions of multivariate analysis. Errors were assumed to follow a normal distribution, have a constant variance (homoscedasticity), and be independent. The assumptions of linearity, homoscedasticity, and multicollinearity were met.

To be noted, data screening for evaluation of assumptions is somewhat different for ungrouped and grouped data. Tabachnick and Fidell (2001) suggested, "If you are going to perform multiple regression, canonical correlation, factor analysis, or structural equation modeling on ungrouped data, there is one approach to screening. If you are going to perform univariate or multivariate analysis variance (including profile analysis) or discriminant-function analysis on grouped data, there is another approach to screening" (p. 86). For example, homoscedasticity is known as homogeneity of variance, when data are grouped. In ANOVA-like analyses, it can be assessed with Levene's test of homogeneity of variance or $F_{\max }$ with sample-size ratios, which are not applicable to ungrouped data.

Careful examination of residuals statistics and residuals scatterplots is necessary to test such assumptions of multivariate regression as linearity and homoscedasticity between predicted 
dependent variable scores and errors of prediction. Evaluation of multicollinearity is produced in SPSS by the Collinearity Diagnostics output. If these assumptions are met during initial screening, the regression requires only one run.

The assumption of linearity stipulates that the outcome is a linear function of the independent variables with some error term and all relevant independent variable are included into the model. "If the relationship between the dependent and independent variables can be realistically expressed as a linear function, then this plot of the predicted values and residuals will lack any visible pattern. That is, the model will fit equally well across all predicted values, with the residuals randomly distributed in a band around 0 (the mean value of the residuals). Any systematic variations between the predicted values and residuals should suggest a violation of the linearity assumption" (Ethington, Thomas, \& Pike, 2002, p. 276). Osborne and Waters (2002) illustrated a non-linearity by presenting an example of curvilinear U-shape relationship with standardized residuals by standardized predicted values.

The scatter diagrams were examined to conform to the linearity and homoscedasticity assumptions. According to Stevens (2002), various types of plots for assessing potential problems with the regression model are available. "One of the most useful graphs is the standardized residuals $\left(r_{\mathrm{i}}\right)$ versus the predicted values $\left(\hat{\mathrm{y}}_{\mathrm{i}}\right)$ " (p. 100). Reviewing a scatter diagram is recommended as a "safety maneuver to avoid misinterpretations caused by curvilinearity and /or heteroscedasticity" (http://www.readingstats.com/third/samplesizeandpowera.html\#Top). Figure 9 shows the scatterplot of regression with standardized residuals by standardized predicted values without any violations of the linearity assumptions.

Homoscedasticity stipulates that the variance of the error term is the same across all levels of the independent variables. The assumption of homoscedasticity means that the variance around the 
regression line is the same for all values of the predictor variable $(\mathrm{X})$. A violation of this assumption would be observed when for the values on the X-axis, the points are all very near the regression line and the variability around the regression line is very uneven

(http://davidmlane.com/hyperstat/prediction.html ). "This assumption can be checked by visual examination of a plot of the standardized residuals (the errors) by the regression standardized predicted value" (Osborne \& Waters, 2002). Residuals are expected to be randomly scattered around 0 (the horizontal line) demonstrating a relatively even distribution. Figure 9 shows the scatterplot diagram without any visible violations of homoscedasticity.

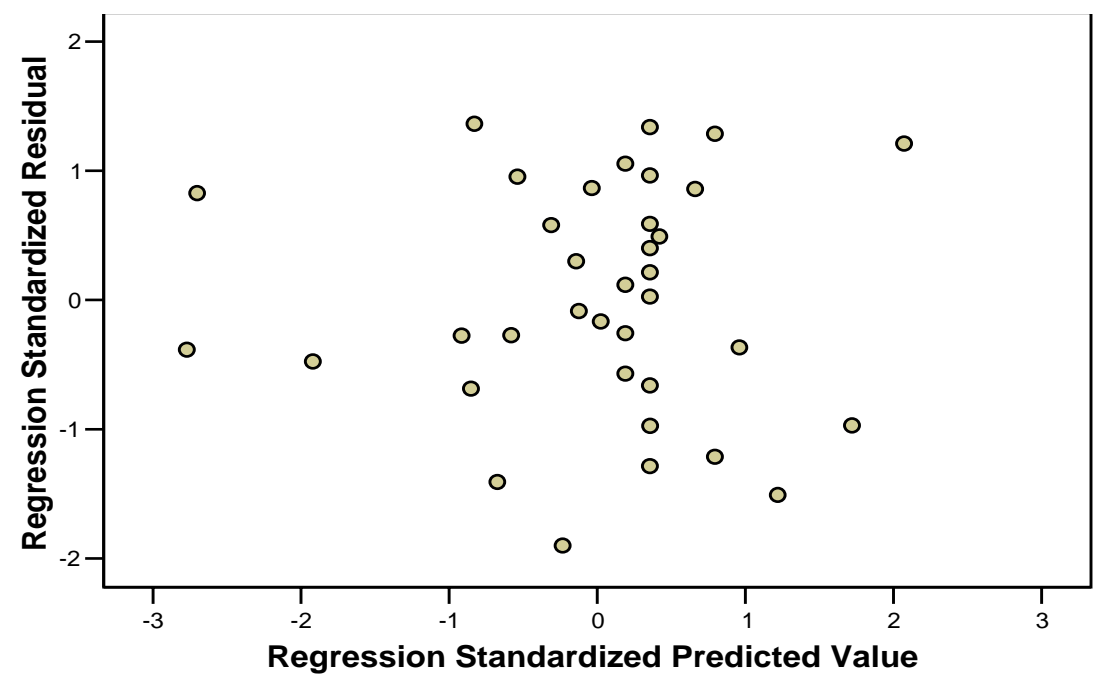

Figure 9. Regression standardized predicted value on Gain.

To check for no violations of homoscedasticity assumption, residuals statistics were obtained, where standard residuals were examined. According to Tabachnick and Fidell (2001), standardized residuals are used to identify outliers. The statistical criterion for identifying an outlier depends on the sample size; the larger the sample, the more likely that one or more residuals are identified. "When $\mathrm{N}=1000$, a criterion of $p=.001$ is appropriate, this $p$ is associated with a standard residuals in excess of about $+/-3.3$ " (p. 122). If a standard residual is in $>+3.3$ or $<-3.3$ standard 
deviations, there is a problem for homoscedasticity. In all regression analyses conducted on Course 1 and Course 2 data, standard residuals were not in excess of $+/$ - 3.3 standard deviations (from minimum to maximum). Specifically, for all regressions performed there was no evidence indicating a violation of the assumption of homoscedasticity. Furthermore, heteroscedasticity (opposite of homoscedasticity) does not invalidate an analysis of ungrouped data. "The linear relationship between variables is captured by the analysis, but there is even more predictability if the heteroscedasticity is accounted for" (Tabachnick \& Fidell, 2001, p. 80).

Multicollinearity concern was addressed by obtaining the tolerance and the variance inflation factor (VIF). It should be noted that the same assumptions of data were addressed similarly while conducting multiple regression series of this study. In logistic regression, the dependent variable to be predicted is dichotomous and has no linear relationship with predictors, no constant error variance. Multicollinearity occurs when the predictor variables themselves are highly correlated with each other. In the case of highly inter-correlated variables (i.e., multicollinearity), the statistical integrity of analysis can be in jeopardy because multicollinearity prevents from isolating the effects of the various predictors (http://www.action-research.com/multibyte.html ). The tolerance and the variance inflation factor (VIF) are two closely related tests for multicollinearity. Tolerance is calculated as $\mathrm{T}=\left(1-\mathrm{R}^{2}\right)$, whereas VIF is its reciprocal: VIF $=1 /\left(1-\mathrm{R}^{2}\right)$. Stevens $(2002)$ suggested if VIF $<10.0$, there would be no reason for concern over multicollinearity. "As a general rule, tolerances that are less than or equal to 0.10 can be seen as indicators of high or extreme multicollinearity. Conversely, VIF statistics in excess of 10.0 are indicators of this same problematic condition" (Ethington, Thomas, \& Pike, 2002, p. 287). Collinearity statistics reported in Table 7 (i.e., Tolerance and VIF) demonstrate no such violations.

The regression model was not statistically significant, $\mathrm{F}(7,28)=1.50$, ns. $\mathrm{R}^{2}$ indicates that 
$27.3 \%$ of the variance of the criterion variable (Gain) is explained by the predictor variables. Thus, the predictors accounted for $27.3 \%$ of the variability in Gain. A moderate level of predictability was obtained. Navigation was a statistically significant predictor of Gain (Table 7). This finding indicates a positive relationship between Navigation and Gain. As Navigation scores increased, Gain scores increased. The people who had higher satisfaction scores with course Navigation tended to demonstrate greater Gain from Pre-test to Post-test scores.

Table 7

Multiple Regression on Gain Using Seven Predictors $(N=36)$

\begin{tabular}{|c|c|c|c|c|c|c|c|}
\hline Predictor Variable & $B$ & $S E B$ & $\beta$ & $t$ & Sig. & Tolerance & VIF \\
\hline Content & -.010 & 7.252 & .000 & -.001 & .999 & .240 & 4.168 \\
\hline Accuracy & -6.387 & 5.160 & -.323 & -1.238 & .226 & .382 & 2.621 \\
\hline Navigation & 13.409 & 5.481 & .724 & 2.447 & $.021 *$ & .297 & 3.370 \\
\hline Look & 2.014 & 5.786 & .102 & .348 & .730 & .303 & 3.295 \\
\hline Flow & -4.269 & 5.945 & -.215 & -.718 & .479 & .290 & 3.448 \\
\hline Assessment & 1.089 & 7.404 & .058 & .147 & .884 & .170 & 5.896 \\
\hline Value & -4.391 & 6.886 & -.218 & -.638 & .529 & .223 & 4.482 \\
\hline
\end{tabular}

Note. ${ }^{*} p<.05$.

Personal Benefit. With the seven predictors (Content, Accuracy, Navigation, Flow, Look, Assessment, and Value), a forward stepwise binomial logistic regression using Wald statistic was 
conducted on Personal Benefit. The model was statistically significant, $X^{2}(1)=4.219, p<.05 ; p=$ .04. The variable Value entered the model using a forward stepwise approach with the Wald statistic determining significance, $p=.084, p<.10$.

Organizational Benefit. A forward stepwise binomial logistic regression using Wald statistic was conducted on Organizational Benefit. The seven predictors were Content, Accuracy, Navigation, Flow, Look, Assessment, and Value. None of the variables entered the model using a forward stepwise approach with the Wald statistic determining significance.

Retention. A multiple regression on Retention using the seven predictors was conducted, where the assumptions of linearity, homoscedasticity, and multicollinearity were met. Figure 10 shows the scatterplot of standardized residuals versus standardized predicted values with no violations of linearity and homoscedasticity.

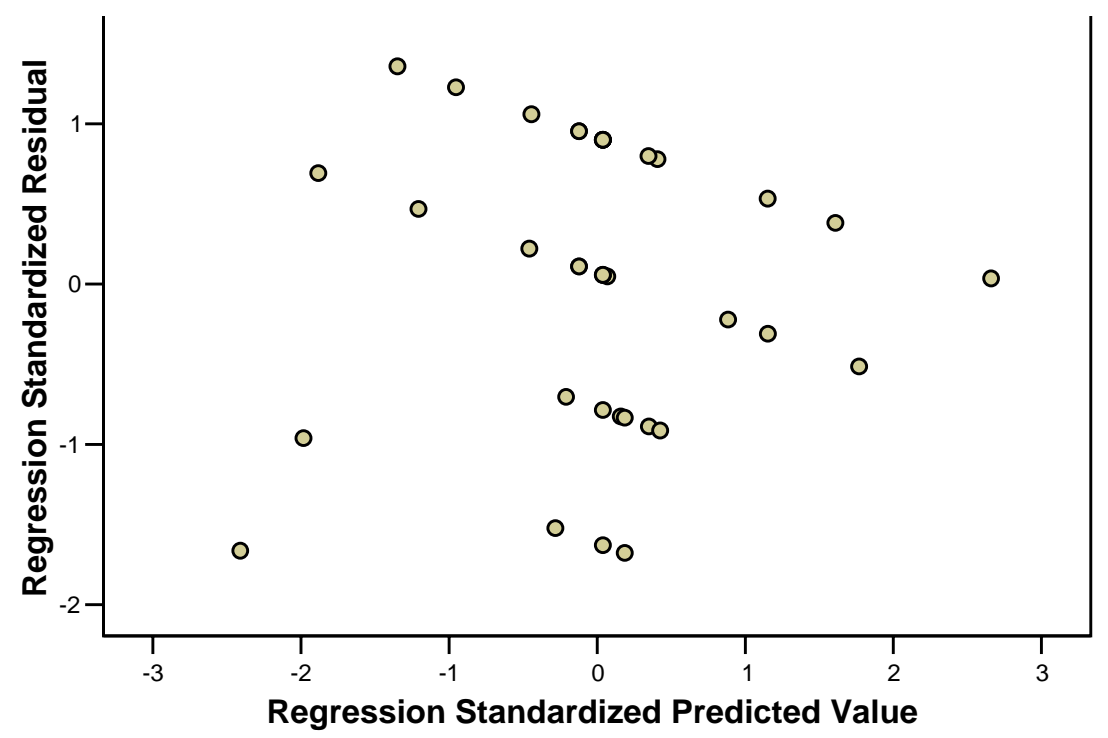

Figure 10. Regression standardized predicted value on Retention.

Collinearity statistics in Table 8 (i.e., Tolerance and VIF) demonstrate that multicollinearity is not a concern. Tolerances are more than 0.10 and thus they cannot be seen as indicators of high or 
extreme multicollinearity. VIF data are not in excess of 10.0.

The regression model was not statistically significant, $F(7,28)=.54$, $n s$. The predictors accounted for $12.0 \%$ of the variability in Retention, and no predictor was statistically significant (Table 8). However, according to the suggestion by Andrews et al. (1998), multiple regression analyses may not be applicable when the dependent variable is ordinal such as in this case. Therefore, chi-square values were generated as a result of individual crosstabulations between the dependent variable (Retention) and each of the seven independent variables (Content, Accuracy, Navigation, Flow, Look, Assessment, and Value). There were no significant results, which was consistent with the multiple regression findings.

Table 8

Multiple Regression on Retention Using Seven Predictors $(N=36)$

\begin{tabular}{|c|c|c|c|c|c|c|c|}
\hline $\begin{array}{l}\text { Predictor } \\
\text { Variable }\end{array}$ & $B$ & $S E B$ & $\beta$ & $t$ & Sig. & Tolerance & VIF \\
\hline Content & .752 & .537 & .507 & 1.401 & .172 & .240 & 4.168 \\
\hline Accuracy & -.568 & .382 & -.426 & -1.485 & .149 & .382 & 2.621 \\
\hline Navigation & -.076 & .406 & -.061 & -.187 & .853 & .297 & 3.370 \\
\hline Look & -.034 & .429 & -.026 & -.080 & .937 & .303 & 3.295 \\
\hline Flow & -.034 & .440 & -.026 & -.078 & .938 & .290 & 3.448 \\
\hline Assessment & .447 & .549 & .351 & .815 & .422 & .170 & 5.896 \\
\hline Value & -.424 & .510 & -.312 & -.832 & .412 & .223 & 4.482 \\
\hline
\end{tabular}


Simulation Scenarios. A multiple regression on Simulation Scenarios using the seven predictors was conducted. The assumptions of linearity, homoscedasticity, and multicollinearity were met. Figure 11 shows the scatterplot of standardized residuals versus standardized predicted values without any violations of linearity and homoscedasticity.

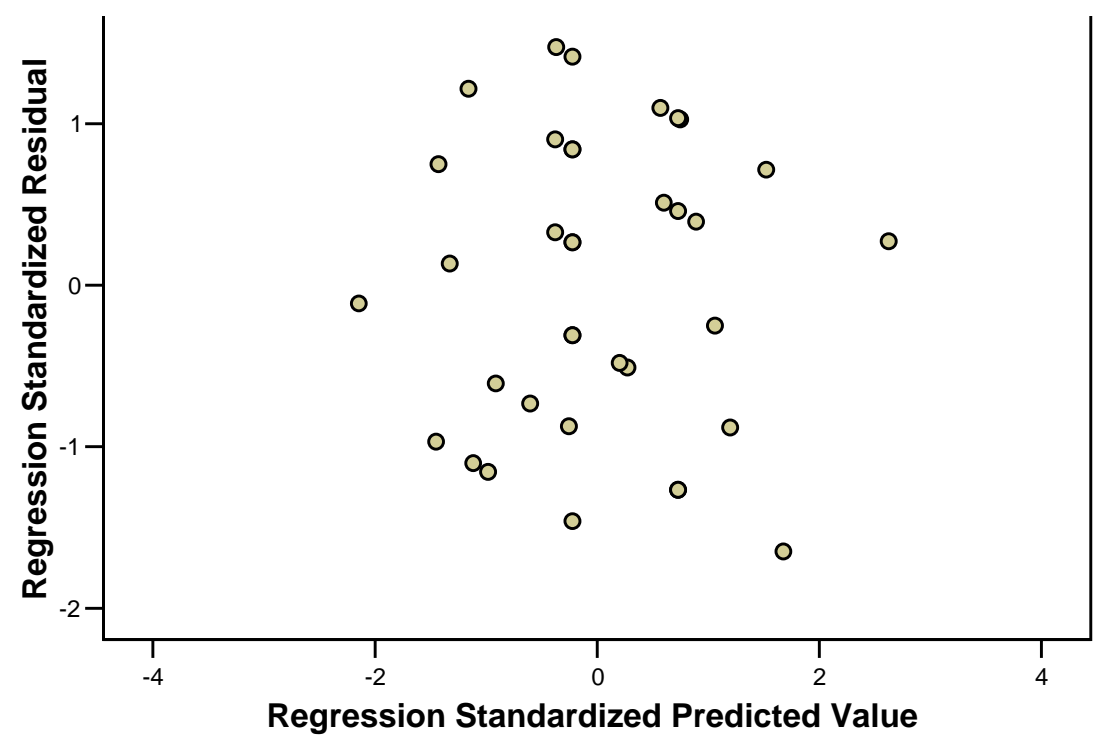

Figure 11. Regression standardized predicted value on Simulation Scenarios.

Collinearity statistics in Table 9 (i.e., Tolerance and VIF) demonstrate that multicollinearity is not a problem. Tolerances are more than 0.10 and, therefore cannot be seen as indicators of high or extreme multicollinearity. VIF data are not in excess of 10.0 .

The model was not statistically significant, $F(7,28)=.81, n s$. The predictors accounted for $16.8 \%$ of the variability in the Simulation Scenarios and no predictor was statistically significant (Table 9).

Since there was no significance found and the data was ordinal, the suggestion by Andrews et al. (1998) was applied that stated that multiple regression analyses may not be applicable when the dependent variable is ordinal such as in this case. Therefore, chi-square values were generated as a 
result of individual crosstabulations between the dependent variable (Simulation Scenarios) and each of the seven independent variables (Content, Accuracy, Navigation, Flow, Look, Assessment, and Value). There were no significant results, which was consistent with the findings of the multiple regression.

Table 9

Multiple Regression on Scenario Using Seven Predictors $(N=36)$

\begin{tabular}{|c|c|c|c|c|c|c|c|}
\hline Predictor Variable & $B$ & $S E B$ & $\beta$ & $t$ & Sig. & Tolerance & VIF \\
\hline Content & -.991 & .787 & -.443 & -1.258 & .219 & .240 & 4.168 \\
\hline Accuracy & -.203 & .560 & -.101 & -.362 & .720 & .383 & 2.621 \\
\hline Navigation & .671 & .595 & .357 & 1.128 & .269 & .297 & 3.370 \\
\hline Look & -.765 & .628 & -.381 & -1.217 & .234 & .303 & 3.295 \\
\hline Flow & -.583 & .646 & -.289 & -.903 & .374 & .290 & 3.448 \\
\hline Assessment & .974 & .804 & .507 & 1.212 & .236 & .170 & 5.869 \\
\hline Value & .233 & .748 & .114 & .311 & .758 & .223 & 4.482 \\
\hline
\end{tabular}


Course 1 Correlation Analysis

Thirty-five correlations were conducted among Learner Satisfaction and Course scores.

Personal Benefit was statistically correlated with Value, $r_{p b}(36)=.36, p<.05$ (Table 10). The positive correlations indicate that as Personal Benefit increased, Value increased. No other correlations were statistically significant.

Table 10

Correlations among Learner Satisfaction and Course (Course 1) ( $N=36)$

\begin{tabular}{|c|c|c|c|c|c|}
\hline Variable & $\begin{array}{c}\text { Gain } \\
\text { (Spearman) }\end{array}$ & $\begin{array}{c}\text { PB } \\
\text { (Point- } \\
\text { Biserial) }\end{array}$ & $\begin{array}{c}\text { OB } \\
\text { (Point- } \\
\text { Biserial) }\end{array}$ & $\begin{array}{c}\text { Retention } \\
\text { (Spearman) }\end{array}$ & $\begin{array}{c}\text { Scenario } \\
\text { (Spearman) }\end{array}$ \\
\hline Content & -.019 & .280 & -.044 & .090 & -.229 \\
\hline Accuracy & -.102 & -.064 & -.252 & -.078 & -.145 \\
\hline Navigation & .273 & .157 & -.264 & .042 & -.074 \\
\hline Look & .157 & .223 & -.252 & .101 & -.180 \\
\hline Flow & .114 & .192 & -.070 & .017 & -.153 \\
\hline Assessment & .015 & .305 & -.254 & .137 & -.006 \\
\hline Value & -.075 & $.358 *$ & .118 & .025 & -.068 \\
\hline
\end{tabular}

Note. ${ }^{*} p<.05$. 


\section{Regression Analysis for Course 2}

Three multiple regressions and two logistic regressions were conducted on the five criterion variables (Gain, Personal benefit, Organizational benefit, Retention, and Simulation) using seven predictors (Content, Accuracy, Navigation, Look, Flow, Assessment, and Value).

Gain. A multiple regression on Gain using the seven predictors was conducted. The assumptions of linearity, homoscedasticity, and multicollinearity were met. Figure 12 shows the scatterplot with standardized residuals versus standardized predicted values to illustrate no violations of linearity and homoscedastisity.

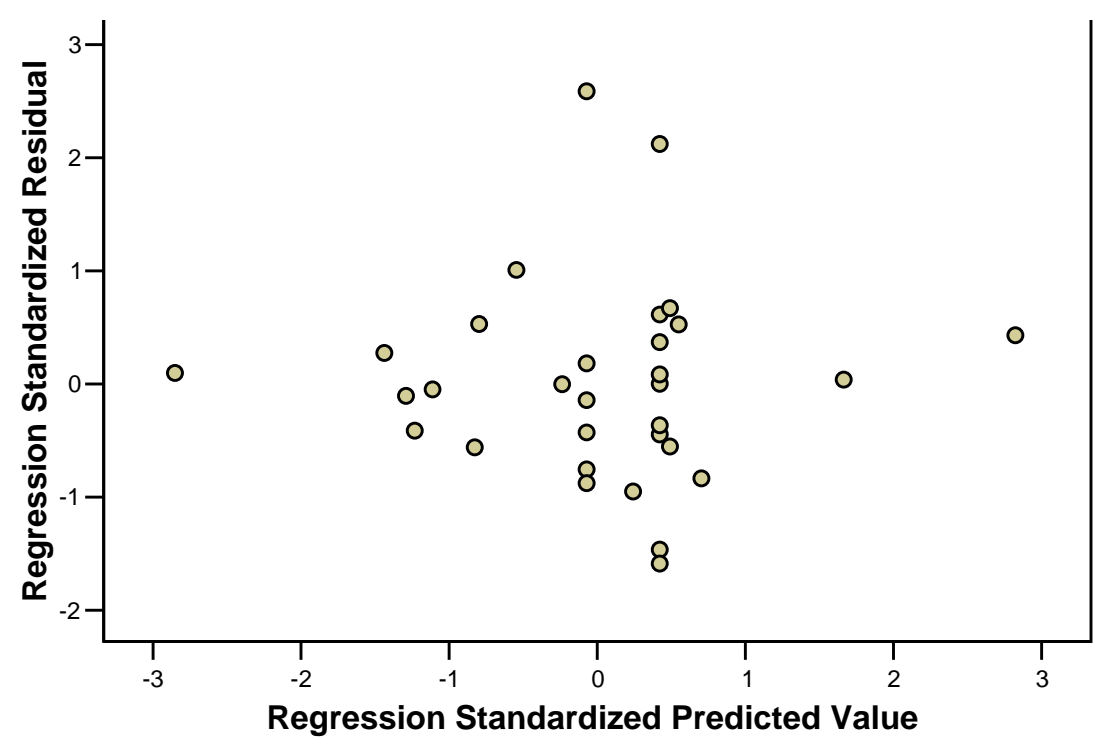

Figure 12. Regression standardized predicted value on Gain.

Collinearity statistics in Table 11 (i.e., Tolerance and VIF) show that multicollinearity is not a problem. Tolerances are more than 0.10 and, therefore, they cannot be seen as indicators of high or extreme multicollinearity. VIF data are not in excess of 10.0.

The regression model was not statistically significant, $F(7,23)=.57, n s$. The predictors accounted for $14.8 \%$ of the variability in Gain, and none of the variables was statistically significant (Table 11). 
Table 11

Multiple Regression on Gain Using Seven Predictors $(N=31)$

\begin{tabular}{|c|c|c|c|c|c|c|c|}
\hline Predictor Variable & $B$ & $S E$ & $\beta$ & $t$ & Sig. & Tolerance & VIF \\
\hline Content & 2.940 & 13.292 & .077 & .221 & .827 & .307 & 3.259 \\
\hline Accuracy & -2.520 & 7.517 & -.084 & -.335 & .740 & .583 & 1.709 \\
\hline Navigation & 1.609 & 13.096 & .052 & .123 & .903 & .208 & 4.800 \\
\hline Look & -16.855 & 10.886 & -.578 & -1.548 & .135 & .266 & 3.762 \\
\hline Flow & -2.753 & 11.607 & -.085 & -.237 & .815 & .291 & 3.438 \\
\hline Assessment & 9.321 & 12.105 & .306 & .770 & .449 & .235 & 4.258 \\
\hline Value & 3.834 & 11.690 & .097 & .328 & .746 & .424 & 2.359 \\
\hline
\end{tabular}

Personal Benefit. A forward stepwise binomial logistic regression using Wald statistic was conducted on Personal Benefit. The seven predictors (Content, Accuracy, Navigation, Flow, Look, Assessment, and Value) were tested. The model was statistically significant, $X^{2}(1)=4.163, p<.05$, $p=.041$. The variable Navigation entered the model using a forward stepwise approach with the Wald statistic determining significance, $p=.07, p<.10$.

Organizational Benefit. A forward stepwise binomial logistic regression using Wald statistic was conducted on Organizational Benefit. The seven predictors were Content, Accuracy, Navigation, Flow, Look, Assessment, and Value. The model was not statistically significant $(p>.05)$. None of the variables entered the model using a forward stepwise approach with the Wald statistic. 
determining significance.

Retention. A multiple regression on Retention using the seven predictors was performed, where the assumptions of linearity, homoscedasticity, and multicollinearity were met. Figure 13 shows the scatterplot with standardized residuals versus standardized predicted values without violations of linearity and homoscedasticity.

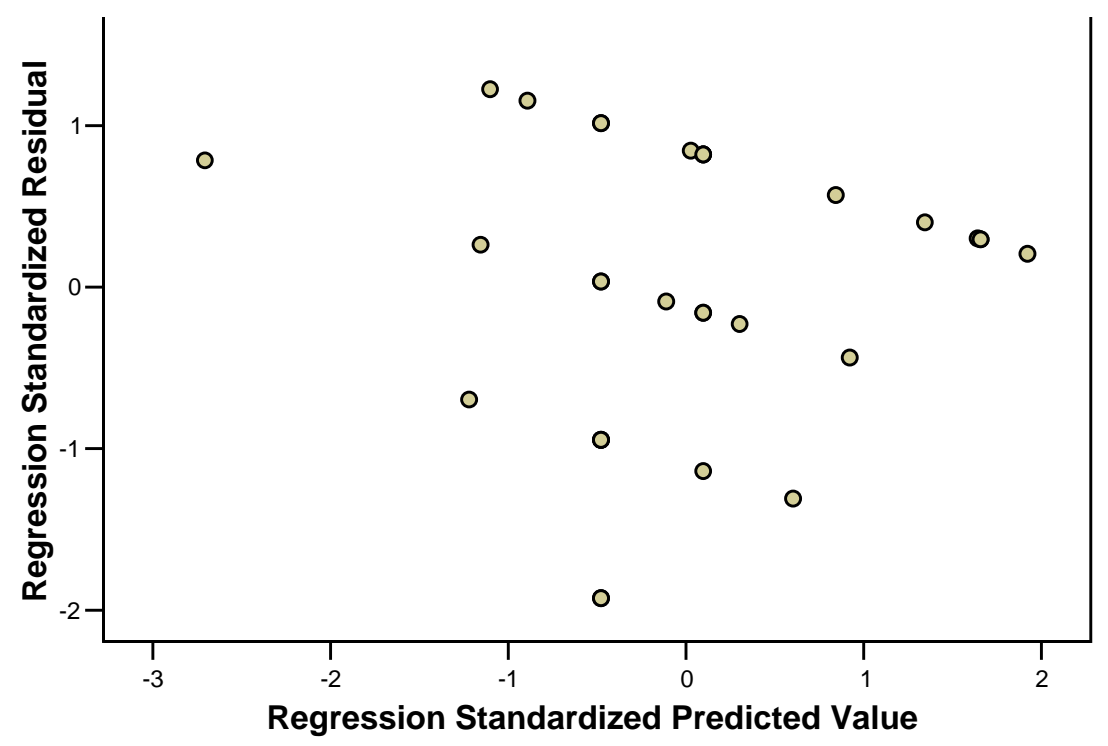

Figure 13. Regression standardized predicted value on Retention.

Collinearity statistics in Table 12 (i.e., Tolerance and VIF) demonstrate that multicollinearity is not a problem. Tolerances are more than 0.10 and, therefore, they cannot be seen as indicators of high or extreme multicollinearity. VIF data are not in excess of 10.0.

The model was not statistically significant, $F(7,23)=.48, n s$. The predictors accounted for $12.9 \%$ of the variability in Retention, and no predictor was statistically significant (Table 12). Andrews et al. (1998) note that multiple regression analyses may not applicable when the dependent variable is ordinal such as in this case. Therefore, chi-square values were generated as a result of individual crosstabulations between the dependent variable (Retention) and each independent one of seven independent variables (Content, Accuracy, Navigation, Flow, Look, Assessment, and Value). 
There were no significant results, indicating no associations between the variables. This was consistent with the findings from the multiple regression.

Table 12

Multiple Regression on Retention Using Seven Predictors $(N=31)$

\begin{tabular}{|c|c|c|c|c|c|c|c|}
\hline Predictor Variable & $B$ & $S E B$ & $\beta$ & $t$ & Sig. & Tolerance & VIF \\
\hline Content & .154 & .553 & .098 & .278 & .783 & .307 & 3.259 \\
\hline Accuracy & -.268 & .313 & -.218 & -.857 & .400 & .585 & 1.709 \\
\hline Navigation & .255 & .545 & .199 & .467 & .645 & .206 & 4.800 \\
\hline Look & .340 & .453 & .284 & .751 & .460 & .266 & 3.762 \\
\hline Flow & -.040 & .483 & -.030 & -.084 & .934 & .291 & 3.438 \\
\hline Assessment & -.428 & .504 & -.342 & -.851 & .404 & .235 & 4.258 \\
\hline Value & .185 & .486 & .114 & .381 & .707 & .424 & 2.359 \\
\hline
\end{tabular}


Simulation Scenarios. A multiple regression on Simulation Scenarios using the seven predictors was conducted. The assumptions of linearity, homoscedasticity, and multicollinearity were met. Figure 14 shows the scatterplot with standardized residuals versus standardized predicted values that demonstrate no problems with linearity and homoscedastisity.

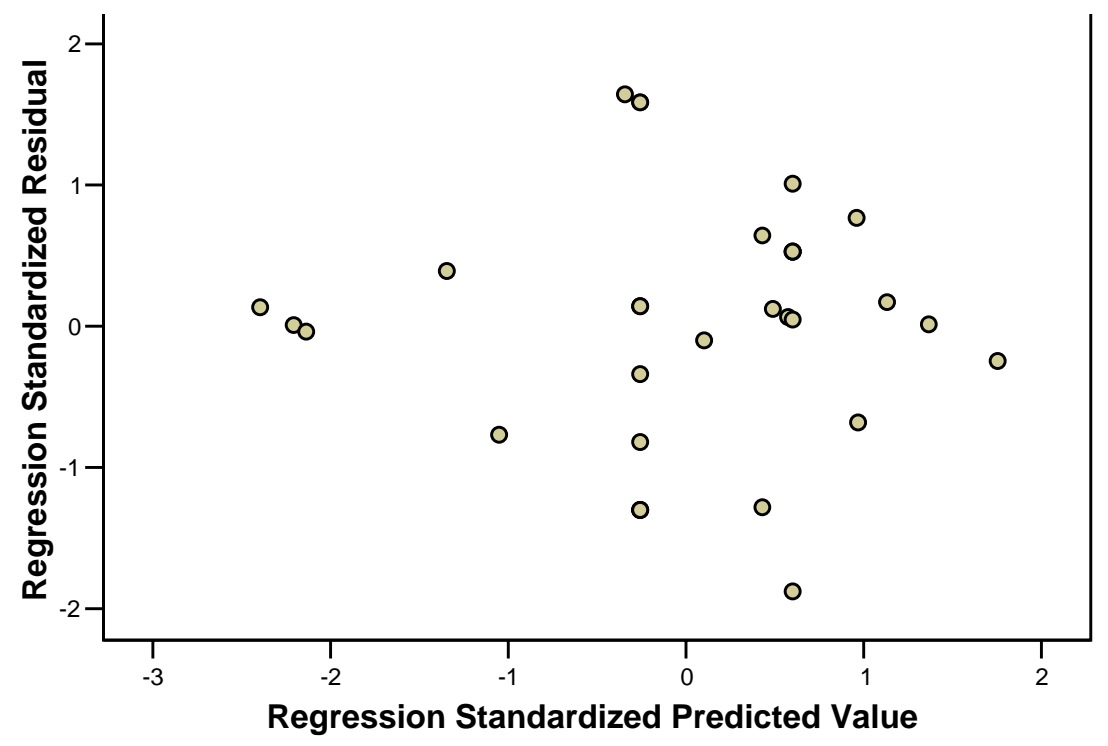

Figure 14. Regression standardized predicted value on Simulation Scenarios.

Collinearity statistics in Table 13 (i.e., Tolerance and VIF) demonstrate that multicollinearity is not a problem. Tolerances are more than 0.10 and, therefore, they cannot be seen as indicators of high or extreme multicollinearity. VIF data are not in excess of 10.0.

The model was not statistically significant, $F(7,23)=1.93, n s$. The predictors accounted for $37.0 \%$ of the variability in Simulation Scenarios. Navigation was a statistical predictor of Simulation Scenarios (Table 13). As the satisfaction with Navigation increased, Simulation Scenarios scores increased. Assessment rating was also a statistically significant predictor of Simulation Scenarios' scores. As Assessment ratings increased, Simulation Scenarios' scores also increased.

As noted, Andrews et al. (1998) point out that multiple regression analyses may not be 
applicable when the dependent variable is ordinal such as in this case. Therefore, chi-square values were generated as a result of individual crosstabulations between the dependent variable (Simulation Scenarios) and each of the seven independent variables (Content, Accuracy, Navigation, Flow, Look, Assessment, and Value).

Table 13

Multiple Regression on Scenario Using Seven Predictors $(N=31)$

\begin{tabular}{|c|c|c|c|c|c|c|c|}
\hline $\begin{array}{l}\text { Predictor } \\
\text { Variable }\end{array}$ & $B$ & $S E B$ & $\beta$ & $t$ & Sig. & Tolerance & VIF \\
\hline Content & .167 & 1.127 & .044 & .148 & .884 & .307 & 3.259 \\
\hline Accuracy & .119 & .637 & .040 & .187 & .854 & .585 & 1.709 \\
\hline Navigation & -2.808 & 1.110 & -.917 & -2.530 & $.019^{*}$ & .208 & 4.800 \\
\hline Look & 1.004 & .923 & .349 & 1.088 & .288 & .266 & 3.762 \\
\hline Flow & .541 & .984 & .169 & .550 & .588 & .291 & 3.438 \\
\hline Assessment & 2.306 & 1.026 & .767 & 2.247 & $.035^{*}$ & .235 & 4.258 \\
\hline Value & -.130 & .991 & -.033 & -.131 & .897 & .424 & 2.359 \\
\hline
\end{tabular}

Note. ${ }^{*} p<.05$.

Although Pearson chi-square was not significant, $p>.05$, when crosstabulation was performed between Simulation Scenarios and Navigation, the likelihood ratio was significant $(\mathrm{LR}=$ 
23.836, $p=.021$, which is analogous to the multiple regression indicating a linear relationship.

Wright (2000) states: “A likelihood ratio test is analogous to an F test in linear regression” (p. 403).

When crosstabulation was performed between Simulation Scenarios and Assessment, chi-square was not significant and the likelihood ratio was not significant.

Course 2 Correlation Analysis

Thirty-five correlations were conducted among Learner Satisfaction and Course scores.

Personal Benefit was statistically correlated with Navigation, $r_{p b}(31)=.45, p<.05$ (Table 14). The positive correlations indicate that as Personal Benefit scores increased, Navigation scores increased. Organizational Benefit was statistically correlated with Accuracy, $r_{p b}(31)=.37, p<.05$ (Table 14). No other correlations were statistically significant. 
Table 14

Correlations among Learner Satisfaction and Course (Course 2) ( $N=31)$

\begin{tabular}{llllll}
\hline Variable & $\begin{array}{l}\text { Gain } \\
(\text { Spearman })\end{array}$ & $\begin{array}{l}\text { PB } \\
(\text { Point- } \\
\text { Biserial })\end{array}$ & $\begin{array}{l}\text { OB } \\
\text { (Point- } \\
\text { Biserial) }\end{array}$ & $\begin{array}{l}\text { Retention } \\
\text { (Spearman) }\end{array}$ & $\begin{array}{l}\text { Scenario } \\
\text { (Spearman) }\end{array}$ \\
\hline Content & -.127 & .224 & .112 & .162 & .156 \\
Accuracy & -.110 & .003 & $.368^{*}$ & -.090 & .024 \\
Navigation & -.103 & $447^{*}$ & .113 & .175 & .087 \\
Look & -.273 & .050 & -.025 & .328 & .295 \\
Flow & -.159 & .210 & -.008 & .286 & .184 \\
Assessment & -.049 & .191 & .075 & .105 & .314 \\
Value & -.034 & .353 & -.217 & .206 & .124 \\
\hline
\end{tabular}

Note. ${ }^{*} p<.05$.

\section{Combined Course Analyses}

The data from both courses were combined as a result of tests of homogeneity.

Tests of Homogeneity

Twelve t-tests were conducted on Learner Satisfaction and Course scores by course.

The assumptions of homogeneity of variance were met $(p>.05)$ for all 12 tests. If the test results in 
significance $(p<=.05)$, the null hypothesis that the groups have equal variances is rejected. There were no differences on these scores by course (Table 15). Accordingly, scores for Course 1 and Course 2 were combined for subsequent analyses. The means and standard deviations are presented in Table 16.

Table 15

t-tests on Research Variables by Course

\begin{tabular}{lccc}
\hline Variable & $t$ & df & $p$ \\
\hline Gain & -.465 & 65 & .644 \\
PB & -1.043 & 65 & .301 \\
OB & .348 & 65 & .729 \\
Retention & .822 & 65 & .414 \\
Scenario & -1.287 & 65 & .203 \\
Content & -.037 & 65 & .971 \\
Accuracy & -.582 & 65 & .563 \\
Navigation & .537 & 65 & .593 \\
Look & .381 & 65 & .705 \\
Flow & 1.142 & 65 & .258 \\
Assessment & .088 & 65 & .930 \\
Value & .381 & 65 & .705 \\
& & & \\
\hline
\end{tabular}


Table 16

Means and Standard Deviations on Scores by Course

\begin{tabular}{|c|c|c|c|c|}
\hline \multirow[t]{2}{*}{ Variable } & \multicolumn{2}{|c|}{ Course 1} & \multicolumn{2}{|c|}{ Course 2} \\
\hline & $M$ & $S D$ & $M$ & $S D$ \\
\hline Gain & 24.16 & 23.27 & 26.44 & 16.79 \\
\hline PB & 0.87 & 0.34 & 0.94 & 0.23 \\
\hline $\mathrm{OB}$ & 0.84 & 0.37 & 0.81 & 0.40 \\
\hline Retention & 3.13 & 0.96 & 2.92 & 1.13 \\
\hline Scenario & 3.06 & 2.29 & 3.69 & 1.70 \\
\hline Content & 3.35 & 0.61 & 3.36 & 0.76 \\
\hline Accuracy & 3.16 & 0.78 & 3.28 & 0.85 \\
\hline Navigation & 3.19 & 0.75 & 3.08 & 0.91 \\
\hline Look & 3.35 & 0.80 & 3.28 & 0.85 \\
\hline Flow & 3.39 & 0.72 & 3.17 & 0.85 \\
\hline Assessment & 3.13 & 0.76 & 3.11 & 0.89 \\
\hline Value & 3.29 & 0.59 & 3.22 & 0.83 \\
\hline
\end{tabular}


Combined Course Regression Analysis

Three multiple regressions and two logistic regressions were conducted on the five criterion variables (Gain, Personal benefit, Organizational benefit, Retention, and Simulation) using seven predictors (Content, Accuracy, Navigation, Look, Flow, Assessment, and Value).

Gain. A multiple regression on Gain using the seven predictors was conducted. The assumptions of linearity, homoscedasticity for all 7 tests, and multicollinearity were met. Figure 15 shows the scatterplot, which indicates no violations of linearity and homoscedasticity.

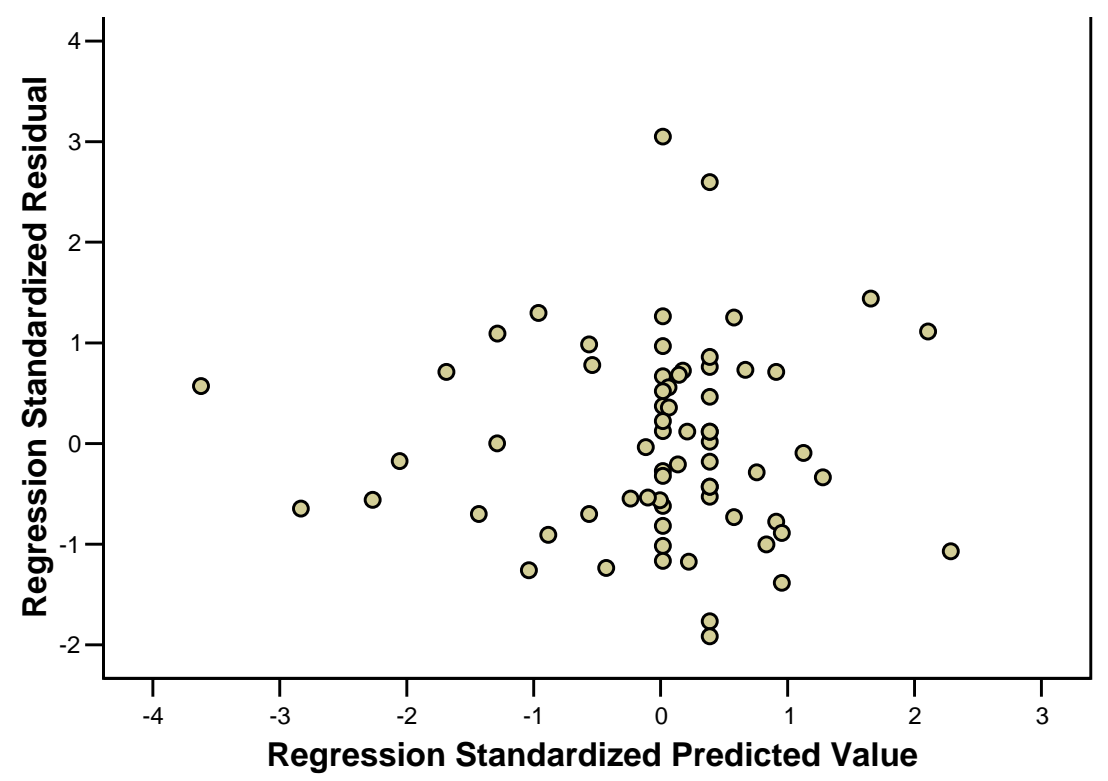

Figure 15 . Regression standardized predicted value on Gain.

Collinearity statistics in Table 17 (i.e., Tolerance and VIF) demonstrate that multicollinearity is not a problem. Tolerances are more than 0.10 and, therefore, they cannot be seen as indicators of high or extreme multicollinearity. VIF data are not in excess of 10.0.

The regression model was not statistically significant, $F(7,59)=.77$, ns. The predictors accounted for $8.4 \%$ of the variability in Gain, and Navigation was a statistically significant predictor. No other variables were statistically significant (Table 17). 
Table 17

Multiple Regression on Gain Using Seven Predictors $(N=67)$

\begin{tabular}{|c|c|c|c|c|c|c|c|}
\hline Predictor Variable & $B$ & $S E B$ & $\beta$ & $t$ & Sig. & Tolerance & VIF \\
\hline Content & .690 & 6.459 & .024 & .107 & .915 & .310 & 3.221 \\
\hline Accuracy & -2.574 & 4.272 & -.105 & -.603 & .549 & .511 & 1.958 \\
\hline Navigation & 10.510 & 4.951 & .439 & 2.123 & $.038 *$ & .362 & 2.759 \\
\hline Look & -5.349 & 5.367 & -.220 & -.997 & .323 & .318 & 3.146 \\
\hline Flow & -5.020 & 5.194 & -.199 & -.966 & .338 & .366 & 2.730 \\
\hline Assessment & 1.474 & 6.089 & .061 & .242 & .810 & .244 & 4.106 \\
\hline Value & -1.863 & 5.973 & -.068 & -.312 & .756 & .329 & 3.042 \\
\hline
\end{tabular}

Note. ${ }^{*} p<.05$.

Personal Benefit. A forward stepwise binomial logistic regression using Wald statistic was conducted on Personal Benefit. The seven predictors (Content, Accuracy, Navigation, Flow, Look, Assessment, and Value) were tested. The model was statistically significant, $X^{2}(1)=6.604, p<.05$; $p=.01$. The variable Value entered the model using a forward stepwise approach with the Wald statistic determining significance, $p=.018$.

Organizational Benefit. A forward stepwise binomial logistic regression using Wald statistic was conducted on Organizational Benefit. The seven predictors were Content, Accuracy, Navigation, 
Flow, Look, Assessment, and Value. None of the variables entered the model using a forward stepwise approach with the Wald statistic determining significance.

Retention. A multiple regression on Retention using the seven predictors was conducted, where the assumptions of linearity, homoscedasticity, and multicollinearity were met. Figure 16 shows the scatterplot that demonstrates no violations of linearity and homoscedasticity assumptions.

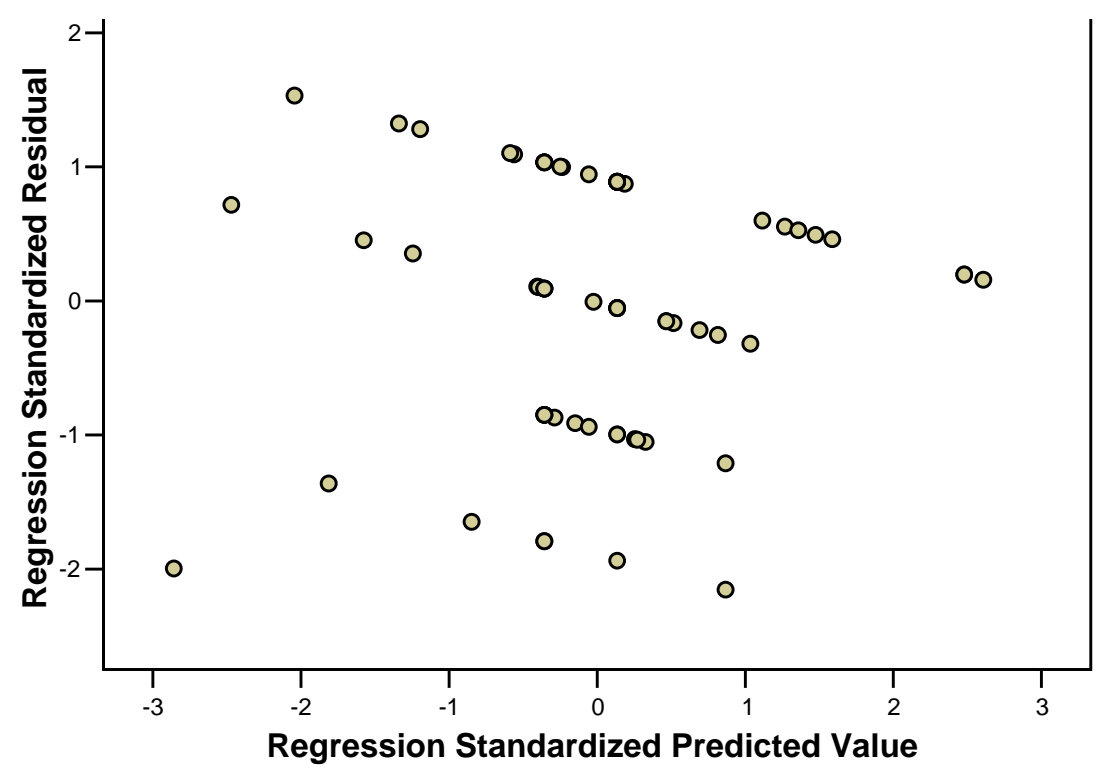

Figure 16. Regression standardized predicted value on Retention.

Collinearity statistics in Table 18 (i.e., Tolerance and VIF) demonstrate that multicollinearity is not a problem. Tolerances are more than 0.10 and, therefore, they cannot be seen as indicators of high or extreme multicollinearity. VIF data are not more than 10.0.

The regression model was not statistically significant, $F(7,59)=.82, n s$. The predictors accounted for $8.9 \%$ of the variability in Retention, and no predictor was statistically significant (Table18).

Andrews et al. (1998) note that multiple regression analyses may not be applicable when the dependent variable is ordinal such as in this case. Therefore, chi-square values were generated as a 
result of individual crosstabulations between the dependent variable (Retention) and each of the seven independent variables (Content, Accuracy, Navigation, Flow, Look, Assessment, and Value). There were no significant results, indicating no associations between the variables, which was consistent with the findings of multiple regressions.

Table 18

Multiple Regression on Retention Using Seven Predictors $(N=67)$

\begin{tabular}{|c|c|c|c|c|c|c|c|}
\hline Predictor Variable & $B$ & $S E B$ & $\beta$ & $t$ & Sig. & Tolerance & VIF \\
\hline Content & .432 & .340 & .284 & 1.272 & .208 & .310 & 3.221 \\
\hline Accuracy & -.367 & .225 & -.284 & -1.634 & .108 & .511 & 1.958 \\
\hline Navigation & -.021 & .261 & -.017 & -.082 & .935 & .362 & 2.759 \\
\hline Look & .214 & .283 & .167 & .759 & .451 & .318 & 3.146 \\
\hline Flow & -.073 & .273 & -.055 & -.266 & .791 & .366 & 2.730 \\
\hline Assessment & -.016 & .321 & -.013 & -.051 & .960 & .244 & 4.106 \\
\hline Value & -.015 & .314 & -.010 & -.048 & .962 & .329 & 3.042 \\
\hline
\end{tabular}


Simulation Scenarios. A multiple regression on Simulation Scenarios using the seven predictors was conducted. The assumptions of linearity, homoscedasticity, and multicollinearity were met. Figure 17 shows the scatterplot that indicated no problems with linearity and homoscedasticity.

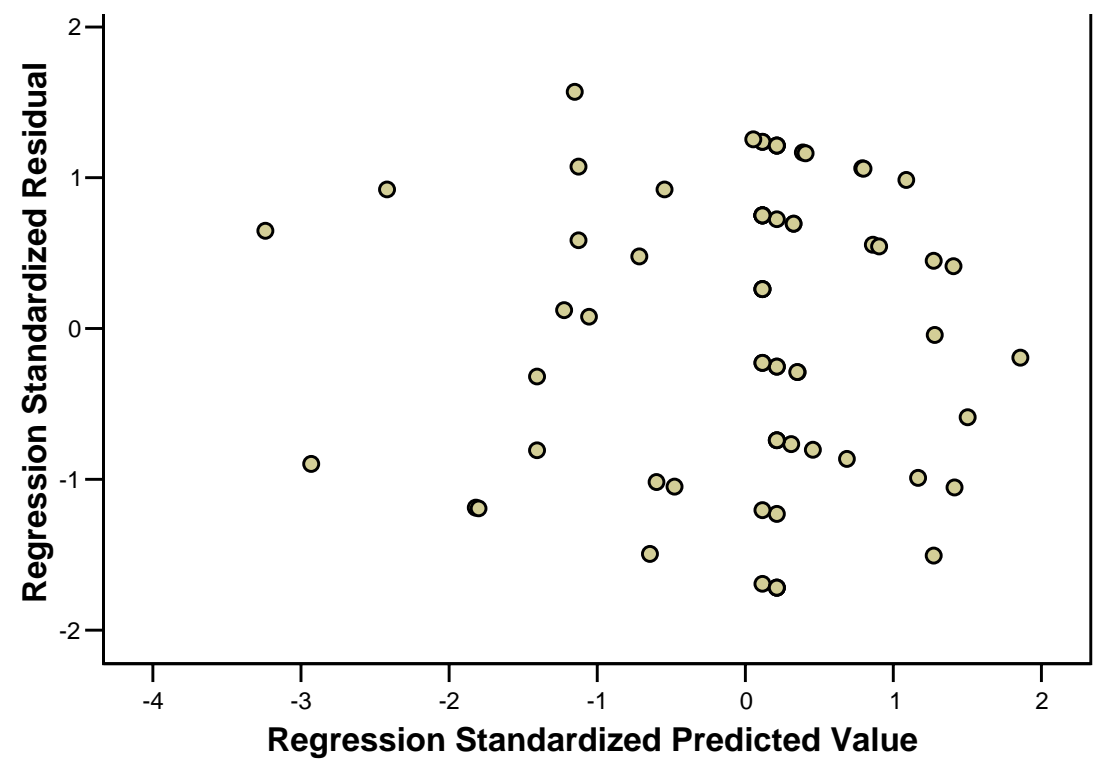

Figure 17. Regression standardized predicted value on Simulation Scenarios.

Collinearity statistics in Table 19 (i.e., Tolerance and VIF) demonstrate that multicollinearity is not a problem. Tolerances are more than 0.10 and, thus, they cannot be seen as indicators of high or extreme multicollinearity. VIF data are less than 10.0 .

The regression model was not statistically significant, $F(7,59)=.64, n s$. The predictors accounted for $7.1 \%$ of the variability in Simulation Scenarios and no predictor was statistically significant (Table 19). Andrews et al. (1998) specify that multiple regression analyses may not be applicable when the dependent variable is ordinal (Simulation Scenarios). Therefore, chi-square values were generated as a result of individual crosstabulations between the dependent variable (Retention) and each of the seven independent variables (Content, Accuracy, Navigation, Flow, 
Look, Assessment, and Value). There were no significant results, indicating no associations between the variables.

Table 19

Multiple Regression on Scenario Using Seven Predictors $(N=67)$

\begin{tabular}{llllllll}
\hline $\begin{array}{l}\text { Predictor } \\
\text { Variable }\end{array}$ & $B$ & $S E B$ & $\beta$ & $t$ & Sig. & Tolerance & VIF \\
\hline Content & -.125 & .656 & -.043 & -.191 & .849 & .310 & 3.221 \\
Accuracy & -.308 & .434 & -.125 & -.711 & .480 & .511 & 1.958 \\
Navigation & -.346 & .503 & -.144 & -.689 & .494 & .362 & 2.759 \\
Look & -.085 & .545 & -.035 & -.156 & .877 & .318 & 3.146 \\
Flow & .286 & .527 & .112 & .542 & .590 & .366 & 2.730 \\
Assessment & 1.023 & .618 & .421 & 1.655 & .103 & .244 & 4.106 \\
Value & & & & & & & \\
\end{tabular}


Combined Course Correlation Analysis

Thirty-five correlations were conducted among Learner Satisfaction and Course scores.

Personal Benefit was statistically correlated with Navigation, $r_{p b}(67)=.24, p<.05$, and Value, $r_{p b}$ $(67)=.33, p<.05$ (Table 20). The positive correlations indicate that as Navigation and Value scores increased, Personal Benefit increased. No other correlations were statistically significant.

Table 20

Correlations among Learner Satisfaction and Course $(N=67)$

\begin{tabular}{|c|c|c|c|c|c|}
\hline Variable & $\begin{array}{c}\text { Gain } \\
\text { (Spearman) }\end{array}$ & $\begin{array}{c}\text { PB } \\
\text { (Point-Biserial) }\end{array}$ & $\begin{array}{c}\text { OB } \\
\text { (Point-Biserial) }\end{array}$ & $\begin{array}{l}\text { Retention } \\
\text { (Spearman) }\end{array}$ & $\begin{array}{c}\text { Scenario } \\
\text { (Spearman) }\end{array}$ \\
\hline Content & -.074 & .164 & .017 & .119 & -.037 \\
\hline Accuracy & -.102 & .150 & -.063 & -.081 & -.035 \\
\hline Navigation & .083 & $.241 *$ & -.112 & .103 & -.004 \\
\hline Look & -.065 & .119 & -.018 & .199 & .056 \\
\hline Flow & -.049 & .173 & -.040 & .141 & -.009 \\
\hline Assessment & -.022 & .235 & -.119 & .126 & .148 \\
\hline Value & -.075 & $.325^{*}$ & .110 & .097 & .008 \\
\hline
\end{tabular}

Note. ${ }^{*} p<.05$. 


\section{Summary of Quantitative Results}

Navigation was a statistically significant predictor of Gain in Course 1, and both courses combined. In Course 2 Navigation was a statistically significant predictor of Simulation Scenarios scores. As Navigation scores increased, Learning Achievement indicators (Gain and Simulation Scenario scores) increased for Course 1, 2, and when courses were combined. Navigation also was positively associated with Personal Benefit in Course 2 and a combined course analysis. Navigation also was a statistically significant predictor of Personal Benefit in Course 2. Ratings of Navigation were associated with learning outcomes (scores of Gain and Simulation Scenarios).

Value was correlated with Personal Benefit and also proved to be a statistically significant predictor of Personal Benefit in Course 1 and when courses were combined. When course value rating was high, as measured by the Satisfaction Questionnaire and Comments following course completion, the course was again valued as a personally beneficial learning experience several months later, as revealed in the Follow-up Questionnaire and Simulation Scenarios' results. Organizational Benefit was correlated with Accuracy in Course 2. Navigation quality and value have associations with personal benefit. Table 21 presents the significant findings from the results of this research. The table shows a pattern of relationships among variables in all three groups. The data analysis has shown that the feeling about navigation quality and value of the courses are related to the degree the participants felt they benefited from these web-based courses. 
Table 21

Significant Associations among Select Variables

\begin{tabular}{|c|c|}
\hline & Significant Associations Established \\
\hline Course 1 & 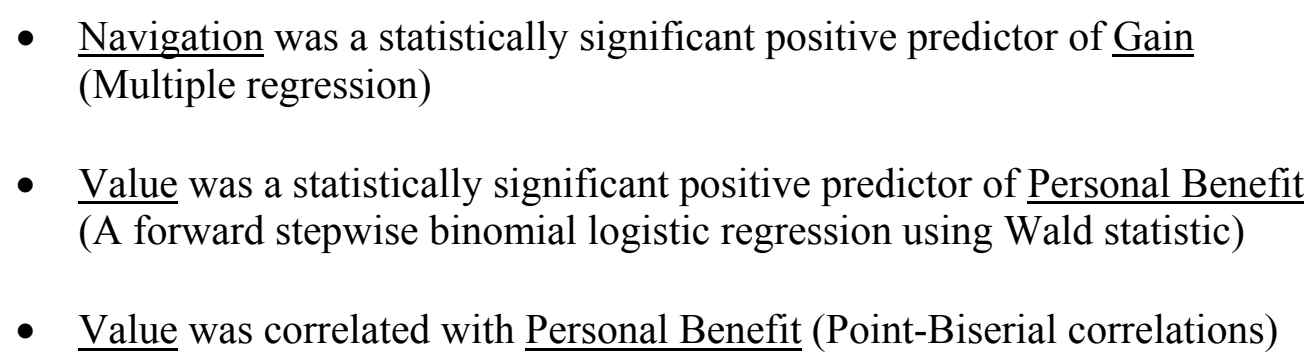 \\
\hline Course 2 & $\begin{array}{l}\text { - } \frac{\text { Navigation had a significant relationship with Simulation Scenarios }}{\text { (Likelihood ratio in crosstabulations) }} \\
\text { - } \frac{\text { Navigation was a statistically significant positive predictor of Personal }}{\text { Benefit (A forward stepwise binomial logistic regression using Wald }} \\
\text { statistic) } \\
\text { - } \frac{\text { Navigation was correlated with Personal Benefit (Point-Biserial }}{\text { correlations) }} \\
\text { - } \frac{\text { Accuracy was correlated with Organizational Benefit (Point-Biserial }}{\text { correlations) }}\end{array}$ \\
\hline $\begin{array}{l}\text { Both } \\
\text { Courses } \\
\text { Combined }\end{array}$ & 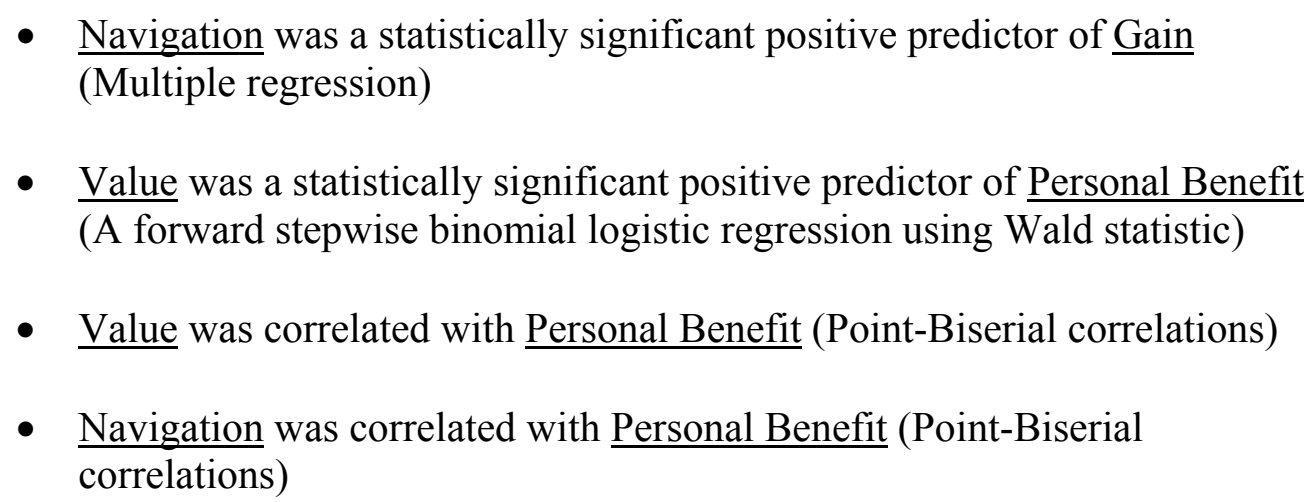 \\
\hline
\end{tabular}




\section{Qualitative Data Analyses}

Including open-ended items on the Satisfaction Questionnaire and Comments instrument provided qualitative data to more fully explain the quantitative results of this study and depict richer context with several major emerging themes to enable further interpretations of the results. The open-ended items of the Satisfaction Questionnaire and Comments (Appendix B) included seven questions concerning (1) most valuable, (2) least valuable, (3) time investment, (4) comparable course, (5) recommendation to a colleague, (6) increased awareness, and (7) competence/selfconfidence. Tests of homogeneity in the quantitative analysis demonstrated that the groups were not statistically significantly different; therefore, allowing for the qualitative data from both courses to be collapsed and coded for major themes per question and overall for both courses. Responses from participants in both courses are summarized in the following paragraphs. The full texts of these open-ended items for Course 1 are reported in Appendix E. The full texts of response items from the participants in Course 2 are reported in Appendix F.

The investigator used two raters for analyzing responses to the open-ended questions to ensure accurate, valid, and reliable presentation and interpretation of results. For Question 1 "What was most valuable to you about the course?" the inter-rater reliability was $90 \%$, and for Question 2 "What was the least valuable to you about the course?" it was $85 \%$. Inter-rater reliability was not calculated for all open-ended responses because the remaining five questions were not truly openended. They had optional comments, but did not require answers open for interpretation (i.e., "yes" or "no"). Therefore, determining the level of agreement among two raters was not applicable. 


\section{Most valuable aspect}

Question 1 asking about the most valuable aspects of the course received the greatest number of responses compared to those for the other questions; 29 (43\%) of 67 responses. One individual, a male participant, expressed his dissatisfaction: "I didn't like it." This assessment comment did not provide a detailed judgment criterion. The comment would be worth consideration were there more, similar responses. Of the 28 remaining responses, $27(97 \%)$ commented on various aspects of the course and $1(3 \%)$ commented on graphical presentation. Participants who provided substantive comments emphasized the importance of learning about coordinated response to WMD incidents. Three emergent themes pertaining to content and subject-matter were observed: (a) learning about incident recognition, reporting, and notification $(\mathrm{n}=12)$, (b) good general overview of information $(n=9)$, (c) learning about potential agents and symptoms $(n=5)$. Visual /graphical $(n$ $=1)$ quality was mentioned, as was ease of navigation $(n=1)$. These data indicate that from the participants' perspective, the course presented valuable information and appeared to be wellorganized.

\section{Least valuable aspect}

The second open-ended question was "What was the least valuable to you about the course?" to which $21(31 \%)$ of 67 participants provided a response. Eight participants simply responded "Nothing." One male said: "Most of the information was new to me so I can't say that any of the content was invaluable." According to Rogers (1983), this is a typical reply from individuals who are not experienced and who may have nothing for comparison. The majority of the participants stated "everything was valuable," compared to those who commented on technical accuracy $(\mathrm{n}=4)$ (e.g., "spelling and grammatical errors were a little distracting. Some of the questions took a lot of extrapolation and knowledge of information which was not presented. A few places were not 
consistent, smallpox stated as airborne and tested as bloodborne, suspected incident to be reported to state while graphic says local, the liability protection for providers of smallpox vaccine is time limited"). Similarly, some participants commented on missing graphics $(n=2)$ (e.g., "Pictures.... they weren't there (some of them)"and "Pictures.... they were blank some of them.") and on registration and navigation $(\mathrm{n}=2)(\mathrm{e} . \mathrm{g}$., "too difficult to register and manage course for content to be very similar to previous trainings" and "the course was somewhat hard to navigate (sign in and starting)."). Redundancy of information was noted in two responses $(n=2)$ (e.g., "Redundant information on history of terrorism, oblique positive references to need for "war on terror"). One male disliked the entire course: "It seemed to be just a waste of time, and I do not feel like I learned anything at all from it." The majority of the responders who answered this question $(\mathrm{n}=10)$ commented on some dissatisfaction with technical accuracy of the courses, especially visual and navigational appeal and not with course content value.

\section{Worth time investment}

Question 3 was “Was this course worth your time investment?” to which 64 (96\%) of 67 responded. Of these 64, 53 respondents (83\%) answered “yes," while 11 people $(17 \%)$ answered “no." Open-ended comments were provided by 13 (20\%) participants, nine of which were positive and five negative. Revealed were two positive themes (a) good general overview (n=6) (e.g., "Good overall knowledge of the subject"), (b) importance of new knowledge of coordinated response $(\mathrm{n}=3)$ (e.g., "Good review. I appreciate the emphasis placed on contacting the local health department as soon as possible to allow support from better-equipped state teams"), and one negative (c) navigation problems $(n=2)$ (e.g., "I found it difficult to navigate the course, buttons on exams should be at the bottom, or once a choice is made just automatically go to next question. I felt like I wasted a lot of time on each module learning where the navigation buttons were located"). One 
person simply did not like it (e.g. "it was boring to read all this dry materials"). Another participant liked the course, but felt it was not appropriate for him at this level: "Due to experiences in planning this information was pretty basic for me but when I was involved in hospital planning much of it would have been good to know." Comparing this comment with one such as "First training I have had in terrorist attack and procedure for events like this" illustrates the degree of variability in the participant knowledge base and levels of preparation. The majority stated that the course was worth their time investment.

\section{Previous comparative experience}

The fourth open-ended question asked was "Have you taken a comparable course (if Yes, please name it and compare its effectiveness to this course)?" to which 64 (96\%) of 67 participants responded. Of the 64 there were 15 (23\%) participants who answered "yes" and in the negative was 49 (77\%) who answered "no.” Comparable courses reportedly taken were from FEMA, California EMS, and HIPPA. Participants were asked to compare the effectiveness of the WMD courses with the effectiveness of other comparable courses. Of those 15 participants who answered "yes," three gave comments. One person gave a comparative comment concerning the navigation quality: "I have completed the NIH protection of human subjects in research course, the navigation was much easier to follow because it was in a central location, and there was also a link to the course from the main page where the module would just start." Another person gave a comparative comment concerning the content quality: "Several FEMA self study courses go into implementation strategies. Threat preparedness in the local health department has exposed me to state and federal level planning programs not available to other sectors. Haz-Mat specialist training also addresses much of this data in greater depth." Thus, the majority of the participants indicated that they never took a comparable course. It is not clear whether or not the participants answered about their lack of previous 
experiences specifically in reference to a content subject-matter or method of course delivery. This finding suggests lacking in experience taking similar courses among learners.

\section{Course recommendation to colleagues}

Question five asked participants "Would you recommend this course to your colleague?" to which $64(96 \%)$ of 67 participants responded. Of these 64 there were $56(88 \%)$ who answered "yes" and $8(12 \%)$ who answered "no." A male and a female, respectively, who said they would not recommend the course made the following comments: "Because it's a waste of time!" and "Not that much real content." However, more than half stated they would recommend this course, indicating satisfaction and that the course was personally valuable to them. Of the 56 who answered "yes," 13 provided additional comments. Their comments were in regard to (a) useful learning experience, (b) easy navigation, (c) convenience, (d) content presentation. The three negative comments from those participants who answered "no" spoke of wasting time and the length of course, though not specifically on volume or time required for completion. The general perspective of those who responded to this question was positive. The participants were satisfied with the course and it was personally valuable to them. The majority would recommend the course to others.

\section{Increased awareness}

Open-ended question six asked "Do you have an increased awareness of the need for a coordinated response to a weapons of mass destruction (WMD) event?" to which 61 (91\%) of 67 participants responded. Of the 61 who responded 55 (90\%) said "yes" and 6 (10\%) said "no," with 11 providing additional comment; two negative and nine positive. The positive emergent themes were (a) content $(n=3),(b)$ importance of subject-matter $(n=6)$, and the negative themes were (c) ineffectiveness $(n=1)$, and $(d)$ inaccuracy $(n=1)$. Only one participant made a comment: "Because I learned nothing. This course really isn't very effective.... and it's boring." Most people expressed 
the notion of being more aware of the need to coordinate the response to WMD, which was the overall goal of this course. The majority of positive responses point to satisfaction, value, and personal benefit.

Increased self-confidence and competence

The seventh open-ended question asked "Will this course contribute a new level of competence and self-confidence among health care providers in planning for a WMD event?" to which 60 (90\%) of 67 participants responded. Of these 60 responses $56(93 \%)$ said "yes," and $3(7 \%)$ said "no." The majority felt more prepared to deal with WMD emergencies after taking this course. They were glad to have gained new knowledge which they felt could be applied to novel situations. This indicates that gaining satisfaction and considering the course of value is relevant to personal benefit (e.g., "I am revising our hospital's lockdown policy based on recommendations of your course" and "I am better educated and prepared from having taken the course"). In total, the courses would lead to a new level of competence among health care providers in planning for a WMD event.

\section{Summary of Qualitative Results}

Overall, there were far more positive comments than negative comments. And the negative responses were directed more toward the Learning Management System (LMS) and course navigation (e.g., difficulty in gaining access to courses though registration, logon, and then progressing between the modules in the course) than presentation of content.

In Course 1, a male and a female commented on registration and navigation: "too difficult to register and manage course for content to be very similar to previous trainings" and "the course was somewhat hard to navigate (sign in and starting)." The users also did not report having a lot of prior opportunities for participating in comparable courses, and perhaps it influenced their experience. 
Perhaps a more seasoned participant would recommend Course 1: "I feel it is a worthwhile learning experience, fairly easy to navigate and person can take it when most convenient to them."

From the answers to the first three questions regarding the most and the least valuable aspects, as well as worthiness of time investment, the participants indicated there were more problems with a system, as represented by comments on navigation, for example. The least valuable aspects of the courses concerned some technical accuracy of the courses, especially visual and navigational appeal.

Overall, the qualitative analysis revealed that from the learners' perspective, the courses offered valuable information and were found to be well-organized. The majority declared that the course was worth their time investment. They were satisfied with the courses. Taking these courses was personally valuable to them. The courses were found fit to accommodate health care providers in gaining a new level of competence in preparation for a WMD event. The participants would recommend these courses to others.

\section{Summary of Overall Analysis: Quantitative and Qualitative}

Navigation was a statistically significant predictor of learning achievement scores and estimate of personal benefit which also was associated with value judgments placed on the course. When participants initially estimated that the courses were valuable, they later indicated that those courses had personal benefit to them. The correlation of value and benefit is supported by other research on a relationship between course satisfaction and perceived usefulness (Drennan, Kennedy, \& Pisarski, 2005). These researchers explained a stronger relationship by the end of the course: "possibly because students had time to use the learning materials offered and were able to form a more educated opinion as to their usefulness" (p. 337). 
Adult learners in this study appeared to intuitively link their learning effectiveness and personal benefit from the courses and their perception or satisfaction with web-based educational courses on bioterrorism. The qualitative analysis revealed that from the learners' perspective, the courses were of value to them and worth their time investment. The participants believed the courses would contribute a new level of competence among their communities of practice in preparation for a WMD event. The participants would recommend these courses to others.

Qualitative data analysis exposed some dissatisfaction with course navigation among the participants (e.g., difficulty in gaining access to courses though registration, logon, and then progressing between the modules in the course) and quality of visuals.

In the quantitative analysis, Navigation was correlated with Personal Benefit participants later derived from the courses. Navigation was a statistically significant positive predictor of learning achievement, which may indicate that some improvement in navigation experience of learners can increase learning outcomes. The participants who had higher satisfaction with course navigation tended to demonstrate greater achievement scores. This outcome is in agreement with other similar studies mentioned in the literature review. 


\section{CHAPTER 5}

\section{CONCLUSIONS, IMPLICATIONS, RECOMMENDATIONS}

The purpose of the study was to explore the potential relationships between (a) measures of learner satisfaction with online courses on WMD and bioterrorism that address the educational needs of responder communities of practice $(\mathrm{CoP})$ and $(\mathrm{b})$ degrees of accomplishment by the learner with those online courses. Analyses dealt with establishing the potential relationship of (a) the variables associated with the Learner Satisfaction with the course and (b) the variables representing the measures of Learning Performance. Multiple measures of learner satisfaction (Content, Accuracy, Navigation, Look, Flow, Assessment, and Value) were administered and examined in relation to multiple measures of learner achievement (Pre-Post Gain, Follow-up Personal Benefit, Follow-up Organizational Benefit, Follow-up Subject-Matter Retention, and Follow-up Simulation Scenarios). For the two courses, course design characteristics were similar, and content was different. Therefore, it was important to examine learner satisfaction with features common to the two courses in relation to learning outcomes. To facilitate potential design improvements in the future, this study identified the predictors of effectiveness and the relations between (a) learner satisfaction with the course characteristics and (b) learner achievement. This research dealt with identifying the elements that had bearing on satisfaction of learning from online courseware.

\section{Conclusions}

Given a web-based course offered through an Integrated Knowledge Base (IKB) portal, there were the following relationships established among (a) measures of Learner Satisfaction with the course (Navigation and Value) and (b) measures of Learning Performance (Pre-Post Gain, Followup Personal Benefit, and Follow-up Simulation Scenarios). 
Following the analysis of data the first conclusion that can be drawn is that the value of the course was related to gaining personal benefit. The participants were eager to take these courses. The majority of participants of this study indicated in their comments in course evaluation that they had not taken any comparable course. They were given continuing education credits, if desired. Their employers encouraged but did not mandate the course completion. Participants volunteered based on personal interest in subject-matter. Thus, they sought personal benefit.

A second conclusion reached is that navigation best predicted learning achievement. Key findings point to navigation as a predictive factor in learning performance. Navigation appears to be a premium issue. This study, as well as the breadth of literature examined, explicitly states that learner satisfaction with navigation in relation to learning is worth further discussion. In the regression models, out of seven potential predictors of learning outcomes, navigation yielded significant prediction of (a) Gain from Pre-test to Post-test and (b) scores on the Simulation Scenarios.

The third conclusion drawn from data analysis is that navigation also was related to the learner's rating of personal benefit. Thus, navigation was important, not only for knowledge acquisition, but also for personal value.

The fourth conclusion drawn from data analysis is that availability of these courses was very important to these responder communities of practice (CoP). The participants were working professionals. The courses were free of charge, self-paced, and convenient. The content was important to learn, related and relevant to professional activities. The learners were offered facts, basic principles of emergency response, and sample scenarios of possible incidents. The courses were designed to heighten the general level of WMD and bioterrorism awareness among CoP members, which the majority of the participants found to be an important objective within their 
reach. The context of this particular subject-matter is new and is currently undergoing evolving changes.

\section{Implications}

This study echoes results from other recent research into the practical and conceptual importance of navigation for online learning environments and opens the door for more investigations into our understanding of experiential knowledge creation in hypermedia. The issue of system navigation is a design issue, and certainly has to be considered from the perspective of knowledge domain complexity and presumed communities of practice (CoP).

The task for the stakeholders is to ease the learner experience in introductory level courseware in terms of navigation and value and increase achievement by addressing the apparent associations of user satisfaction and learning achievement. The designers, course developers, funding agencies, and learners from the responder communities of practice $(\mathrm{CoP})$ need to become aware of such links in order to improve learning outcomes of the exponentially increasing pool of web-based bioterrorism course participants.

Usability concentrates on giving the learner access to desirable information the easiest way. Easy access to content without navigational burdens underlies usability, which became a research field of its own. The system should be visible to allow the user's actions to be predictable. The disparity between the psychology of the user and the physical world of the system can be minimized by designing user-centered interface with intended uninterrupted activity flow. It is the designer who has to systematically organize navigational options in an intuitive way for users, so that they are able to use the courseware. Otherwise, if the innovation appears too difficult for the potential adopters they will not continue working with it: "The complexity of an innovation, as perceived by members of a social system, is negatively related to its rate of adoption" (Rogers, 1983, p. 231). To ensure the 
growth of web-based bioterrorism course participants and the quality of their learning the issue of navigation has to be revisited.

Navigation is aided by something like a "cognitive map" or a "mental picture" developed by the user. While moving within the system, the learners gain a "container" schema of the shape of the text. A cognitive map represents a hierarchical structure with sub-branches (sub-zones) and distances. As one uses the courseware, the concept of container shape and routes is being formed as schemas resulting from personal experiences. “One never navigates directly in the designer's knowledge structure, argument, or intentions. One navigates in a physical representation of these, which cannot be totally equivalent to them" (Fastrez, 2002, p. 11). The notion of user experientialism, construction of one's own knowledge domains, becomes essential in web-based instruction, when the learners decode a finalized knowledge structure provided by experts, opposed to directly absorbing it. The users make navigational choices from a number of options and, therefore, the media does not allow them to reach an ideal coherent path, rather reconstruct their own understanding without the whole in a pre-constructed totality.

The user has to mobilize more cognitive resources (than with a book) to maintain orientation within the document. The user needs to concentrate on the text on the page, for example, the content, but navigation requires additional amount of attention, and may deplete some of the cognitive energy of the user trying to focus on the text comprehension. The limited space of the display screen allows the users to view a fragment of the content at once, making the rest invisible. Research has shown the direct link between the capacity of the user to understand the structure and ease with which one navigates through the document (Fastrez, 2001). Navigation and comprehension collide to become an intrinsic factor of information usage. If, as this study uncovered, the people who had higher satisfaction with course navigation tended to demonstrate greater learning achievement scores, then 
more attention should be devoted to the issue of navigation in the process of courseware design, development, and evaluation phases.

\section{Recommendations}

For continuing this research, taking a larger set of data is recommended. The types of data were limiting and various for the initial design of this research. In the future more repeated sampling would be recommended.

The choice of measurements was not under the primary investigator's control in this study. There should be more dimensions for the independent variables, so as to know more specifically the components of evaluating course aspects.

Needed are specific feedback mechanisms for program evaluators or course developers to have user feedback on dimensions of Navigation or Accuracy from the semiotics of the learner while she/he is rating the course components. The choices should be provided or learners should be prompted for clarification.

Demographic data were collected on a voluntary basis, therefore, further inferences from the inconsistently filled out sections on specifics of one's occupation or educational level, for example, were not possible. Better instruments and methods of completing them are needed.

For online modes of learning in preparation of CoP for WMD events, given that cognitive overload increases when there are many steps to reach the intended destination, the recommendation is to review user access and ease of navigation. Vora (1998) notes, "Do not require navigation more than three levels deep" (p. 161). In the LMS for the participants of this study, the registering instructions without videoconferencing options were posted on September 21, 2004. They are presented in Appendix G. As can be observed there were many steps that the users had to undertake to register, to enter the system and operate within it, which presented navigational difficulties for 
some users as the qualitative comments illustrate. Logically, not requiring irrelevant information from the user will shorten user access to courses in the future. By easing the navigation process the designers and developers can improve the learner's satisfaction with the course, and the learner's outcome from the instructional process is likely to increase. 


\section{REFERENCES}

Abell, A. (2001). Competing with knowledge: The information professional in the knowledge management age. London: Library Association Publishing.

Alley, L. R. (1999). Diverting a crisis in global human and economic development: A new transnational model for life long continuous learning and personal knowledge management. Higher Education in Europe, 24(2), 187-195.

Alkaabi, A. (1999). The development of management information system performance assessment model. Unpublished doctoral dissertation, George Washington University, Washington, D.C.

Andrews, F. M., Klem, L., O'Madley, P. M., Rogers, W. L., Welch, K. B., \& Davidson, T. N. (1998). Selecting statistical techniques for social science data: A guide for SAS users. Cary, NC: SAS Institute.

Arnold, V. (1995). Discussion of an experimental evaluation of measurements of information system effectiveness. Journal of Information Systems, 9(2), 85-91.

Baber, C. (2002). Subjective evaluation of usability. Ergonomics, 45(14), 1021-1026.

Bailey, J., \& Mageau, T. (2004). Making the case: Research efforts on educational technology. THE Journal, 31(10), 36-40.

Bailey, J. E., \& Pearson, S. W. (1983). Developing a tool for measuring computer user satisfaction. Management Science, 29(5), 530-545.

Baroudi, J. J., \& Orlikowski, W. J. (1998). A short form measure of user satisfaction: A psychometric evaluation and notes on use. Journal of Management Information Systems, 4(4), 44-59. 
Bell, D. S., Fonarrow, G. S., Hays, R. D., \& Mangione, C. M. (2000). Self-study from web-based and printed guideline materials: A randomized, controlled trial among resident physicians. Annals of Internal Medicine, 132(12), 938-946.

Benamar, E. (1992). An evaluation methodology for executive support systems. Unpublished master's thesis, Ferris State University, Big Rapids, Michigan.

Benbunan-Fich, R., Hiltz, S. R., \& Harasim, L. (2005). The online interaction learning model: An integrated theoretical framework for learning networks. In S. R. Hiltz \& R. Goldman (Eds.), Learning together online: Research on asynchronous learning networks (pp. 19-37). Mahwah, NJ: Erlbaum.

Benson, A. D. (2003, Winter). Assessing participant learning in online environments. New Directions for Adult \& Continuing Education, 100, 69-79.

Benson, D. (n.d.).Beyond navigation as a metaphor. Retrieved September 14, 2005 from http://www.sics.se/humle/projects/persona/web/littsurvey/abstracts.html\#Chapter3

Berkenholz, R. (1999). Effective adult learning. Danville, IL: Interstate Publishers.

Black, R. (1997). Web sites that work. San Jose, CA: Adobe Press.

Brennan, R. J. (2002). Learning the lessons of September 11: Terrorism and beyond. Emergency Medicine, 14(3), 214-215.

Brickell, G. (1993). Navigation and learning style. Australian Journal of Educational Technology, 9(2), 103-114. Retrieved August 17, 2005, from http://www.ascilite.org.au/ajet/ajet9/brickell.html

Burkman, J. R. (2002). End-user expectation incongruencies and integrated information systems: Effects on satisfaction and trust. Unpublished doctoral dissertation, Indiana University, Bloomington. 
Candy, P. C. (2000). Knowledge navigators and lifelong learners: Producing graduates for the information society. Higher Education Research \& Development, 19(3), 261-277.

Chen, F. M., Hickner, J., Fink, K. S., Galliher, J. M., \& Burstin, H. (2002). On the front lines: Family physicians' preparedness for bioterrorism. The Journal of Family Practice, 51(9), $745-750$.

Clark, R. E., \& Craig, T. (2001). What about multimedia effects on learning? In R. E. Clark (Ed.), Learning from media: Arguments, analysis, and evidence (pp. 89-101) Greenwich, CT: Information Age Publishing.

Clarke, R. (1988). Legal aspects of knowledge-based technology. JIT, 3(1), 9-16.

Clarke, T. (2001). Part one-knowledge management: The knowledge economy. Education + Training, 43(4/5), 189-196.

Coll, R., \& Wingertsman, J. C. (1990). The effect of screen complexity on user preference and performance. International Journal of Human-Computer Interaction, 2(3), 255-265.

Cone, J. D., \& Foster, S. L. (1993). Dissertations and theses from start to finish: Psychology and related fields. Washington, DC: American Psychological Association.

Crozier, J. (1999). Ways to evaluate educational software. Media \& Methods, 35(4), 50.

Crowther, M. C., Keller, C. C., \& Waddoups, G. L. (2004). Improving the quality and effectiveness of computer-mediated instruction through usability evaluations. British Journal of Educational Technology, 35(3), 289-303.

Curran, C. (2001). The phenomenon of on-line learning. European Journal of Education, 36(2), $113-$ 132.

Davitz, J. R., \& Davitz, L. L. (1996). Evaluating research proposals: A guide for the behavioral sciences. Upper Saddle River, NJ: Prentice Hall. 
DeLone, W. H., \& McLean, E. R. (1992, March). Information systems success: The quest for the dependent variable. Information Systems Research, 60-95.

Dillon, A. (2001). Beyond usability: Process, outcome, and affect in human-computer interactions. The Canadian Journal of Information and Library Science, 26(4), 57-68.

Dillon, A., \& Vaughan, M. (1997). "It's the journey and the destination": Shape and the emergent property of genre in evaluating digital documents. New Review of Multimedia and Hypermedia, 3, 91-106. Retrieved September 14, 2005 from http://www.gslis.utexas.edu/ adillon/publications/journey\&destination.pdf

Dimitrova, M., Sharp, H., \& Wilson, S. (2001). Are experts able to predict learner problems during usability evaluations? Paper presented at the annual meeting of ED-MEDIA, Tampere, Finland.

Doll, W. J., \& Tokzadeh, G. (1998). Developing a multidimentional measure of system-use in an organizational context. Information \& Management, 33, 171-185.

Drennan, J., Kennedy, J., \& Pisarski, A. (2005). Factors affecting student attitudes toward flexible online learning in management education. The Journal of Educational Research, 98(6), 331338.

Duarte Silva, A. P., \& Stam, A. (1995). Discriminant analysis. In L. G. Grimm \& P. R. Yarnold (Eds.), Reading and understanding more multivariate statistics (pp. 277-318).Washington, DC: American Psychological Association.

Eastwood, G. L. (2003). Academic health centers and the war on terrorism. Journal of Public Health Management and Practice, 9(5), 433-436. 
Ethington, C., Thomas, S. L., \& Pike, G. R. (2002). Back to the basics: Regression as it should be. In J. C. Smart, \& W. G. Tierney (Eds.), Higher education: Handbook of theory and research, 17, (pp. 263-295). New York, NY: Agathon Press.

Evans, C., \& Sabry, K. (2003). Evaluation of the interactivity of web-based learning systems: Principles and process. Innovations in Education and Teaching International, 40(1), 89-99.

Fastrez, P. (2001). Characteristic(s) of hypermedia, and how they relate to knowledge. Education Media International, 38(2/3), 101-110.

Fastrez, P. (2002). Navigation entails as design principles for structuring hypertext. Education, Communication \& Information, 2(1), 7-22.

Farrell, I. H. (2000). Navigation tools' effect on learners' achievement and attitude. (Doctoral dissertation, Virginia Polytechnic Institute and State University, 2000). Dissertation Abstracts International, 61(06A), 2267.

Fenton, R. (1996). Performance assessment system development. Alaska Educational Research Journal, 2(1), 13-22.

Fu, L., \& Salvendy, G. (2002). The contribution of apparent and inherent usability to a user's satisfaction in a searching and browsing task on the Web. Ergonomics, 45(6), 415-424.

Gatian, A. W. (1994). Is user satisfaction a valid measure of system effectiveness? Information \& Management, 29, 60-95.

Gelderman, M. (1998). The relation between user satisfaction, usage of information systems and performance. Information \& Management, 34, 11-18.

Glick, D. F., Jerome-D’Emilia, B., Nolan, M. A., \& Burke, P. (2004). Emergency preparedness: One community’s response. Family \& Community Health, 27(3), 266-273. 
Goodhue, D. L. (1988, October). I/S satisfactoriness: An outcome measure for MIS research. Working Paper series, Management Information Systems Research Center, Curtis L. Carlson School of Management, University of Minnesota, Minneapolis.

Gravetter, F. J., \& Wallnau, L. B. (2000). Statistics for behavioral sciences (5th ed.). Belmont, CA: Wadsworth/Thomson Learning.

Hall, B. (1997). Web-based training cookbook. New-York: John Wiley \& Sons, Inc.

Hamilton, S. (1980). Evaluation of information system effectiveness: A comparison of evaluation approaches and evaluator viewpoints. Working Paper series, Management Information Systems Research Center, Graduate School of Business Administration, University of Minnesota, Minneapolis.

Hassan, S., \& Li, F. (2001, June). Web usability criteria: the SCANMIC model. Paper presented at the annual meeting of ED-MEDIA, Tampere, Finland.

Haugh, R. (2004). UAMS' digital strategy embraces the physician. $H \& H N$ : Hospitals \& Health Networks, 78, 8-13.

Hedberg, J. G., Harper, B., \& Brown, C. (1993). Reducing cognitive load in multimedia navigation. Australian Journal of Educational Technology, 9(2), 157-181. Retrieved August 17, 2005, from http://www.ascilite.org.au/ajet/ajet9/hedberg.html

Henneman, R. L. (1999). Design for usability: Process, skills, and tools. Information, Knowledge, Systems Management, 1(2), 133-144.

Hertzum, M., \& Jacobsen, N. E. (2001). The evaluator effect: A chilling fact about usability evaluation methods. International Journal of Human-Computer Interaction, 13(4), 421-444. 
Higgins, M. G., Jr. (2001). "If you build it, will they come?” A study of the effects of system structure on the institutionalization of knowledge management within organizations. Unpublished doctoral dissertation. University of Georgia, Athens. Retrieved April 1, 2004 from: higgins_guy_m_200112_phd.pdf

Hwang, M. I., \& Thorn, R. G. (1999). The effects of user engagement on system success: A metaanalytical integration of research findings. Information \& Management, 35, 229-236.

Isaacs, L. (2004). A one-stop safety resource. American City \& County, 119(3), 48.

Ives, B., \& Olson, M. H. (1984). User involvement and MIS success: A review of research. Management Science, 30(5), 586-603.

Ives, B., Olson, M., \& Baroudi, J. (1983). The measurement of user information satisfaction. Communications of the ACM, 26(10), 785-793.

Jacobs, G. (1999). Evaluation of courseware: a controversial viewpoint. Journal of Audiovisual Media in Medicine, 22(1), 27-31.

Johnson, S. D., \& Aragon, S. R. (2003, Winter). An instructional strategy framework for online learning environments. New Directions for Adult \& Continuing Education, 100, 31-44.

Jones, C. M., \& Lui, M. (2001, June). Web-based instruction: The effect of design considerations on learner perceptions and achievement. Paper presented at the annual meeting of ED-MEDIA, Tampere, Finland.

Jones, T., \& Paolucci, R. (1999). Research framework and dimensions for evaluating the effectiveness of educational technology systems on learning outcomes. Journal of Research on Computing in Education, 32(1), 17-27.

Kearsley, G. (1986). Authoring: A guide to the design of instructional software. Reading, MA: Addison-Wesley. 
Kidney, G. W., \& Puckett, E. G. (2003). Rediscovering first principles through online learning. Quarterly Review of Distance Education, 4(3), 203-213.

Kim, S., Brock, D. M., Orkand, A., \& Astion, M. L. (2001). Design implications from a usability study of GramStain-Tutor ${ }^{\mathrm{TM}}$. British Journal of Educational Technology, 32(5), 595-606.

King, W. R., \& Rodriguez, J. I. (1978). Evaluating management information systems. MIS Quarterly, 2(3), 43-51.

Kirkpatrick, D. (1994). Evaluating training programs. San Francisco, CA: Berrett-Koehler.

Langefords, B. (1977). Discussion of determining management information needs: A comparison of methods. MIS Quarterly, 1(4), 53-56.

Lathlean, J., \& Le May, A. (2002). Communities of practice: An opportunity for interagency working. Journal of Clinical Nursing, 11(3), 394-401.

Levingston, L. (1991). The effect of color on performance in an instructional gaming environment. Journal of Research on Computing in Education, 24(2), 246-254.

Li, E. Y. (1997). Perceived importance of information system success factors: A meta- analysis of group differences. Information \& Management, 32, 15-28.

Luppicini, R. (2003). Categories of virtual learning communities for educational design. Quarterly Review of Distance Education, 4(4), 409-507.

Luan, J., \& Serban, A. M. (2002, Spring). Technologies, products, and models supporting knowledge management. New Directions for Institutional Research, 113, 85-105.

Lucas, H. C., Jr. (1975). Performance and use of an information system. Management Science, 21(4), 908-915.

Luyben, P. D., Hipworth, K., \& Pappas, T. (2003). Effects of CAI on the academic performance and attitudes of college students. Teaching of Psychology, 30(2), 154-158. 
Macdonald, J. (2004). Developing competent e-learners: The role of assessment. Assessment \& Evaluation in Higher Education, 29(2), 215-226.

MacGregor, S. K., \& Lou, Y. (2004). Web-based learning: How task scaffolding and website design support knowledge acquisition. Journal of Research on Technology in Education, 37(2), 161176.

Maier, R. (2002). Knowledge management systems: Information and communication technologies for knowledge management. Berlin: Springer-Verlag.

Malhotra, Y. (2004). Why knowledge management systems fail? Enablers and constraints of knowledge management in human enterprises. In M. E. D. Koenig \& T. K. Srikantaiah (Eds.) Knowledge management lessons learned: What works and what doesn't (pp. 87-112). Information Today, Inc. (American Society for Information Science and Technology Monograph Series).

Maurer, H., \& Sapper, M. (2001, June). E-Learning has to be seen as part of general knowledge management. Paper presented at the annual meeting of ED-MEDIA, Tampere, Finland.

McKeen, J. D., Guimaraes, T., \& Wetherbe, J. C. (1994, December). The relationship between user participation and user satisfaction: An investigation of four contingency factors. MIS Quarterly, 18(4), 427-451.

Mehlenbacher, B. (2002). Assessing the usability of on-line instructional materials. New Directions for Teaching and Learning, 91, 91-98.

Meyer, K. A. (2003). The web's impact on student learning. T H E Journal, 30(10), 14-19.

Mikk, J., \& Luik, P. (2003). Characteristics of multimedia textbooks that affect post-test scores. Journal of Computer Assisted Learning, 19(4), 528-537. 
Moreno-Muñoz, A., Plaza-Alonso, A., de-Castro-Lozano, C., \& Dormido-Bencomo, S. (2002). Hypermedia design methodology in World Wide Web applications. International Journal of Human-Computer Interaction, 14(2), 251-270.

Murphy, M. (2000). Adult education, lifelong learning and the end of political economy. Studies in the Education of Adults, 32(2), 166-181.

Nicolaou, A. I., Masoner, M. M., \& Welker, R. B. (1995). Intent to enhance information systems as a function of system success. Journal of Information Systems, 9(2), 93-108.

Osborne, J. W., \& Waters, E. (2002). Four assumptions of multiple regression that researchers should always test. Practical Assessment, Research \& Evaluation, 8(2). Retrieved September 29, 2005 from http://PAREonline.net/getvn.asp?v=8\&n=2.

Ozok, A. A., \& Salvendy, G. (2000). Measuring consistency of web page design and its effects on performance and satisfaction. Ergonomics, 43(4), 443-471.

Pet, D., \& Wilson, T. (1996). Color research and its application to the design of instructional materials. Educational Theory, Research and Development, 44(3), 19-35.

Phelps, R., \& Mok, M. (1999). Managing the risks of intranet implementation: An empirical study of user satisfaction. Journal of Information Technology, 14(1), 39-52.

Proctor, R. W., Vu, K.-P. L., Salvendy, G., Degen, H., Fang, X., Flach, J. M., Gott, S. P., Herrman, D., Krömker, H., Lightner, N. J., Lubin, K., Najjar, L., Reeves, L., Rudorfer, A., Stanney, K., Stephanidis, C., Strybel, T. Z., Vaughan, M., Wang, H., Weber, H., Yang, Y., \& Zhu, W. (2002). Content preparation and management for web design: Eliciting, structuring, searching, and displaying information. International Journal of Human-Computer Interaction, 14(1), 25-92. 
Pollock, G. (1996). The essential elements of multimedia: Content is not the only answer. In C. McBeath and R. Atkinson (Eds.), The Learning Superhighway: New world? New worries? Proceedings of the Third International Interactive Multimedia Symposium, 323-327. Perth, Western Australia, 21-25 January. Promaco Conventions. Retrieved August 17, 2005, from http://www.aset.org.au/confs/iims/1996/lp/pollock.html

Quilter, S. M., \& Chester, C. (2001). The relationship between web-based conferencing and instructional outcomes. International Journal of Instructional Media, 28(1), 13-23.

Remenyi, D. (1996). A holistic approach to IT functional evaluation. In L. Willcocks (Ed.), Investing in information systems: Evaluation \& management (pp.269-289). London: Chipman \& Hall.

Reynolds, D., Treharne, D., \& Tripp, H. (2003). ICT - the hopes and the reality. British Journal of Educational Technology, 34(2), 151-168.

Rice, R. E., Hiltz, S. R., \& Spencer, D. H. (2005). Media mixes and learning networks. In S. R. Hiltz \& R. Goldman (Eds.), Learning together online: Research on asynchronous learning networks (pp.215-237). Mahwah, NJ: Erlbaum.

Richardson, J. T. E. (2003). Approaches to studying and perceptions of academic quality in a short web-based course. British Journal of Educational Technology, 34(4), 433-443.

Richardson, J. T. E., \& Price, L. (2003). Approaches to studying and perceptions of academic quality in electronically delivered courses. British Journal of Educational Technology, 34(1), 45 -57.

Rogers, E. M. (1983). Diffusion of innovations. New York, NY: The Free Press.

Rubio, D. M., Berg-Weger, M., Tebb, S. S., Lee, E. S., \& Rauch, S. (2003). Objectifying content validity: Conducting a content validity study in social work research. Social Work Research, $27(2), 94-105$. 
Seddon, P., \& Kiew, M. Y. (1994, December). A partial test and development of the DeLone and McLean model of IS success. Proceedings of the Fifteenth International Conference on Information Systems, 99-108.

Serafeimidis, V. (2002). A review of research issues in evaluation of information systems. In W. Van Grembergen (Ed.), Information systems evaluation management (pp. 167-194). Hershey, PA: IRM Press.

Serban, A. M., \& Luan, J. (2002). Overview of knowledge management. New Directions for Institutional Research, 113, 5-16.

Seward, H. H. (1973). Measuring user satisfaction to evaluate information system. Unpublished doctoral dissertation, Harvard University, Cambridge, MA.

Shany, N., \& Nachmias, R. (2001, June). The relationship between performance in a virtual course and thinking styles, gender, and ICT experience. Paper presented at the annual meeting of ED-MEDIA, Tampere, Finland.

Shi, X., Holahan, P. J., \& Jurkat, M. P. (2004). Satisfaction formation processes in library users: Understanding multisource effects. Journal of Academic Librarianship, 30(2), 122-132.

Sing, C. C., \& Der-Thanq, V. C. (2004). A review on usability evaluation methods for instructional multimedia: An analytical framework. International Journal of Instructional Media, 31(3), 229-239.

Sipior, J. C., Ward, B. T., \& Wagner, W. P. (1998). Is it time to consider legal liability in system success measurement? In E. J. Garrity \& G. L. Sanders (Eds.), Information systems success measurement (pp. 79-93). Hershey, PA: Idea Group Publishing. Sørensen, C., \& Snis, U. (2001). Innovation through knowledge codification. Journal of Information Technology, 16(2), 83-97. 
Srinivasan, A. (1985). Alternative measures of system effectiveness: Associations and implications. Measures of System Effectiveness, 9(3), 243-253.

Stevens, J. P. (2002). Applied multivariate statistics for the social sciences. Mahwah, NJ: Lawrence Erlbaum Associates, Publishers.

Stone, D. N. (1990). Assumptions and values in the practice of information systems evaluation. Journal of Information Systems, 4(3), 1-17.

Storey, V. C., \& Goldstein, R. C. (1993). Knowledge-based approaches to database design. MIS Quarterly, 17(1), 25-46.

Strickland, L. S. (2002). Fighting terrorism with information. The Information Management Journal, $36(4), 27-34$.

Stromquist, N., \& Samoff, J. (2000). Knowledge Management Systems: On the promise and actual forms of information technologies. Compare: A Journal of Comparative Education, 30(3), $323-333$.

Tabachnick, B., \& Fidell, L. (2001). Using multivariate statistics. Boston, MA: Allyn \& Bacon.

Tague-Sutcliffe, J. M. (1996). Some perspectives on the evaluation of information retrieval systems. Journal of the American Society for Information Science, 47(1), 1-3.

Taylor, T. C. (1994). Color guard. Sales and Marketing Management, 146(8), 21.

Thurow, L. C. (1999). Building Wealth: The new rules for individuals, companies, and nations in a knowledge-based economy. New York: HarperCollins Publishers.

Thurmond, V. A., Wambach, K., Connor, H. R., \& Frey, B. B. (2002). Evaluation of student satisfaction: Determining the impact of a web-based environment by controlling for student characteristics. The American Journal of Distance Education, 16(3), 169-189. 
Tricker, T., Rangecroft, M., Long, P., \& Gilroy, P. (2001). Evaluating distance education courses: The student perception. Assessment \& Evaluation in Higher Education, 26(2), 165-177. Tselios, N. K., Avouris, N. M., Dimitracopoulou, A. D., \& Daskalaki, S. (2001). Evaluation of distance-learning environments: Impact of usability on student performance. International Journal of Educational Telecommunications, 7(4), 355-378.

Urquhart, C., Chambers, M., Connort, S., Lewis, L., Murphy, J., Roberts, R., \& Thomas, R. (2002). Evaluation of distance learning delivery of health information management and health informatics programmes: a UK perspective. Health Information \& Libraries Journal, 19(3), $146-158$.

Vaas, L. (2002). Knowledge management: Value is relative. eWeek, 19(13), 40-41.

Van Rekom, P. (2000). Data warehouse: A case study of the factors effecting user satisfaction. Unpublished doctoral dissertation, University of Southern California, Los Angeles.

Vora, P. (1998). Human factors methodology for designing websites. In C. Forsythe, E. Grose, \& J. Ratner (Eds.), Human factors and web development (pp. 153-175). Mahwah, NJ: Lawrence Erlbaum Associates.

Wang, K., Hejelmervik, O. R., \& Bremdal, B. (2001). Introduction to knowledge management: Principles and practice. Trondheim: Tapir Academic Press.

Wasko, M. (2002). Why should I share?: Examining knowledge contribution in networks of practice. Unpublished doctoral dissertation, University of Maryland, College Park.

Weinfurt, K., P. (2000). Repeated measures analyses. In L. G. Grimm \& P. R. Yarnold (Eds.), Reading and understanding more multivariate statistics (pp. 317-362).Washington, DC: American Psychological Association. 
Williams, J. R. (2004). Developing performance support for computer systems: A strategy for maximizing usability and learnability. Boca Raton: CRC Press.

Williams, R. (1994). The non-designer's design book: Design and typographic principles for the visual novice. Berkeley, CA: Peachpit Press.

Wixom, B. H., \& Watson, H. J. (2001). An empirical investigation of the factors affecting data warehousing success. MIS Quarterly, 25(1), 17-41.

Wong, G., Greenhalgh, T., Russell, J., Boynton, P., \& Toon, P. (2003). Putting your course on the web: Lessons from a case study and systematic literature review. Medical Education, 37, 1020-1023.

Wright, R. E. (2000). Survival analysis. In L. G. Grimm \& P. R. Yarnold (Eds.), Reading and understanding more multivariate statistics (pp. 363-407).Washington, DC: American Psychological Association.

Yoon, Y., Guimaraes, T., \& O’Neai, Q. (1995, March). Exploring the factors associated with expert systems success. MIS Quarterly, 19(1), 83-106.

Zmud, R. W. (1979). Individual difference and MIS success: A review of empirical literature. Management Science, 25(10), 966-979. 
Appendix A

Pre-Test and Post-Test Samples 
Appendix A.

Pre-Test and Post-Test Samples

HRSA 1: Pre-Test

\begin{tabular}{l} 
Exam \\
\hline Question 2 of 20 \\
Early reporting of a potential incident is likely to \\
result in \\
deployment of inappropriate resources for \\
the most part. \\
inaccurate or distorted assessment of the \\
situation. \\
both internal and external positive \\
interventions. \\
compromised information on the agent(s) \\
involved. \\
Exam
\end{tabular}

Question 3 of 20

The most common weapons of terror in the United States have been

O explosive agents.

O radiological agents.

O chemical agents.

O biological agents. 
HRSA 1: Post-Test

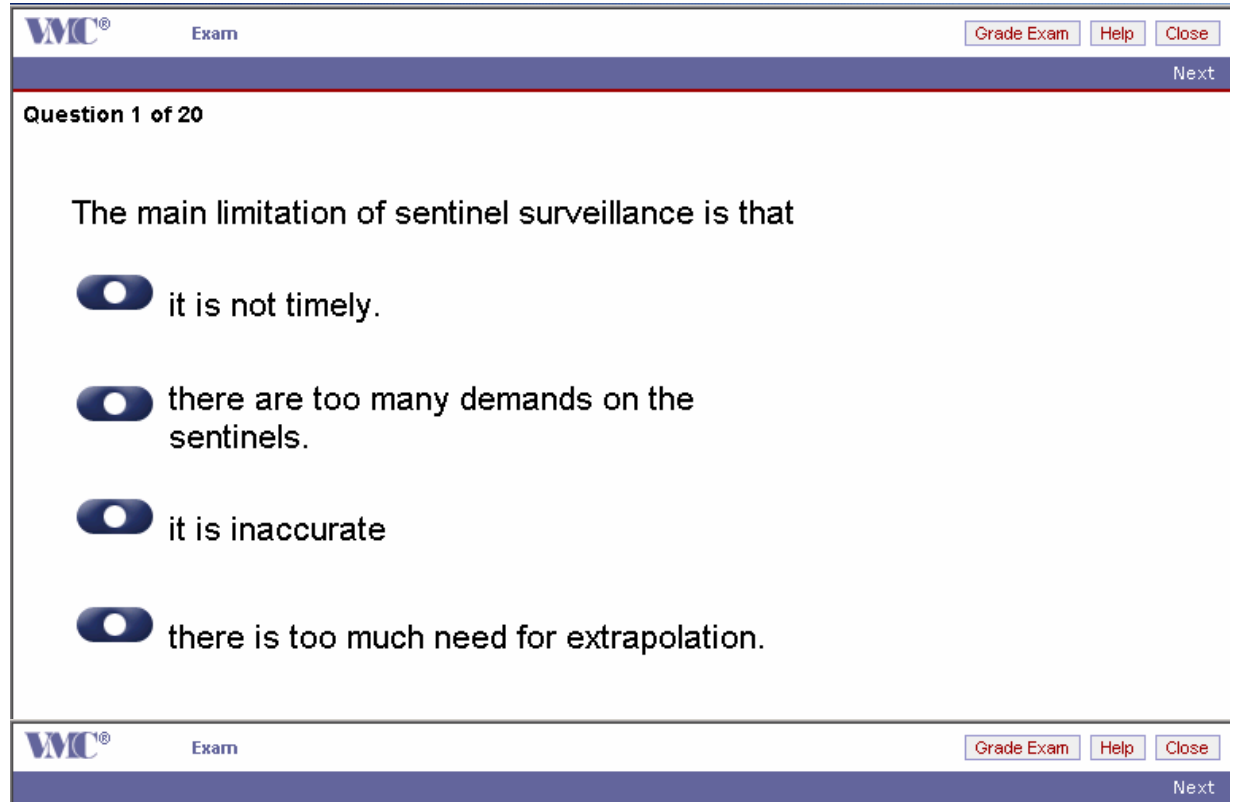

Question 2 of 20

Early symptoms of acute radiation sickness

include

C fever, shortness of breath.

C gastrointestinal disorders.

C joint pain and cough.

C swollen lymph nodes. 
HRSA 2: Pre-Test

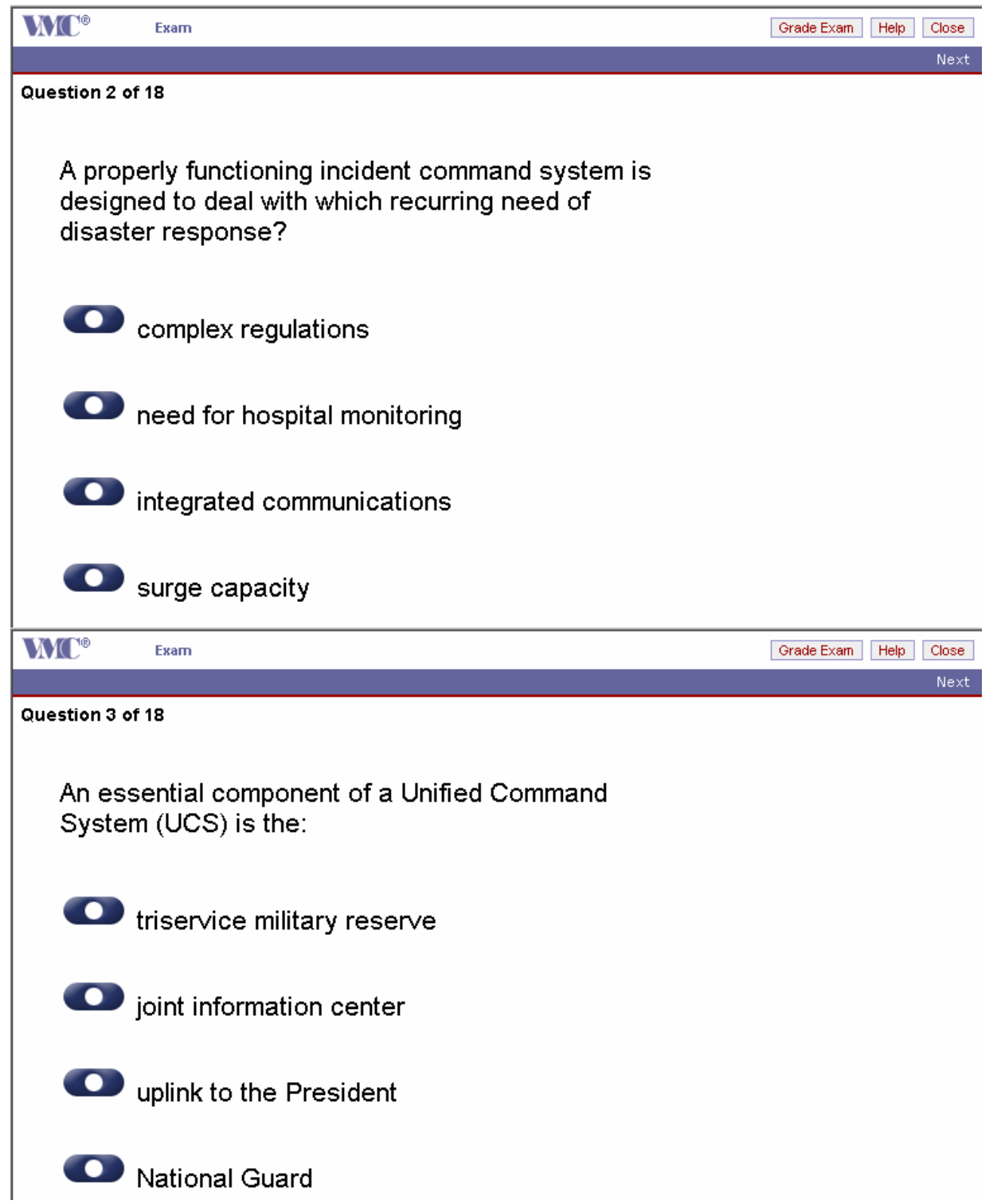


HRSA 2: Post-Test

$\begin{array}{lll}\text { WMC Exam } & \text { Grade Exam Help Close } \\ \text { Next }\end{array}$

Question 1 of 18

Which of the following is most likely to be operable in a crisis?

Cell phones

O the Internet

ham radio

Dublic telephones

YMC Exam ${ }^{1}$ Grade Exam Help Close

Question 2 of 18

Which of the following is a primary priority of an incident command system?

O personnel career development

C criminal investigation

C troop mobilization

life safety 


\section{Appendix B}

Satisfaction Questionnaire and Comments 
Appendix B.

Satisfaction Questionnaire and Comments

For evaluative items below, the following scale is used:

$1=$ Poor $\quad 2=$ Acceptable $\quad 3=$ Good $\quad 4=$ Excellent

\section{SUMMATIVE EVALUATION OF CONCEPT, CONTENT, PRESENTATION AND OPERATION OF THE COURSE}

\section{HRSA COURSE 1 EVALUATION}

1. The content(relevance, inclusion) was

Poor

2. The accuracy(correct,error-free) was

3. The navigation(access, movement) was

4. The look(media,graphics) was

5. The flow(logic, sequence) was

6. The assessment(quizzes, exercises) was

7. The tracking(ability to know where I was in the course module) was

8. The value(to me, in my organization) was

$\begin{array}{ccc}\text { Acceptable Good } & \text { Excellent } \\ 0 & 0 & 0 \\ 0 & 0 & 0 \\ 0 & 0 & 0 \\ 0 & 0 & 0 \\ 0 & 0 & 0 \\ 0 & 0 & 0 \\ 0 & 0 & 0 \\ 0 & 0 & 0\end{array}$


SUMMATIVE EVALUATION OF THE COURSE

1. What was most valuable to you about the course?

Comment(Why)?

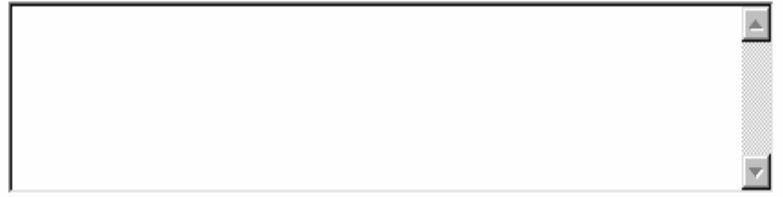

2. What was the least valuable to you about the course?

Comment(Why)?

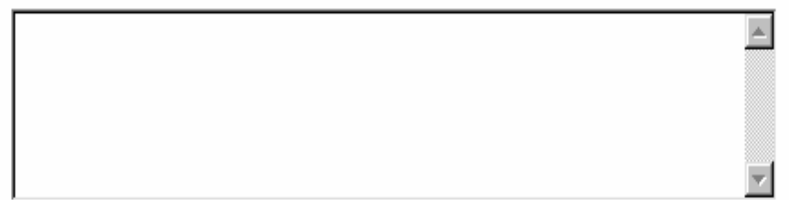

3. Was this course worth your time investment?

$\mathrm{Yes} C \mathrm{~N}_{0} \mathrm{C}$

Comment(Why)?

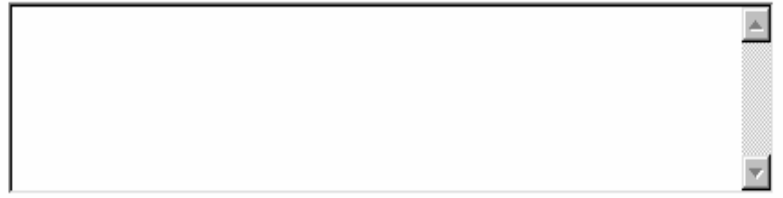

4. Have you taken a comparable course(if $Y E S$, please name it and compare its effectiveness to this course)?

Yes $C$ No $C$

Comment(Why)?

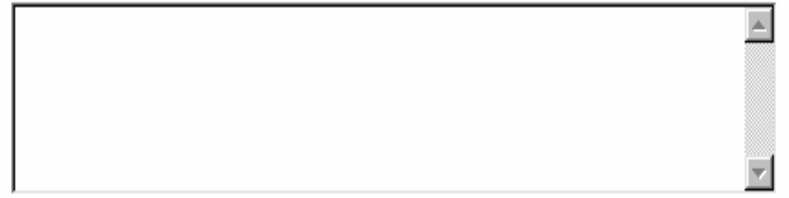


5. Would you recommend this course to your colleague?

Yes $\odot$ No $C$

Comment(Why)?

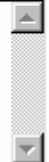

6. Do you have an increased awareness of the need for a coordinated response to a Weapons of Mass Destruction(WMD) event? Yes $\subset$ No $C$

Comment(What is different or new)?

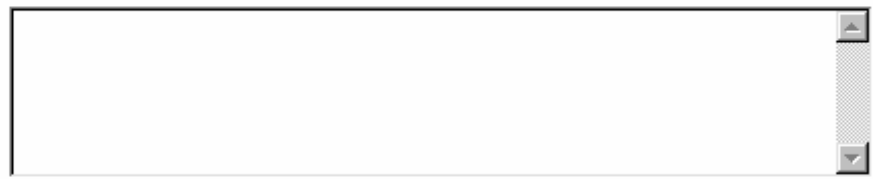

7. Will this course contribute a new level of competence and self-confidence among health care providers in planning for a WMD event? $\mathrm{Yes} \subset \mathrm{No} \mathrm{C}$

Comment(Why)?

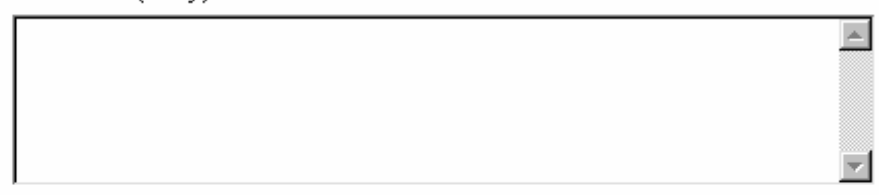


Appendix C

Follow-up Questionnaire and Simulation Scenarios for Course 1 
Appendix C.

Follow-up Questionnaire and Simulation Scenarios for Course 1

Dear Course Taker:

Several months ago, you completed the course offered by West Virginia University's VMC ${ }^{\circledR}$, titled "Recognition of a Terrorist Event or Public Health Emergency" (HRSA Course 1). As the planned follow-up to that course, please:

TO BEGIN, click "REPLY" so that your responses will come back to us.

NEXT, answer the multiple-choice questions below by typing a capital letter " $\mathrm{X}$ " beside your choice (in the brackets).

NEXT, answer the SIMULATION SCENARIO essay question below by typing words or sentences in the spaces provided.

LAST, click "SEND" so that we will receive your follow-up responses.

1. Which type of agent is involved most frequently in cases of harmful exposure?

[ ] a. chemical

[ ] b. biological

[ ] c. radiological

[ ] d. nuclear

2. The CDC category of biological agents that can be easily disseminated OR transmitted personto-person, may cause high mortality, could cause public panic and social disruption with potential for major public health impact is

[ ] a. Category A.

[ ] b. Category B.

[ ] c. Category C.

[ ] d. Category D.

3. Implementation of surveillance protocols and distribution of health communication information to critical response agencies are responsibilities of

[ ] a. local health departments.

[ ] b. emergency management agencies.

[ ] c. healthcare providers.

[ ] d. the emergency broadcast system.

4. Notification that an incident has potentially occurred should take place when

[ ] a. an incident is suspected.

[ ] b. an incident is confirmed.

[ ] c. a supervisor gives authorization for notification.

[ ] d. at least two or more signs of an incident have been observed. 
5. Was this course of personal benefit to YOU in being prepared for a terrorist event or public health emergency?

[] a. YES

[] b. NO

Type your EXPLANATION HERE:

6. Has your participation in this course been of benefit to YOUR ORGANIZATION?

[] a. YES

[ ] b. NO

Type your EXPLANATION HERE:

\section{SIMULATION SCENARIO}

In your professional capacity, suppose you observe an instance that may be caused by a terrorist attack or may be a public health emergency.

Please, type the name of your "position" or "professional capacity."

Think back to what you learned in the course and type your answers to the following scenarios that may be caused by a terrorist attack or may be a public health emergency.

\section{Scenario 1}

Suppose there are 8,000 people attending a basketball game between two rival universities. Just after half-time on one side of the arena, many people, within seconds of each other, begin showing the following symptoms: pupil constriction, runny nose, shortness of breath, convulsions (seizures), stopped breathing.

What is the likely cause of these symptoms?

What agency should be contacted?

Type your answers here.

\section{Scenario 2}

Suppose the emergency department of a local hospital is beginning to see patients with symptoms of: nausea, vomiting, diarrhea, loss of white blood lymphocytes, gastroenteritis.

What is the likely cause of these symptoms?

What agency should be contacted?

Type your answers here. 


\section{Scenario 3}

Suppose a terrorist group announced that they would perpetrate an attack that would kill many people. Several days later, students and teachers from the local high school began missing school and seeking medical attention. The symptoms were: malaise, headache, backache, weakness, fever, and rash. The rash of bumps began in the mouth/face and spread down the body. Bumps became blisters, then lesions (all at the same time), than scabs.

What is the likely cause of these symptoms?

What agency should be contacted?

Type your answers here.

We express major appreciation for your commitment to human services. Once you have completed your answers to this questionnaire, please submit your responses by clicking "SEND." 


\section{Appendix D}

Follow-up Questionnaire and Simulation Scenarios for Course 2 
Appendix D.

Follow-up Questionnaire and Simulation Scenarios for Course 2

Dear Course Taker:

Several months ago, you completed the course offered by West Virginia University's Virtual Medical Campus, titled "A Multidisciplinary Response for Threat Preparedness" (HRSA Course 2). As the planned follow-up to that course, please respond to the following questions. THANK YOU FROM ALL OF US.

TO BEGIN, click "REPLY" so that your responses will come back to us.

NEXT, answer the multiple-choice questions below by typing a capital letter " $\mathrm{X}$ " beside your choice (in the brackets).

NEXT, answer the SIMULATION SCENARIO questions below by typing words in the spaces provided.

LAST, click "SEND" so that we will receive your follow-up responses.

1. The entire response to an emerging disaster is coordinated by:

[ ] a. the incident command system

[ ] b. the state police

[ ] c. the state public health department

[ ] d. the FBI

2. An essential component of a Unified Command Structure (UCS) is the:

[ ] a. triservice military reserve

[ ] b. National Guard

[ ] c. uplink to the President

[ ] d. joint information center

3. Quarantine is used primarily to:

[ ] a. isolate hospital patients

[ ] b. isolate homebound patients

[ ] c. restrict the movement of hospital patients

[ ] d. restrict the movement of exposed individuals who are well

4. A "point of distribution" is:

[ ] a. a special clinic for providing mass prophylaxis

[ ] b. the unique storage point for the strategic national stockpile

[ ] c. the single master facility for local incident commands

[ ] d. the controlling agency for joint information centers 
5. Was this course of personal benefit to YOU in being prepared for a terrorist event or public health emergency?

[] a. YES

[ ] b. NO

Type your EXPLANATION HERE:

6. Has your participation in this course been of benefit to YOUR ORGANIZATION?

[] a. YES

[ ] b. NO

Type your EXPLANATION HERE:

\section{SIMULATION SCENARIO}

In your professional capacity, suppose you observe an instance that may be caused by a terrorist attack or may be a public health emergency.

Please, type the name of your "position" or "professional capacity."

Think back to what you learned in the course and type your answers to the following scenarios that may be caused by a terrorist attack or may be a public health emergency.

\section{Scenario 1}

All available first responders and health care professionals are called in to work at the scene of an incident that has been in progress for a few hours.

What is the system all responders will be using at the scene of the incident?

What do you do when first arriving at the scene of an incident?

Type your ANSWERS HERE:

\section{Scenario 2}

While working at an incident, you happen to notice something that could possibly be used as a piece of evidence.

What is the system used for documenting the movement and location of physical evidence from the time it is obtained to the time it is presented in court?

What is a reason for using this system to protect criminal evidence obtained from the scene of an incident?

Type your ANSWERS HERE: 


\section{Scenario 3}

Suppose a health care facility needs to temporarily protect staff and patients against additional entrance until decontamination procedures are in place.

What is a method to control access to the facility?

What is a disease that might prompt such action (method)?

Type your ANSWERS HERE:

We express major appreciation for your commitment to human services. Once you have completed your answers to these questions, please submit your responses by clicking "SEND." 
Appendix E

Results for Open-Ended Questions for Course 1 
Appendix E.

Results for Open-Ended Questions for Course 1

Table 24

"What was most valuable to you about the course?" Open-Ended Responses.

Participant and Response
$\begin{aligned} & \text { 1. M: Learning of the need for early reporting of unusual incidence for coordinated response } \\ & \text { efforts }\end{aligned}$
$\begin{aligned} & \text { 2. M: Learning how to identify a possible terrorist incident and who to notify first. Why? I had } \\ & \text { not seen all the information prior to taking this course. }\end{aligned}$

3. M: I was not aware of the all the potential weapons that terrorists had at their fingertips and know I do.

4.

5. M: General information

6. M: Information on all agents

7. F: I enjoyed the photos because it made learning fun.

8. F: Explanation of events

9. M: Concise, useful information on agents of terrorism

10. F: I didn't like it.

11.

12. F: Learning that the local health dept. is the place to report and when to report, even if only suspected incident

13.

14. M: Identifying that Public Health Department was first place to turn.

15. F: Information about actual symptoms of exposure, types of infections/injuries

16. F: The organized and systematic presentation allow for easily assimilation of the information regarding reporting of suspected terrorist or other public health incident.

17. F: Learning to recognize symptoms

18. F: Just receiving the information in general was helpful in case I may need it at a later date.

19.

20.

21.

22.

23. M: Review of material had previously; not easily retained

24. M: Occult signs of a terror attack

25. M: Understanding reporting as will facilitate prompt action

26.

27. 
Table 24 continued

28.

29.

30.

31.

32. The content and the ease in which it was obtained was most valuable.

33.

34. M: Knowing who to call

35 .

36. 
Table 25

"What was the least valuable to you about the course?" Open-Ended Responses.

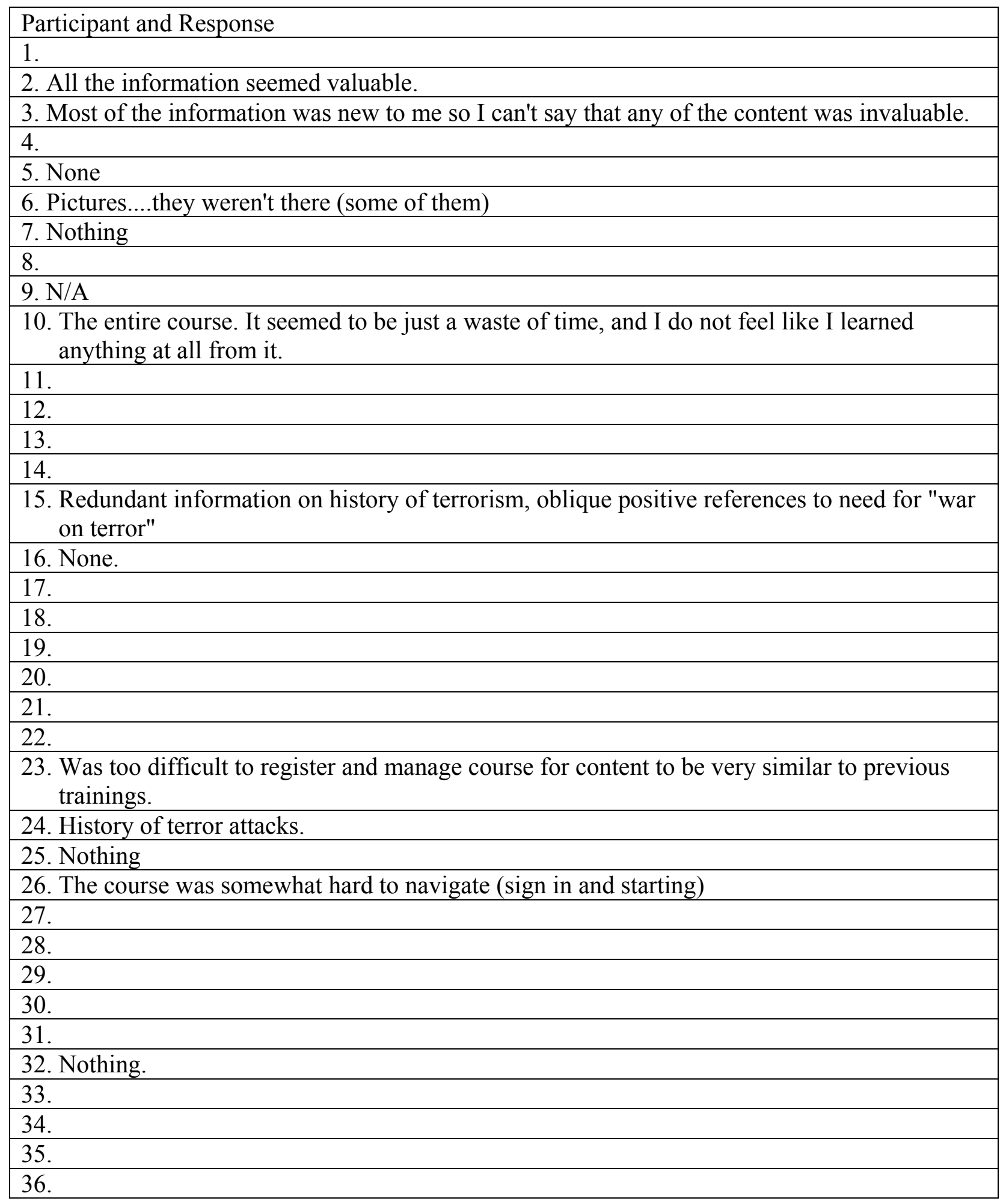


Table 26

“Was this course worth your time investment?" Open-Ended Responses.

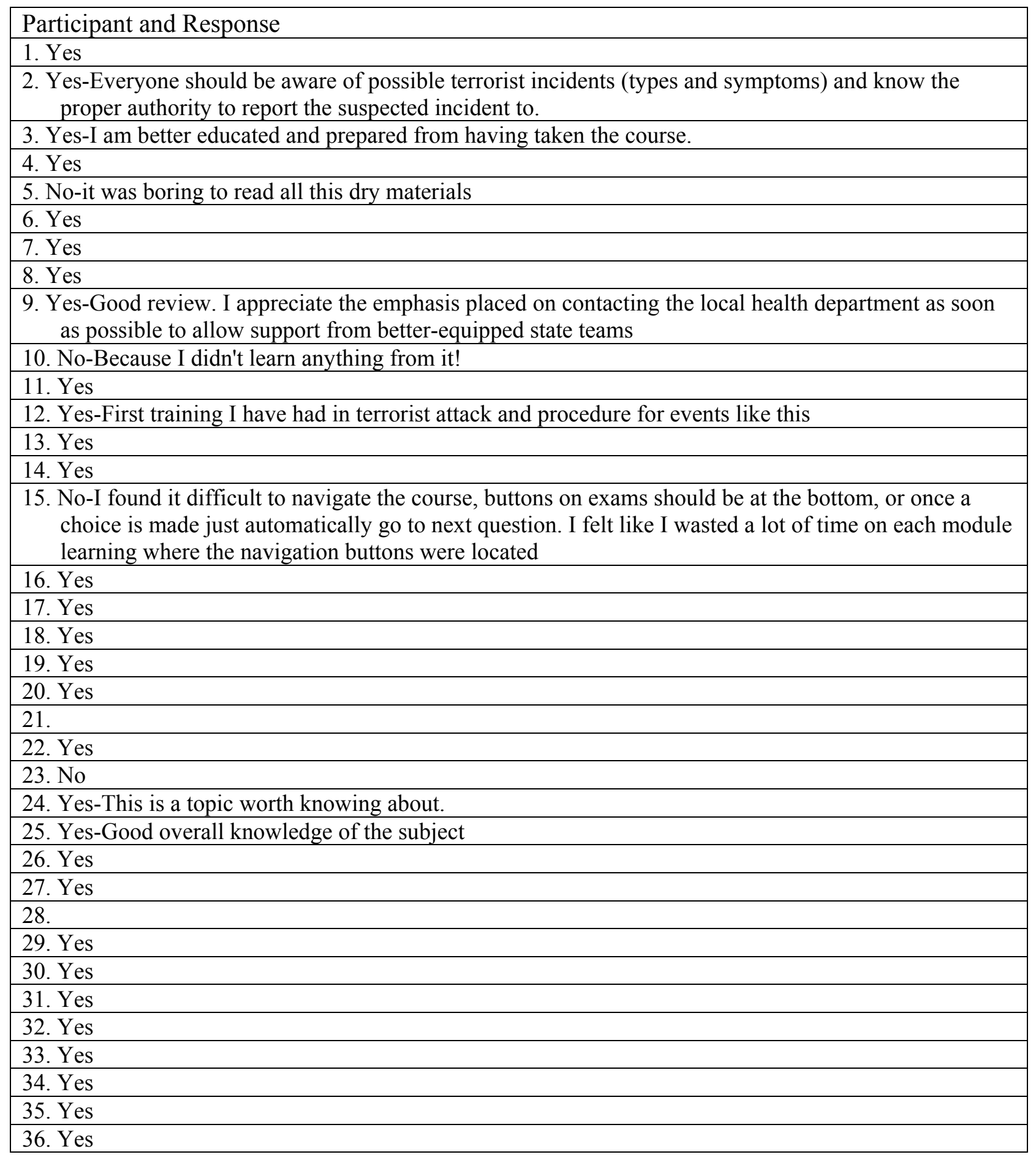


Table 27

"Have you taken a comparable course (if Yes, please name it and compare its effectiveness to this course)?” Open-Ended Responses.

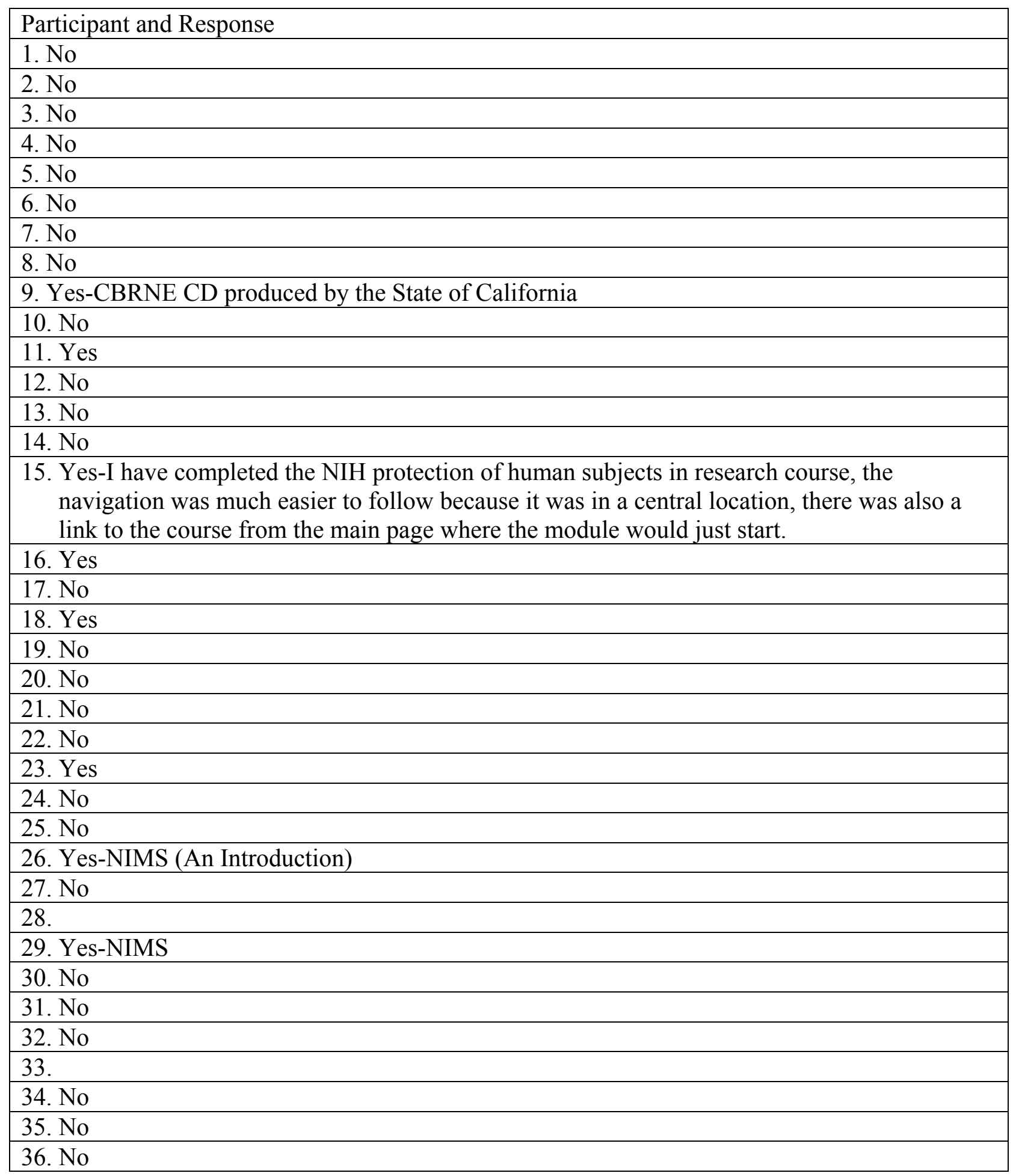


Table 28

"Would you recommend this course to your colleague?" Open-Ended Responses.

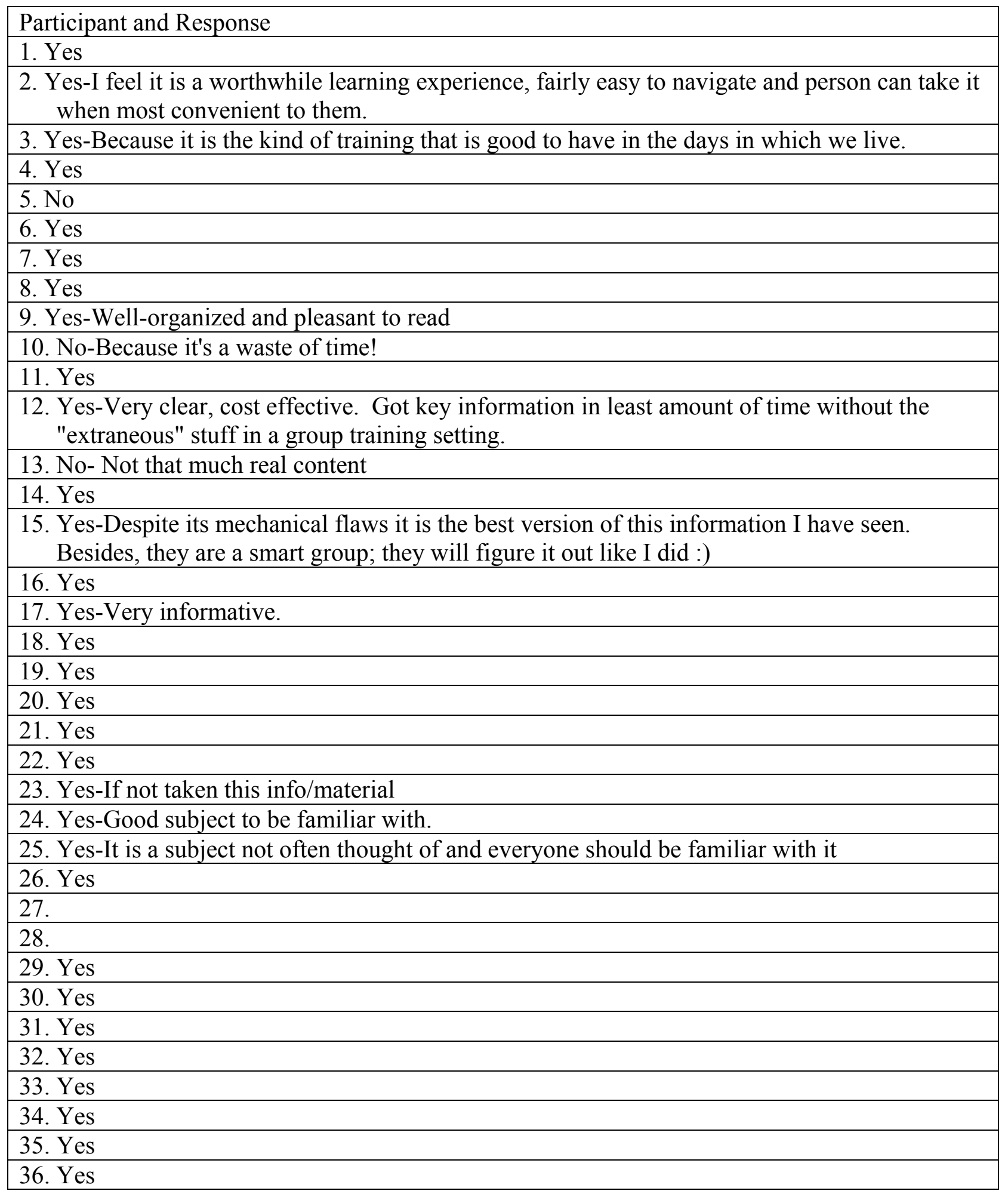


Table 29

"Do you have an increased awareness of the need for a coordinated response to a weapons of mass destruction (WMD) event?" Open-Ended Responses.

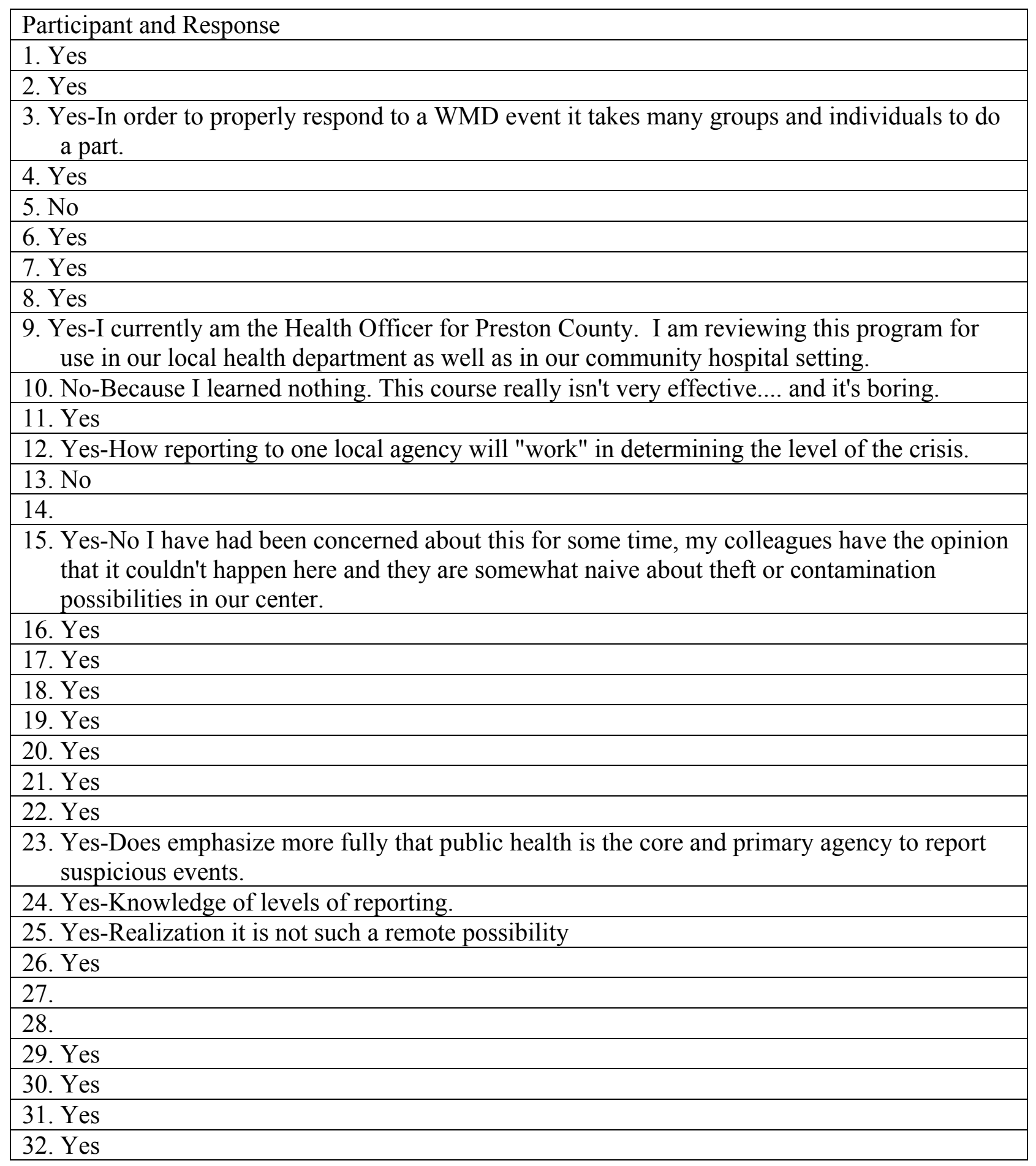


Table 29 continued

\begin{tabular}{|l|}
\hline 33. Yes \\
\hline 34. Yes \\
\hline 35. Yes \\
\hline 36. Yes \\
\hline
\end{tabular}


Table 30

"Will this course contribute a new level of competence and self-confidence among health care providers in planning for a WMD event?” Open-Ended Responses.

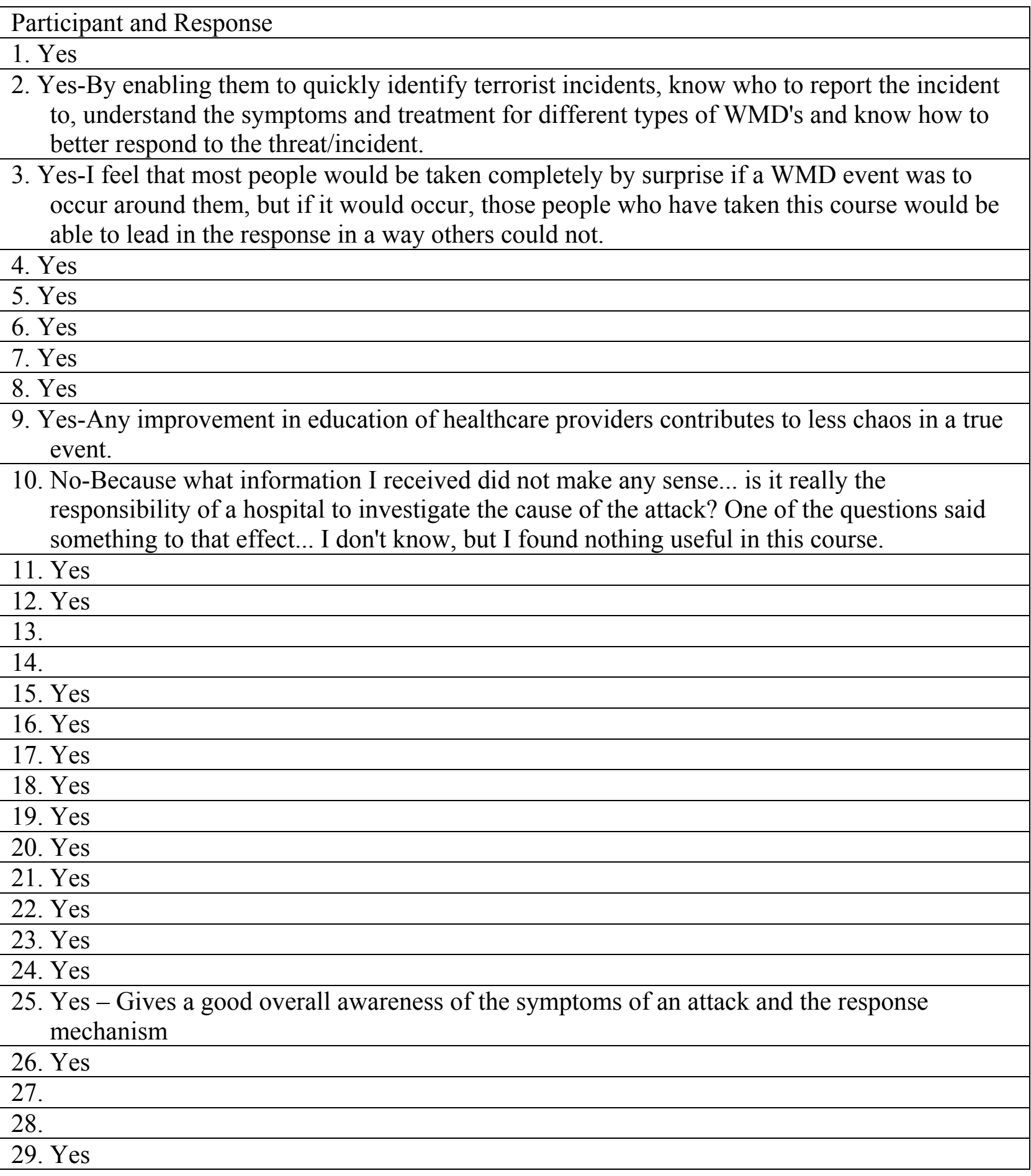


Table 30 continued

\begin{tabular}{|l|}
\hline 30. Yes \\
\hline 31. Yes \\
\hline 32. Yes \\
\hline 33. Yes \\
\hline 34. Yes \\
\hline 35. Yes \\
\hline 36. Yes \\
\hline
\end{tabular}


Appendix F

Results for Open-Ended Questions for Course 2 
Appendix F.

Results for Open-Ended Questions for Course 2

Table 31

"What was most valuable to you about the course?" Open-Ended Responses.

\begin{tabular}{|l|}
\hline Participant and Response \\
\hline 1. \\
\hline 2. \\
\hline 3. Overview of process of how to deal with suspected or actual incident \\
\hline 4. \\
\hline 5. \\
\hline 6. Good information \\
\hline 7. \\
\hline 8. \\
\hline 9. \\
\hline 10. \\
\hline $\begin{array}{l}11 . \\
\text { hold little of interest for the practitioner. It was well organized, and provided an }\end{array}$ \\
\hline understandable introduction to the planning process. \\
\hline 12. \\
\hline 13. \\
\hline 14. \\
\hline 15. Learning about the procedures likely to take place during crisis event; no previous \\
$\quad$ knowledge of this. \\
\hline 16. \\
\hline 17. New information about this topics \\
\hline 18. Reinforcing prior knowledge. \\
\hline 19. \\
\hline 20. \\
\hline 21. \\
\hline 22. Discussion of PIO AND JIC. Good discussion of different levels of PPE. \\
\hline 23. \\
\hline 24. \\
\hline 25. \\
\hline 26. \\
\hline 27. \\
\hline 28. \\
\hline 29. Content \\
\hline 30. \\
\hline 31. It broadened my understanding of the multi-organizational response \\
\hline
\end{tabular}


Table 32

"What was the least valuable to you about the course?" Open-Ended Responses.

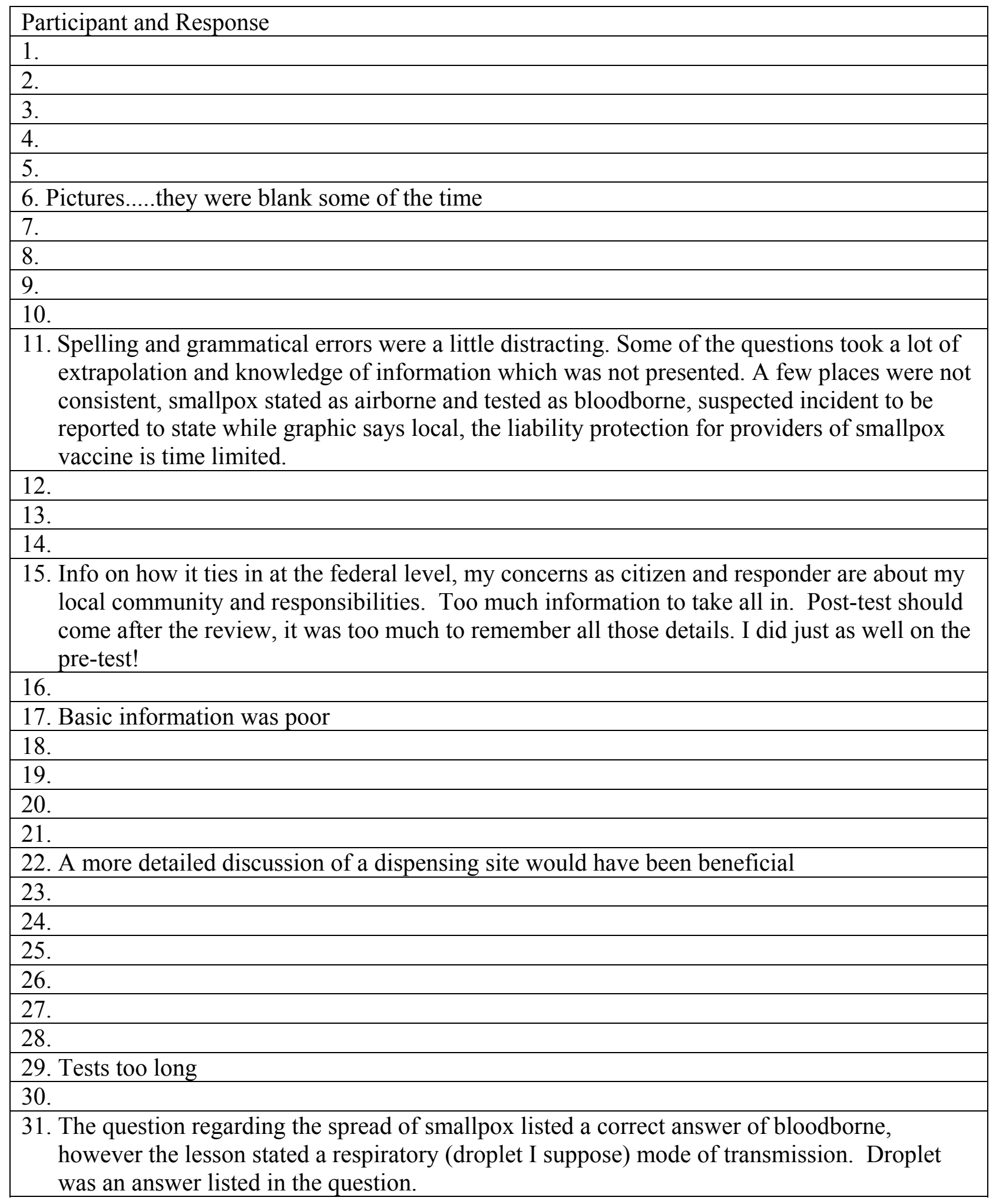


Table 33

“Was this course worth your time investment?" Open-Ended Responses.

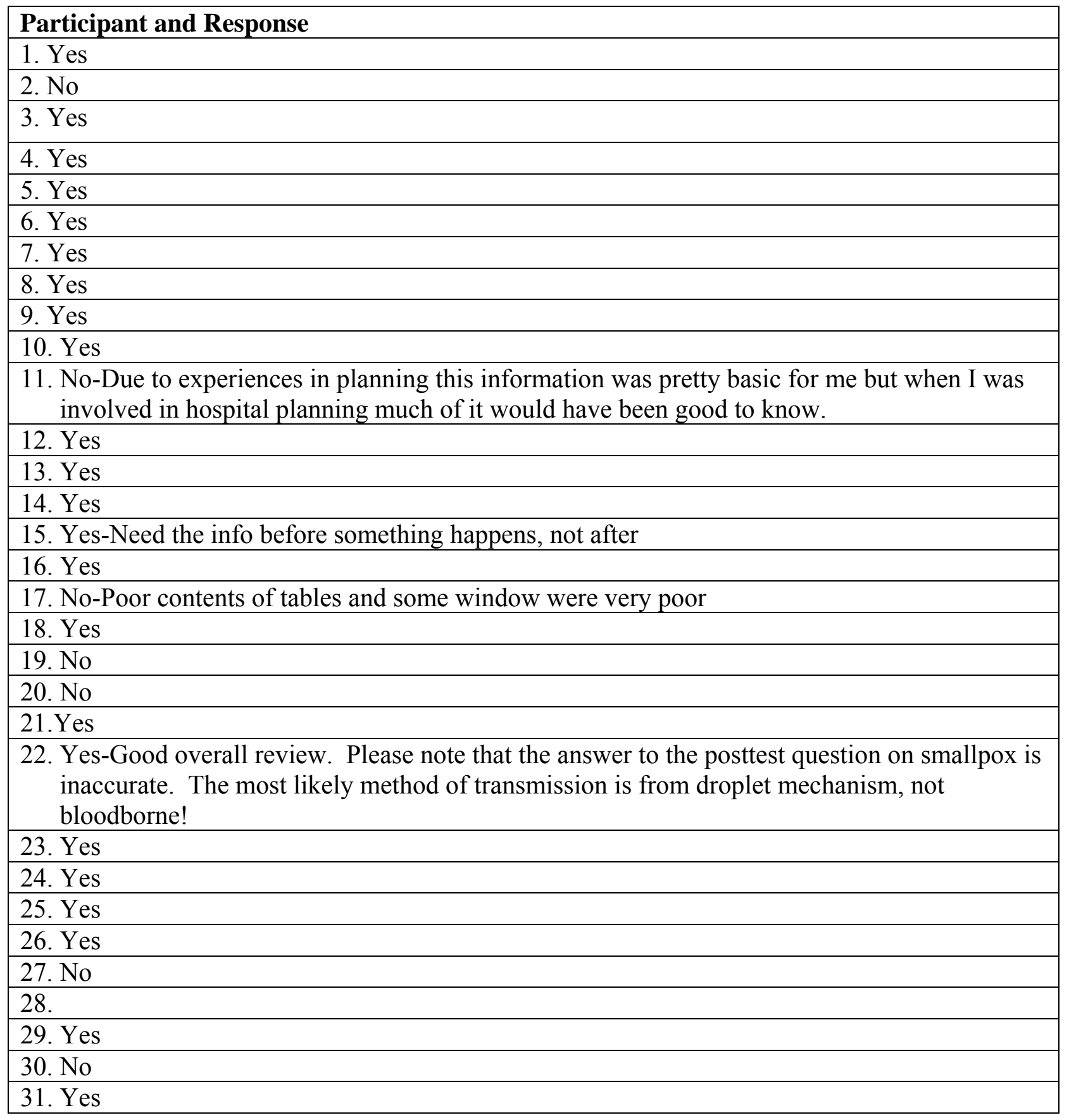


Table 34

"Have you taken a comparable course (if Yes, please name it and compare its effectiveness to this course)?” Open-Ended Responses.

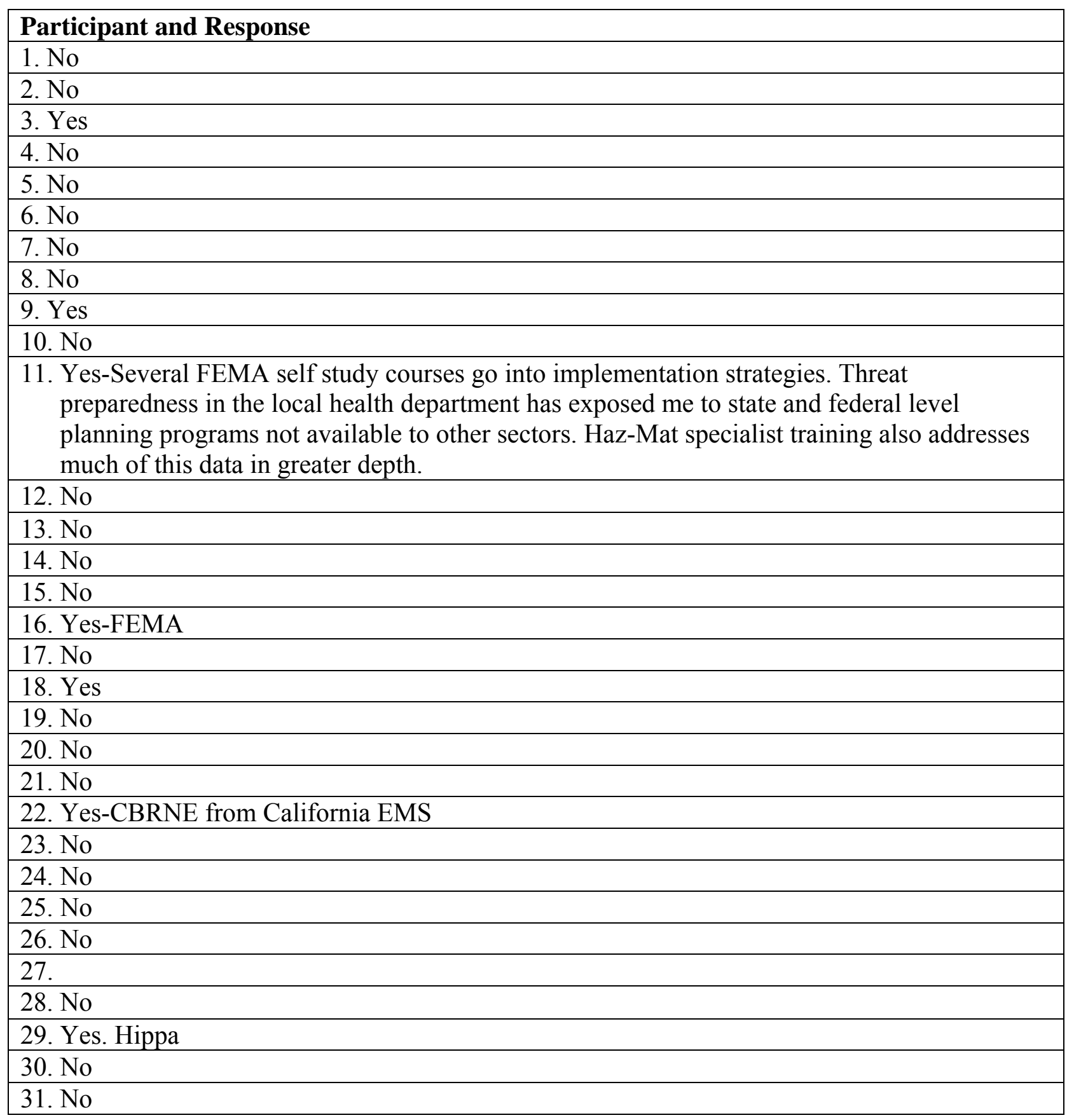


Table 35

"Would you recommend this course to your colleague?" Open-Ended Responses.

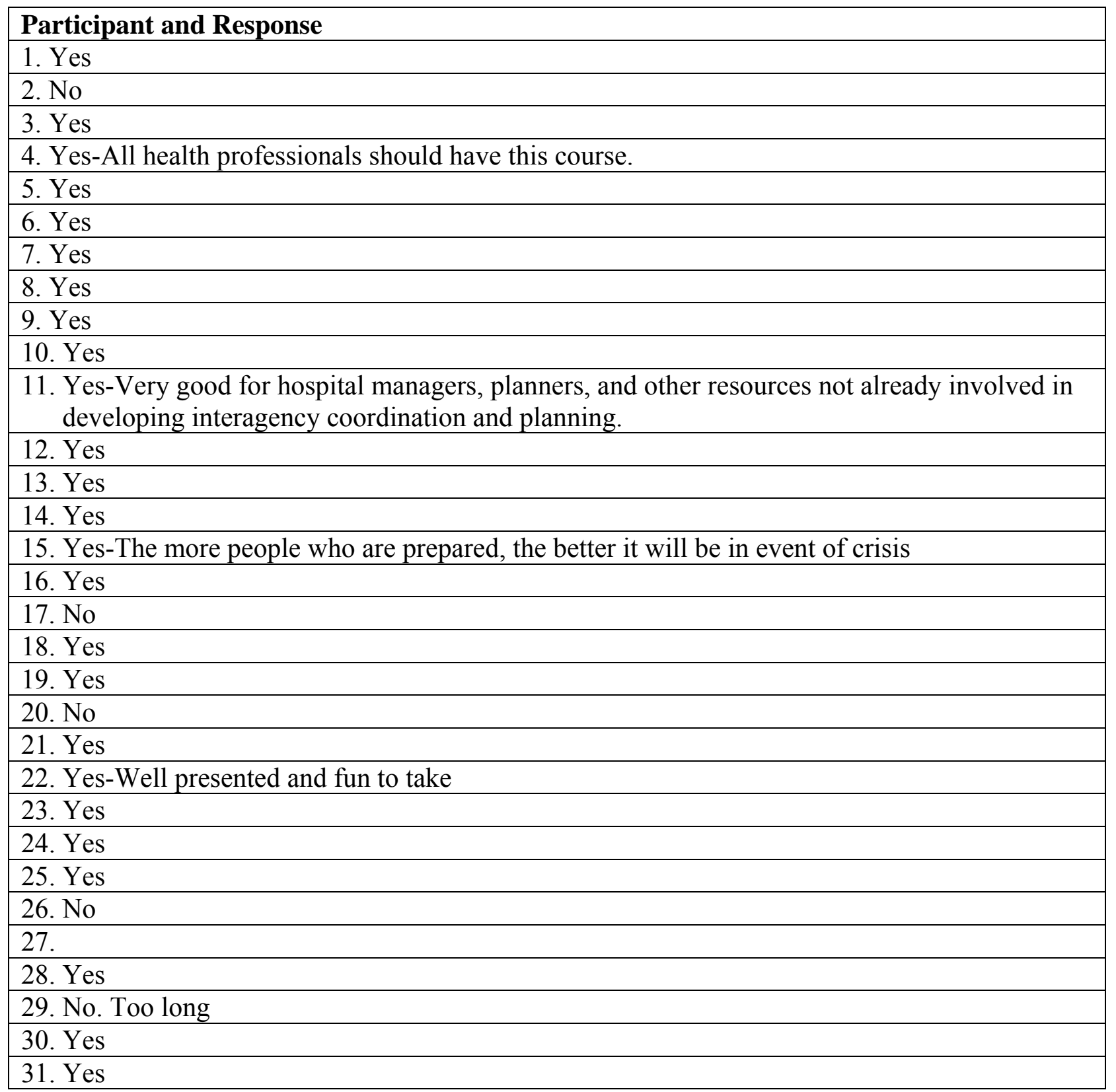


Table 36

"Do you have an increased awareness of the need for a coordinated response to a weapons of mass destruction (WMD) event?” Open-Ended Responses.

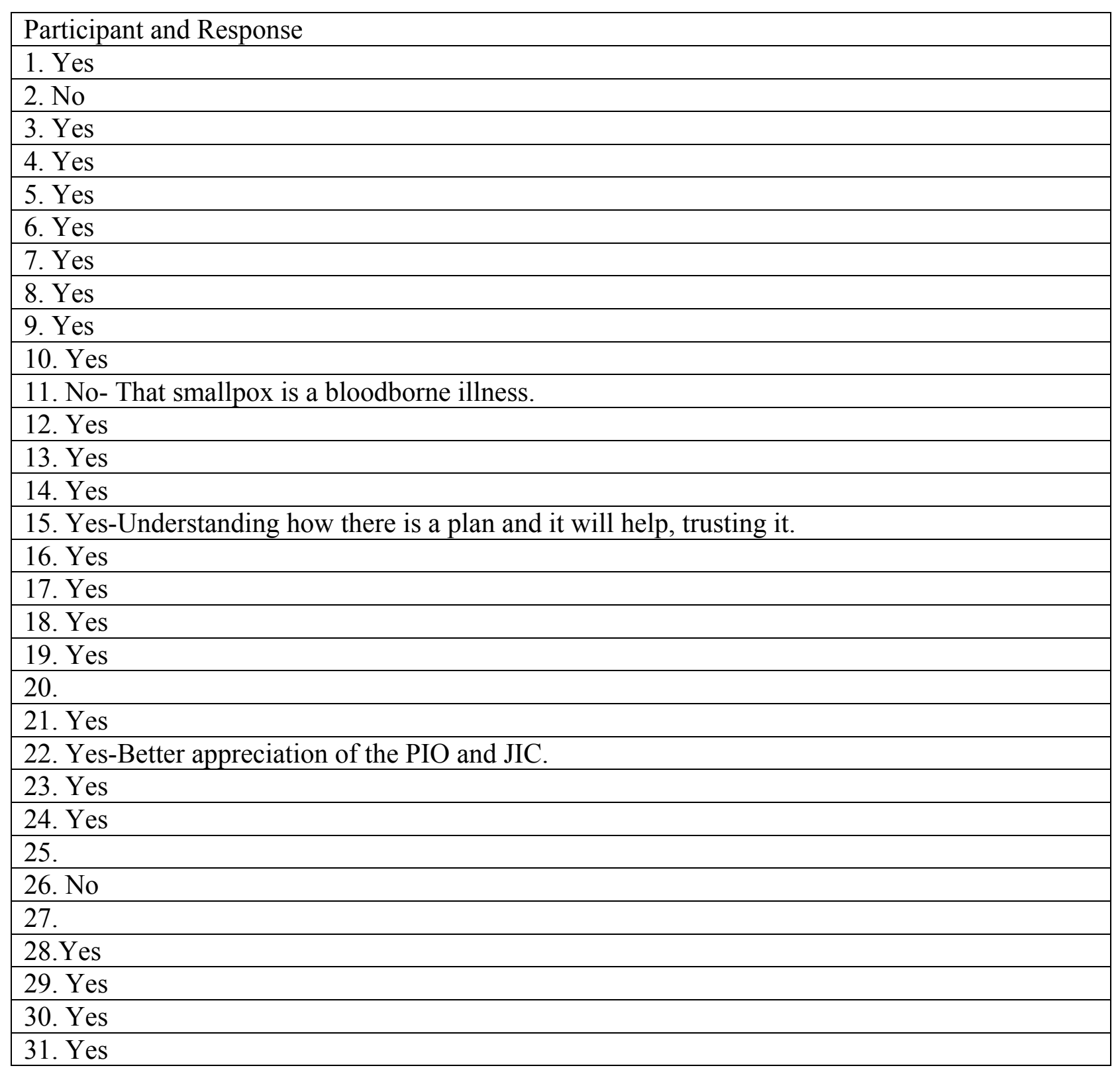


Table 37

"Will this course contribute a new level of competence and self-confidence among health care providers in planning for a WMD event?” Open-Ended Responses.

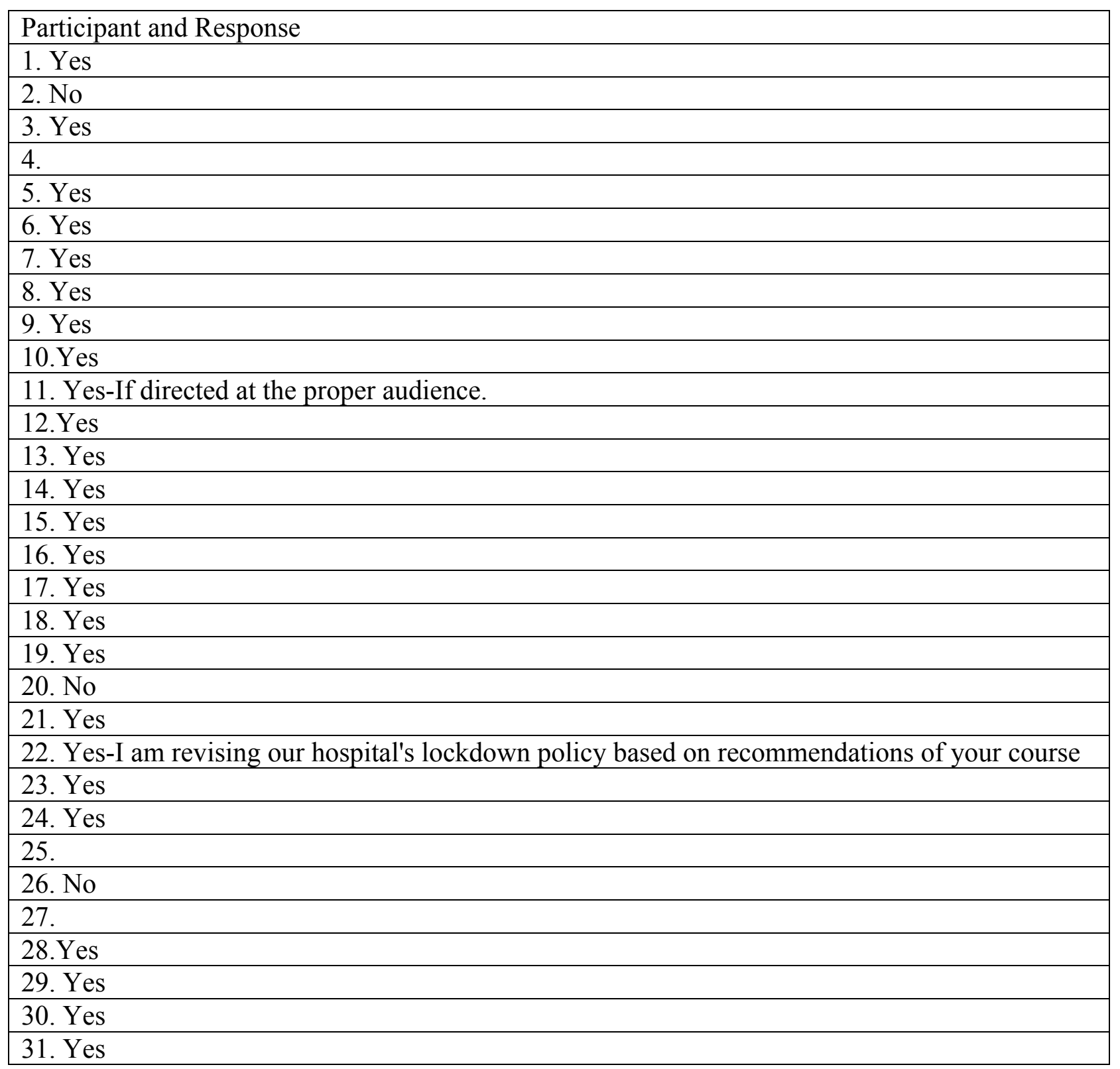




\section{Appendix G}

Registration Instructions for Course 1 and 2 Participants 
Appendix G.

Registration Instructions for Course 1 and 2 Participants.

\section{REGISTRATION (Step 1 of 3)}

The following registration procedures will allow you to access the Integrated Knowledge Base (IKB) and the Learning Management System (LMS) courses.

1. In Internet Explorer, go to http://ikb.vmc.wvu.edu

2. Click on the 'If you don't have an account click here' link.

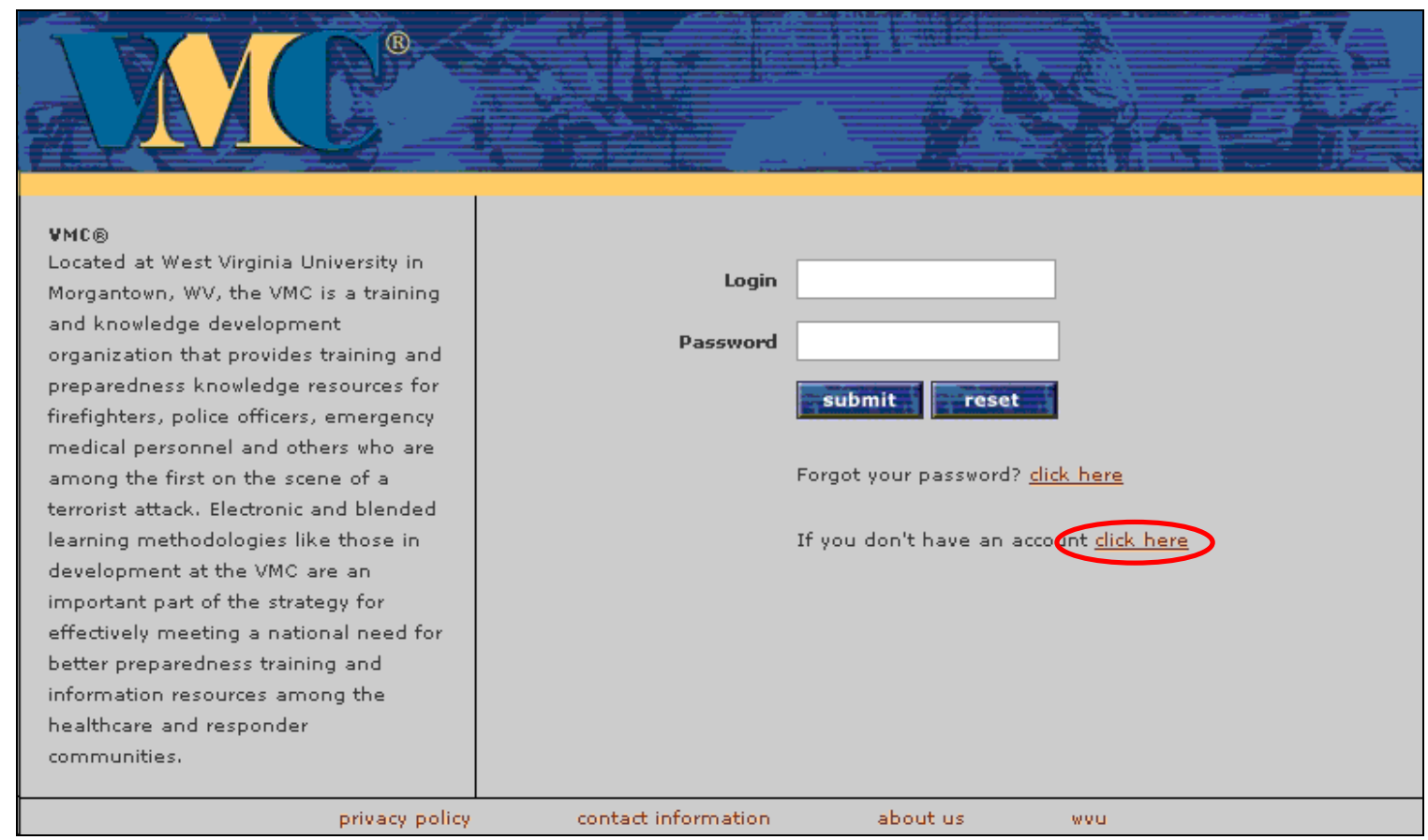

3. Fill in the information as required.

4. A strong password is required.

(Click password help for more instructions)

5. Your password must be at least eight alphanumeric characters long.

- It must contain both upper and lower case English characters (a-z, A-Z)

- It must contain at least one digit.

- It must contain at least one of the following special characters.

(!@\#\$\%^\&*( )_+ - $=\backslash\{\}[$ [ ? / ) (spaces not included)

- Do not use the special character $>$ in your password. 

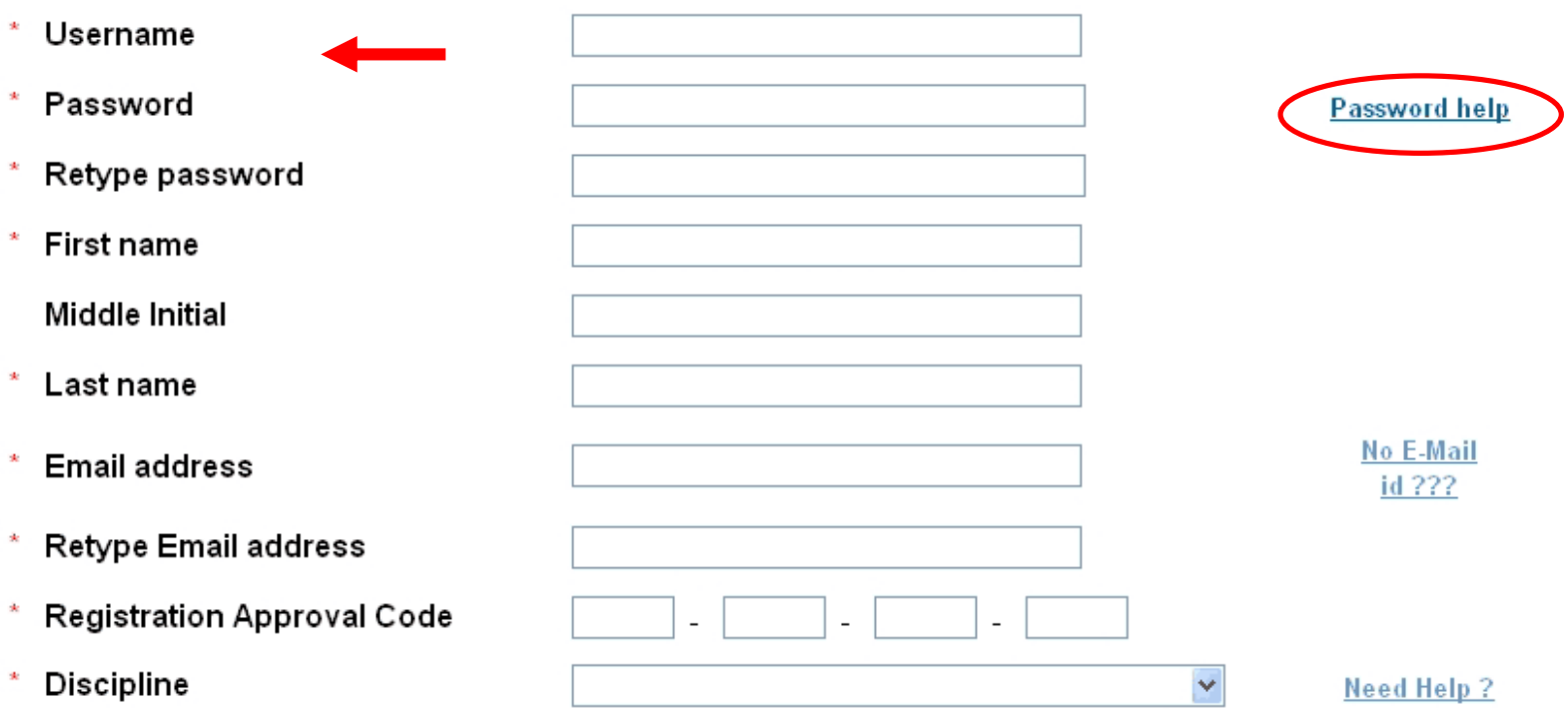

6. Enter the HRSA Approval code $=56 \mathrm{w} 2 \mathrm{y}-\mathrm{y} 956 \mathrm{w}-343 \mathrm{bn}-\mathrm{py} 6 \mathrm{xs}$

\section{Registration Approval Code}

$$
56 w 2 y-y 956 w-343 b n-\text { py6xs }
$$

7. Click 'Next' to submit the registration info, then...

* Job Duty

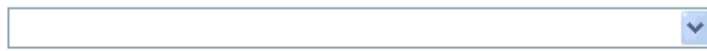

The following information is requested to fulfill our reporting requirements for the Federal agency that funds our project. Completion is voluntary

Gender

Male: $\bigcirc$ Female: $\bigcirc$

Age

Which best describes your racial / ethnic background?

Do you consider yourself to have ever been from an economically or educationally disadvantaged background? (Check yes if you are the first generation of your family to go to college or if your family, to your best knowledge, was below the federal poverty level when you were growing up) Yes: $\bigcirc$ No: 0 
... follow the confirmation instructions and click 'Submit.'

$\begin{array}{ll}\text { Organization/Affiliation(secondary) } & - \\ \text { Organization/Affiliation(tertiary) } & - \\ \text { Department/Agency name } & \text { WUU } \\ \text { Department/Agency address } & \text { Morgantown } \\ \text { * Department/Agency city } & \text { WN } \\ \text { Department/Agency state } & \text { US } \\ \text { * Department/Agency country } & 26506 \\ \text { Department/Agency ZipCode } & - \\ \text { Department/Agency contact } & 293-0405 \\ \text { Department/Agency phone number } & - \\ \text { Student Job Duty } & - \\ \text { Student Job Duty(secondary) } & - \\ \text { Student Job Duty/tertiary) } & - \\ \text { Language } & - \\ \text { Timezone } & - \\ \text { Gender } & - \\ \text { Age } & - \\ \text { Racial/Ethnic Background } & - \\ \text { Economically/Educationally Disadvantaged } & -\end{array}$

Submit Edit Details

8. When registration is successful, follow the 'click HERE to go to the Login Page' link.

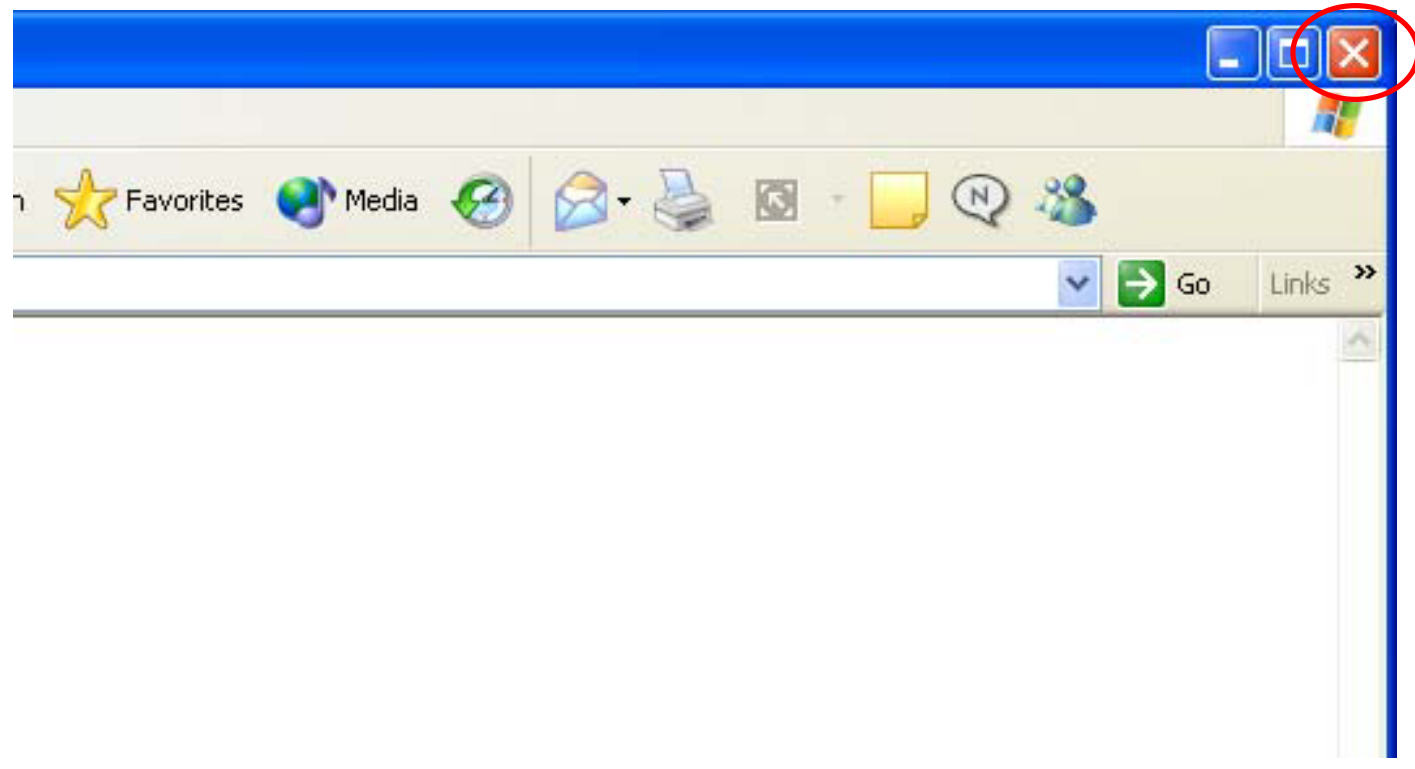


LOGIN TO THE LEARNING MANAGEMENT SYSTEM (Step 2 of 3)

1. Login with the username and password you just registered with and click 'Submit.'

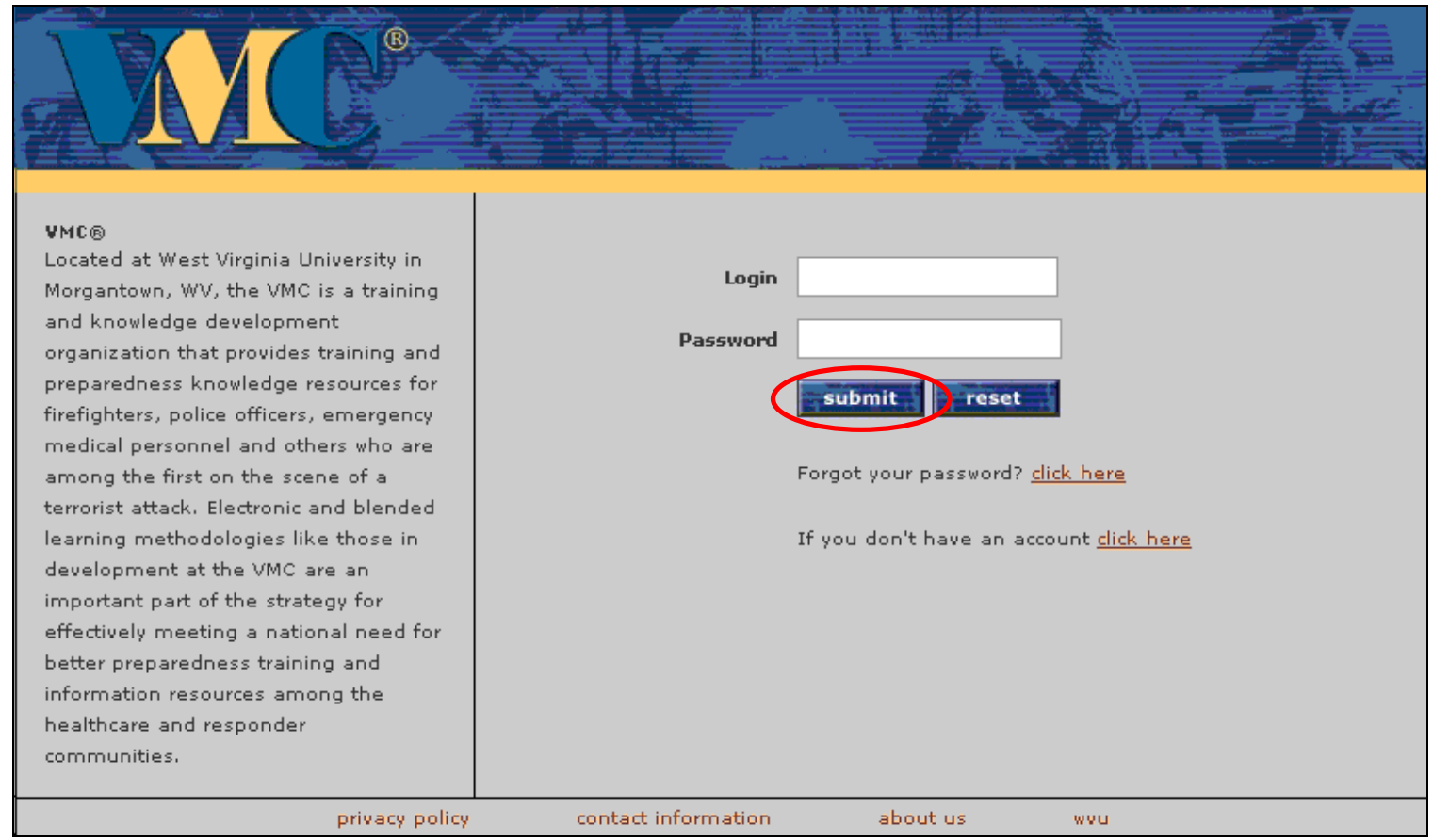

2. Click on the 'Training' tab.

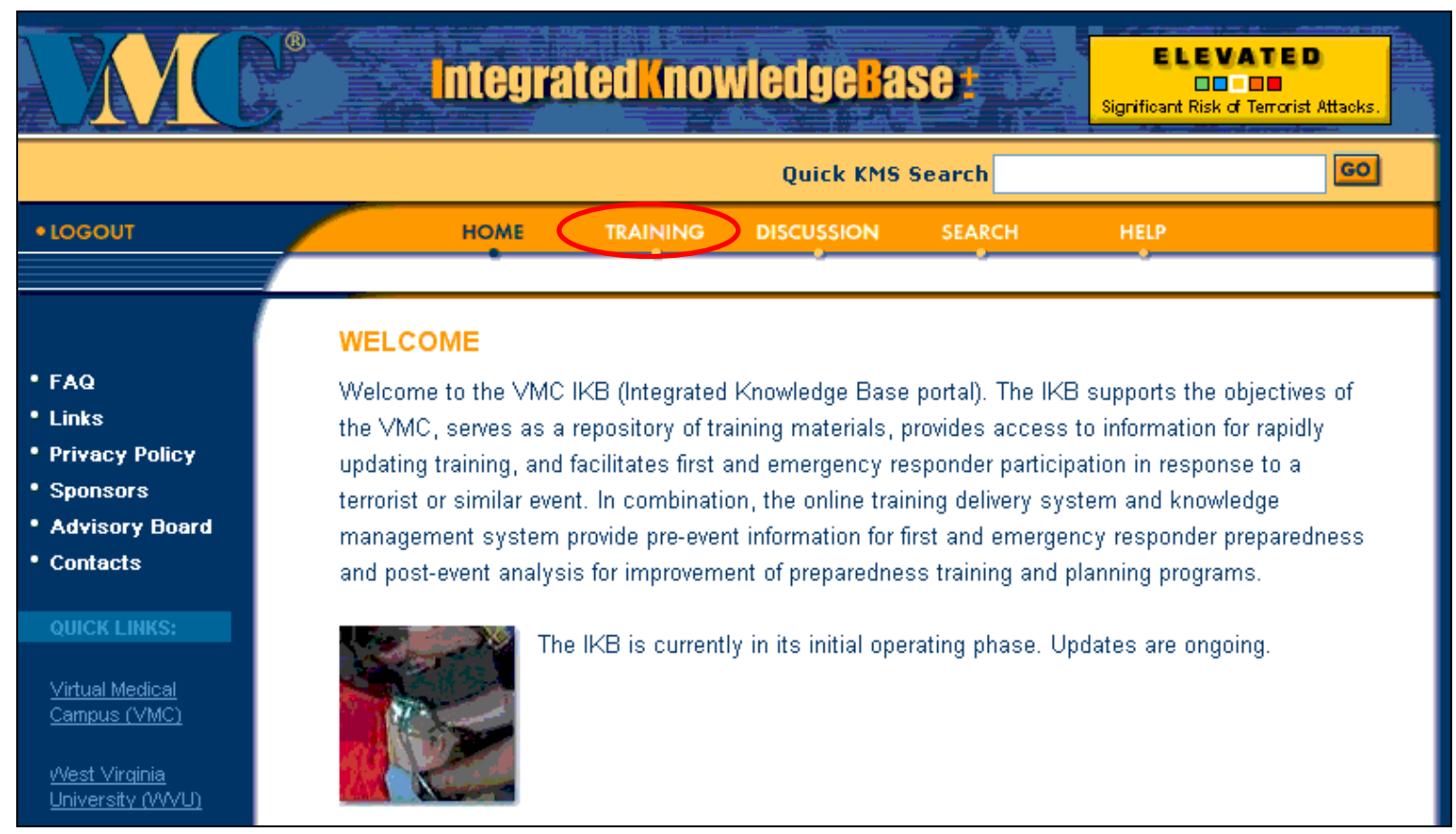


3. In the window that opens, click on the 'Take courses with VMC Learning...' link.

\section{TRAINING}

From this page, you are able to:

- Tak courses with VMC Learning Management System.

- Obtain IIIITImation about other types of courses available.

- Link to directions on how to use the learning management system (LMS).

- Obtain information about other types of training and exercises offered by the VMC.

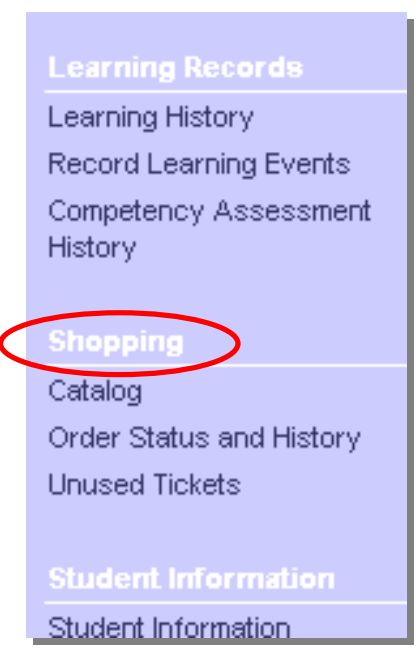

ACCESSING COURSES (Step 3 of 3)

To access courses, you must first add them to your development plan in the LMS. Please use the following steps to add the courses to your development plan.

1. Click the 'Catalog' link in the left-hand menu under 'Shopping.'

2. Click the 'Search' button without giving any search criteria. 


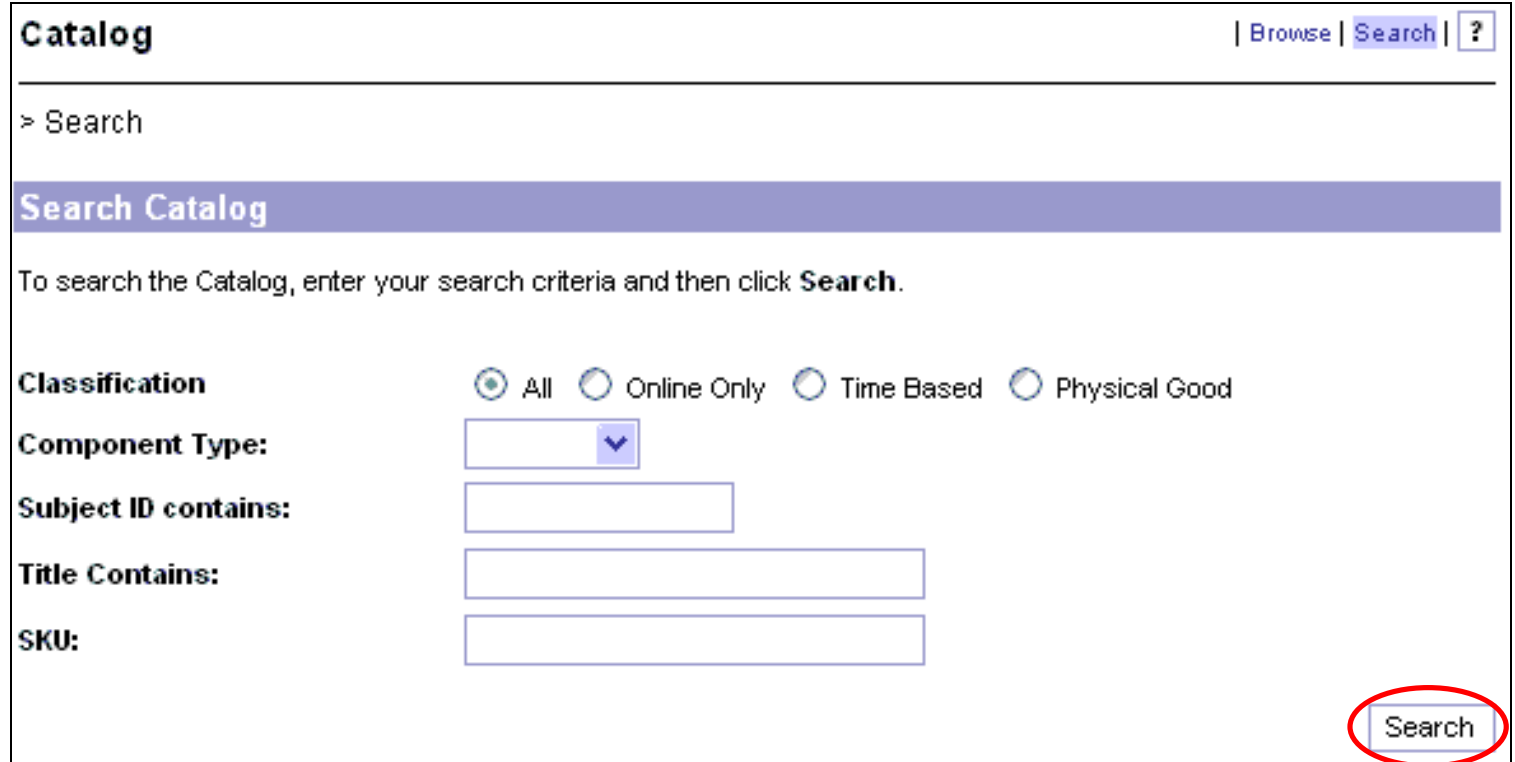

3. From the list of courses in the search results, choose the course you wish to access and click on 'Add to development plan'.

\begin{tabular}{|c|c|}
\hline Catalog & | Bronse | Search | ? \\
\hline \multicolumn{2}{|l|}{$=$ Search $>$ Results } \\
\hline \multicolumn{2}{|l|}{ Catalog Search Results } \\
\hline \multicolumn{2}{|c|}{ Click title for Component Description. Click plus icons to see and purchase schedules. } \\
\hline $\begin{array}{l}\text { Component Title } \\
\text { Component Type/Component ID }\end{array}$ & Price (\$) \\
\hline \multicolumn{2}{|l|}{ Reporting } \\
\hline \multicolumn{2}{|l|}{$\begin{array}{l}\text { COURSE HRSA01 (Rev 6/4/2004 12:00:00 AM Eastern } \\
\text { Standard Time) }\end{array}$} \\
\hline Catalog ID:VMCSTAFF-CATALOG & \\
\hline
\end{tabular}

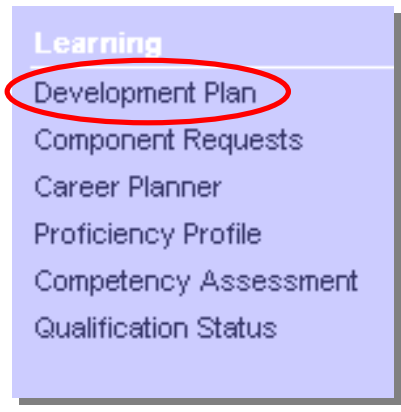

4. Click the 'Development Plan' link on the left-hand menu.

5. Click the 'Launch' link next to the course you would like to enter. 


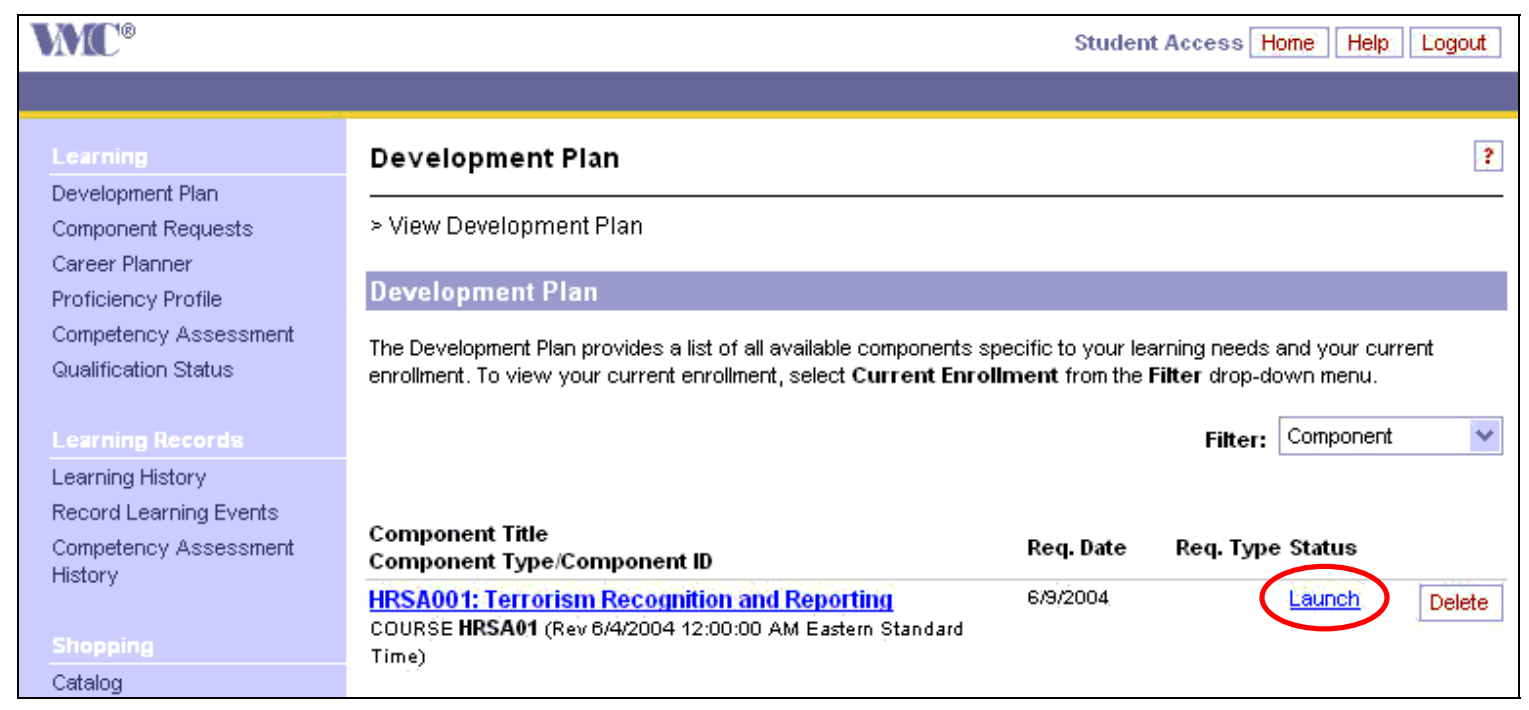

6. After you complete the posttest, you also need to complete the course summary to receive credit for the course. Make sure you return to your content structure and click on the 'Course Summary.'

\section{Content Structure}

Component Type: COURSE

Component ID: HRSA.01

Revision Date: $\quad$ 6/4/2004 12:00:00 AM Eastern Standard Time

Component Title:

Click here to return to the content structure. 


\section{Content Structure}

Component Type: Component ID:

COURSE

HRSA.01

Revision Date: 6/4/2004 12:00:00 AM Eastern Standard Time

Component Title:

The sub-objects need to be completed in sequential order

Module 1: Introduction to WMD

Completed On 6/18/2004 11:12:46 AM Eastern Standard Time iV. Introduction

Completed On 6M8/2004 11:12:46 AM Eastern Standard Time Module 2: Terrorism and WMD

The sub-modules need to be completed in sequential order.

11. Lesson 1: Identifying Weapons of Mass Destruction

Completed On 6/30/2004 03:28:35 PM Eastern Standard Time IV Lesson 2: Surveillance and Identification

Completed On 6/30/2004 03:28:51 PM Eastern Standard Time 1. Lesson 3: Internal and External Reporting

Completed On 6/30/2004 03:29:05 PM Eastern Standard Time Course Summary

When you are finished with the summary, click the 'Exit' button in the top right corner.

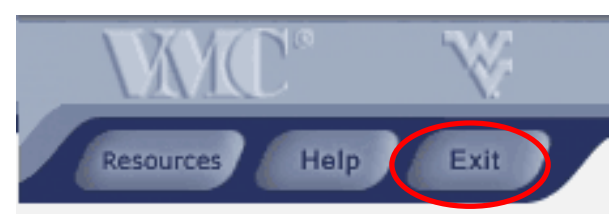

There should now be checkmarks next to each completed section in your content structure. Upon completion of the course, it will disappear from your development plan. 
Content Structure

Component Type: COURSE

Component ID: HRSA01

Revision Date: $\quad$ 6/4/2004 12:00:00 AM Eastern Standard Time

Component Title: $\quad$ HRSA001: Terrorism Recognition and Reporting

The sub-objects need to be completed in sequential order

(V) Module 1: Introduction to WMD

Completed On 6/18/2004 11:12:46 AM Eastern Standard Time ivi Introduction

Completed On 6M8/2004 11:12:46 AM Eastern Standard Time $\checkmark$ Module 2: Terrorism and WMD

The sub-modules need to be completed in sequential order. Completed On 7/1/2004 08:37:28 AM Eastern Standard Time 1. Lesson 1: Identifying Weapons of Mass Destruction

Completed On 6/30/2004 03:28:35 PM Eastern Standard Time IV Lesson 2: Surveillance and Identification

Completed On 6/30/2004 03:28:51 PM Eastern Standard Time VI. Lesson 3: Internal and External Reporting

Completed On 6/30/2004 03:29:05 PM Eastern Standard Time E. Course Summary

Completed On 7/1/2004 08:37:28 AM Eastern Standard Time 